\title{
Die sessilen peritrichen Infusorien und Suctorien von Basel und Umgebung. voN
}

\section{ALFRED KEISER}

(aus Basel).

Mit 5 Textfiguren.

\section{Vorwort.}

In den faunistisch-biologischen Arbeiten über die verschiedensten Gewässer finden sich hier und dort Angaben über sessile Peritrichen und Suctorien zerstreut, welche sich auf die von diesen Infusorien besetzten Substrate beziehen. Von einigen wenigen Arten war bekannt, dass sie sich immer wieder auf den gleichen Trägern aufzuhalten oder festzusetzen pflegen. Von Dendrocometes paradoxus und Spirochona gemmipara weiss man allgemein, dass ihr specifischer Wirt Gammarus pulex ist. Ebenso ist bekannt, dass Trichodina pediculus und Kerona pediculus gewöhnlich auf Hydra zu beobachten sind. Der grösste Teil der übrigen Arten der Peritrichen und Suctorien wurde bald auf diesem Träger, bald auf jenem nachgewiesen. Es erhob sich die Frage, ob einem Epizoon in der Wahl der Wirte weitere oder engere Grenzen gesteckt seien, 
oder ob ein sessiles Infusor sogar jede beliebige Unterlage besiedeln könne. Die Aufgabe der vorliegenden Studie war es, die angedeutete Frage näher zu prüfen, und an Hand eigener Funde und Experimente eventuelle Gesetzmässigkeiten aufzudecken. Dann sollte auch der Anpassung der Symphorionten an die Wirte besondere Aufmerksamkeit geschenkt werden.

Die Arbeit beschäftigte mich vom Sommer 1917 bis zum Winter 1919. Sie entstand in der zoologischen Anstalt der Universität Basel unter Leitung von Herrn Prof. Dr. F. Zsснокке. Meinem hochverehrten Lehrer bin ich für das rege Interesse und die vielen Anregungen, durch die er meine Arbeit förderte, zu aufrichtigstem Dank verpflichtet.

Meinen besten Dank spreche ich auch Herrn Priv. Doc. Dr. R. Menzel aus für seine freundlichen Ratschläge und Herbeischaffung von Literatur.

Während eines kurzen Aufenthaltes in Genf habe ich in verschiedenen Instituten meine Literaturnachweise ergänzt. Herrn Prof. Dr. E. André (Genf), der mir seine Privat-und Instilutsbibliothek bereitwilligst zur Verfügung stellte, und Herrn Prof. Dr. M. Bедот (Genf), von dem ich die Erlaubnis erhielt, die Bibliothek des (Museum d'histoire naturelle » zu benützen, sei mein herzlichster Dank ausgesprochen. Auch Herrn Dr. E. Penard, der mich durch Ueberlassung seiner Separata manche Lücke ausfüllen liess, möchte ich hier bestens danken.

Obwohl ich stets bestrebt war, das umfangreiche Trägermaterial selbst zu bestimmen, musste doch ein Teil desselben an Specialisten zur Determination übergeben werden. So bearbeitete Dr. Ch. Walter (Basel) die Hydracarinen, Dr. Ed. Handschin (Genf) die Wasser-Coleoptern, cand. phil. P. Wolf (Basel) die Ostracoden und cand. phil. A. Portmann (Basel) die LibellenLarven. So wurde in der Bestimmung der Träger eine möglichst grosse Zuverlässigkeit erzielt. Allen diesen Herren sei an dieser Stelle mein bester Dank ausgesprochen. 


\section{Material und Untersuchungs-Methoden.}

Das Material, welches von mir nach sessilen Infusorien durchsucht wurde, stammte aus Tümpeln und Weihern der nähern und weitern Umgebung von Basel. Infolge der Kriegsverhältnisse war es mir nicht möglich, die Altwässer des Rheins in der Oberrheinischen Tiefebene zu besuchen, was zu bedauern ist, da gerade diese Lokalität für meine Untersuchungen eine reiche Fundgrube geworden wäre.

Auf eine Charakterisierung der Gewässertypen, aus denen Material entnommen wurde, verzichte ich, da sie in einer druckfertig verliegenden Arbeit von P. WoLf, “Die Ostracoden von Basel nnd Umgebung"), im Abschnitt “Stehende Gewässer » näher beschrieben worden sind.

Das eingebrachte Material ist womöglich noch am gleichen Tage, oder doch aber am nächsten untersucht worden, um die Verhältnisse, wie sie in der freien Natur sich finden, möglichst genau kennen zu lernen. Mit der Zeit wird das natürliche Gleichgewicht in den Aufbewahrungsbehältern durch Fäulnis und andere Faktoren gestört; einzelne Arten verschwinden, andere nehmen an Individuenzahl zu. Diese Verschiebung der Infusorienfauna entspricht aber nicht den Verhältnissen in der Natur, sie ist künstlich und kommt nur unter anormalen Bedingungen zu Stande.

Die Untersuchung der Infusorien geschah immer in lebendem Zustande. Zur raschen Orientierung über Lage und Gestalt des Kernes leistet die Färbung intra vitam mit Methylgrün in $2 \%$ wässeriger Lösung gute Dienste. Wo es wünsçhenswert schien, wurden Dauerpräparate in Canada-Balsam hergestellt.

Meine Beobachtungen, die hier und da noch Lücken aufwiesen, habe ich durch Literaturangaben zu ergänzen versucht. Es scheint mir hier der Ort zn sein, auf Mängel, die faunistischbiologischen Studien über Infusorien oft anhängen, hinzuweisen. Eine genaue Determination der Epizoen ist an konser- 
viertem Material recht schwierig, in den meisten Fällen überhaupt nicht mehr möglich. Als grosser Nachteil muss es empfunden werden, wenn die Epizoen wohl bestimmt, aber ohne Wirte angegeben werden. Solche Angaben sind für unsere Arbeit wertlos gewesen. Nicht viel besser verhielt es sich in Fällen, wo für die Bezeichnung der Träger nur ganz allgemeine Begriffe, wie Entomostraca, Wasserkäfer etc. gebraucht wurden. So schmolz die Menge der verwendbaren Notizen auf eine kleine Zahl zusammen.

Ich war bemüht, die hydrobiologischen Arbeiten nach für meine Studien tauglichen Angaben zu durchsuchen, und habe, um mir nichts entgehen zu lassen, viele Zeitschriften durchblättert. Aber auch in der Beschaffung der Literatur hat der Krieg hindernd gewirkt; die Universitätsbibliothek Basel hat während diesem die Vermittlung von Büchern aus dem Ausland einstellen müssen und so musste manche Arbeit, von der ich vieles erhoffte, unberücksichtigt bleiben.

\section{Specieller Teil.}

Abkürzungen.

Für die nachfolgenden Listen gelten nachstehende Abkürzungen :

\section{Liste der besetzten Teile der Träger.}
A. = Antennen.
Ko. $=$ Kopf.
Ab. = Abdomen.
$\mathrm{Kr}$. = Kiemenblättchenrand.
B. = Beine.
C. = Cephalothorax.
F. = Furka.
Cg. = Coxagelenke.
M. = Mundteile.
E. = Elytren.
Schf. = Schalenfläche.
Er. = Elytrenrand.
Schb. = Schwanzborsien.
K. = Körper.
Schr. = Schalenrand.
$\mathrm{Kb} .=$ Kiemenblältchen.
Th. = Thoracalbeine.
Thr. = Thoraxschildrand. 
2. Liste der Häufigkeit.

$++=$ massenhaft.

$$
\begin{aligned}
& +\quad=\text { häufig. } \\
& \text { I }=\text { selten. }
\end{aligned}
$$

Die Zeichen der Häufigkeit beziehen sich auf die Menge der auf den Wirten gezählten Infusorienindividuen, und zwar stellen sie Durchschnittswerte dar.

In der Anordnung und Nomenklatur für die Ciliaten folge ich der von André (1912) im Catalogue des Invertébrés de la Suisse gegebenen. Der Systematik der Suctoria habe ich die Monographie von Collin (1912) zu Grunde gelegt.

\section{Klasse: INFUSORIA \\ Unter-Klasse: CILIATA \\ Ordnung: Hypotricha.}

Familie: Oxytrichinae Ehrenberg (Stein emend.

Unt.-Fam.: Urostylininae Bütschli.

Genus: Kerona Ehrenberg.

Kerona pediculus (O. F. Müller).

Kerona wurde von Perty (1852) für die Schweiz neu festgestellt und unter dem Namen Alastor polyporum beschrieben. Weitere Funde der Art aus der Schweiz fehlen gänzlich. Auch André (1912) bemerkt ausdrücklich, dass es ihm nicht gelungen sei, Kerona in der Umgebung von Genf zu finden. Meine eigene Fundortliste zeigt nur wenige Daten; ich fand Kerona, die sich kletternd auf ihren Wirten bewegt, aber auch einer freischwimmenden Lebensweise fähig ist, auf folgendem Träger : 


\begin{tabular}{|c|c|c|c|c|}
\hline Träger. & | Besetzte Teile. & Häufigk. & Fundort. & Datum. \\
\hline Hydra vulgaris. & $\begin{array}{c}\text { K. \& Tentakeln. } \\
\text { K. }\end{array}$ & $\begin{array}{l}++ \\
+\end{array}$ & $\begin{array}{l}\text { Bot. Garten Basel } \\
\text { Stauweiher Augst }\end{array}$ & $\begin{array}{ll}20 . & 5 . \\
19 . & 6 .\end{array}$ \\
\hline
\end{tabular}

O. F. Müller (1786) und Schrank (1803) fanden Cyclidium pediculus (=Kerona pediculus) auf Hydra. Ehrenberg (1838) auf Körper und Fangarmen von Hydra sulgaris und Hydra oligactis. Perty (1852) auf Hydra sulgaris und Hydra oligactis. DALla-Tor é (1891) auf Hydra spec. Svec 1897 auf den Armen von Plumatella, Cristatella und Hydra fusca. Francé (1897) und Henderson (1905) auf Hydra fusca.

An Hand dieser Angaben und meiner eigenen wenigen Befunde glaube ich feststellen zu können, dass Kerona pediculus an keinen specifischen Wirt gebunden ist. Ihr Vorkommen scheint sich nicht einzig und allein auf das Gerus Hydra zu beschränken, wie dies die Funde von Svec zeigen. Immerhin glaube ich annehmen zu dürfen, dass das Vorkommen auf Bryozoen zu den Seltenheiten gehört. Jedenfals hat Kerona die Vorstufe des specifischen Symphorismus ${ }^{1}$ erreicht, und unterscheidet sich in dieser Hinsicht auch biologisch von Trichodina pediculus, der, wie gezeigt werden soll, in der Wahl ihrer Wirtstiere weitere Grenzen gezogen sind.

\section{Ord. Peritricha.}

Unt.-Ord. Scaiotrichidae

Fam. Spirochoninak Stein.

Genus: Spirochona Stein.

Spirochona gemmipara Stein.

Spirochona gemmipara ist eine weitverbreitete Art, doch ist sie in ihrem Verbreitungsgebiet in horizontaler und vertikaler Richtung ganz an dasjenige ihres Wirtes, Gammarus pulex,

1 Unter Symphorismus verstehen wir das Zusammenleben von zwei artverschiedenen Tieren, wobei das Getragene einen Vorteil hat (DeEgener 1918). 
gebunden. Dieses Verhalten ist von Thienemans (1913) näher geprüft worden. Gammarus lebt im allgemeinen nur in sauerstoffreichen Gewässern, seiner Anpassungsfähigkeit an sauerstoffärmeres Wasser sind indessen ziemlich weite Grenzen gezogen. Diese Möglichkeit der Anpassung besitzt Spirochona nicht. In verhältnismässig sauerstoffarmen Gewässern kommt wohl Gammarus noch vor, nicht aber das Infusor. Während meiner Beobachtungen konnte dieses Verhalten zu wiederholten Malen festgestellt werden. Als Fundorte für Spirochona kann ich folgende angeben :

\begin{tabular}{|c|c|c|c|c|}
\hline Träger. & Besetzte Teile. & Häufigk. & Fundort. & Datum. \\
\hline Gammarus pulex & $\mathrm{Kr}$. & ++ & Schusterinsel. & 16. 7. \\
\hline$"$ & " & ++ & " & 23. 8 . \\
\hline ” & $"$ & ++ & $”$ & 9. 2 . \\
\hline$"$ & ) & + & ") & 26. 2 . \\
\hline$"$ & ") & $1-+$ & Münchenstein. & 21. 1 . \\
\hline$"$ & $"$ & + & Arlesheim. & 5. 2 . \\
\hline$"$ & n & + & Allschwil, & 13. 2. \\
\hline$"$ & $"$ & i & $"$ & 6. 1 . \\
\hline$”$ & $"$ & + & Lange Erlen(Basel). & 14. 4. \\
\hline$"$ & $"$ & + & Görbelhofer Weiher & 11. 10 . \\
\hline ") & " & I & Kaltbrunnental. & 29. 10 . \\
\hline
\end{tabular}

In der Literatur begegnen wir Spirochona gemmipara des öftern. Stein $(1851,1854)$ fand sie immer am Rand der Kiemenblätter von Gammarus. Hertwig (1877) sagt von Spirochona, dass ihr Vorkommen bei Gammar'us pulex allein auf die Kiemenblätter beschränkt sei; ebenso wenig wie Stern hat er sie an andern Körperteilen des Krebses gefunden. Als Aufenthaltsort suchen diese Infusorien speziell den freien Rand der Kiemen auf und siedeln sich hier oft in ausserordentlicher Zahl, bis 30 und mehr Individuen an, ganz selten sind die Flächen der Kiemenblätter besetzt. Auf dieses Verhalten hat auch Plate (1886) hingewiesen. Claparede und Lachmann (185859), (1860-61), Bütschli (1877), Richard (1899), Roux (1901, Henderson (1905), Sakowsky (1906), Fauré-Fréniet (1906, 1910), Thienemann (1913), Mermod (1914) auf Gammarus pulex. Kent (1880-82) hat Spirochona ebenfalls auf Gammarus gefunden und will sie noch auf andern Entomostracen beobachtet haben.

Meine Funde, verbunden mit diesen Angaben aus der 
Literatur, zeigen, dass Spirochona gemmipara ein specifischer Symphoriont s. str. ist. Aber nicht nur die Wahl des Wirtes ist eine sepecifische geworden, sondern auch die Wahl der an ihm zu besetzenden Organe. Wie obige Tabelle zeigt, wurden nie andere Körperteile mit Spirochona behaftet gefunden, als die freien Enden der Atmungsorgane. Von Wichtigkeit scheint mir gerade der Umstand zu sein, dass es immer die freien Kiemenenden sind, die aufgesucht werden. Nach Thienemann ist Spirochona in höchstem Grade oxyphil und euryhalin, ist also an eine bestimmte chemische Zusammensetzung des Wassers und damit auch an einen bestimmten Sauerstoffgehalt gebunden. Rascher Wasserwechsel und erneute Sauerstoffzufuhr wird für sie eine Lebensbedingung sein. Diese Voraussetzung findet das Infusor an den Orten erfült, wo sein Leib frei ins Wasser hervorragen kann, und wo stete Strömung herrscht. Die Wassercirculation wird durch die Bewegung der Kiemenblättchen unterhalten.

Die Bewegung der Kiemen übt aber auch eine Wirkung auf die äussere Gestalt der Spirochona aus. Der spindelförmige Körper ist an seinem hintern Ende abgestumpft und sitzt ohne Ausbildung eines Stieles der Unterlage auf. In dieser Erscheinung sehe ich eine Anpassung des Infusors an die rasche und fortwährende Bewegung der Respirationsorgane des Krebses. Ein langer Stiel wäre für dasselbe von Nachteil, da in diesem Falle der feste Zusammenhang mit der Unterlage verloren ginge. Epistylis steini, das dieselben Körperteile von Gammarus bewohnt, ist durch einen dicken und kurzen Stiel gekennzeichnet; eine Ausbildung eines solchen konnte aber hier erfolgen, da Epistylis steini im Gegensatz zu Spirochona gemmipara nicht den freien Rand der Kiemen besetzt, sondern sich auf der Fläche aufhält. 
Unt. Ord. Dexiotrichidae

Fam. Vorticellinae Ehrenberg.

Unt.-Fam. Urceolarininak Stein.

Genus: Urceolaria Stein.

Urceolaria mitra (v. Siebold).

Die Art ist, wie alle übrigen Vertreter dieser Unt. Familie keine sessile Form, sondern eine freibewegliche. Während meiner Untersuchungen sind mir indessen keine freischwimmenden Exemplare zu Gesicht gekommen, und es fehlen auch dementsprechende Angaben in der Literatur. Mit Hilfe eines Haftapparates wird es dem Infusor ermöglicht, auf der Haut seiner Wirte herumzuklettern. Auf folgenden Trägern konnte ich Urceolaria finden :

\begin{tabular}{|c|c|c|c|c|}
\hline Träger. & Besetzte Teile. & Häufigk. | & Fundort. & Datum. \\
\hline $\begin{array}{l}\text { Polycelis nigra. } \\
\text { Polyc. cornuta. }\end{array}$ & $\begin{array}{c}\text { Haut. } \\
\text { " }\end{array}$ & $\begin{array}{l}+ \\
+\end{array}$ & $\begin{array}{c}\text { Schusterinsel. } \\
\text { " }\end{array}$ & $\begin{array}{rr}26 . & 2 . \\
7 . & 3 .\end{array}$ \\
\hline
\end{tabular}

v. Siebold (1845-1850), der Entdecker des Infusors, fand seine Trichodina mitra auf verschiedenen Planarien. Perty (1852) auf Planaria, Stein (1854) auf Planaria torva, niemals aber auf Planaria lactea (=Dendrocoelum lacteum) und Planaria nigra (=Polycelis nigra), Hallez (1879) auf Planarien, Kent (1880-82) auf Planaria torva. Fabre-Domergue (1888) wies das Infusor auf Grund seiner morphologischen und anatomischen Charaktere zum Genus Urceolaria, er beobachtete dasselbe auf Planaria spec. Thí́вAud (1908) auf Polycelis nigra. Fehlmann (1911) auf Dendrocoelum lacteum var. bathycola. Mermod (1914) auf der Haut von Planarien und André (1916) auf Polycelis cornuta.

Aus dieser Reihe von Beobachtungen und aus meinen Befunden geht hervor, dass Urceolaria mitra auf den verschiedensten Arten von Tricladen sich aufhält. Auf Dendrocoelum lacteum, das ich oft untersuchte, konnte ich das Infusor nie finden. Obgleich sich das Vorkommen von Urceolaria 
einzig und allein auf Strudelwürmer beschränkt, kann von einem specifischen Symphorismus bei ihr nicht gesprochen werden.

Genus: Anhymenia Fabre-Domergue.

Anhymenia steini (Claparède und Lachmann).

Die zweite sich freibewegende Art der Urceolarininae ist Anhymenia steinii. Da sie sehr selten zu sein scheint, fand ich sie nur zweimal :

\begin{tabular}{|l|c|c|c|c|}
\hline Träger. & Besetzte Teile, & Häufigk. & Fundort. & Datum. \\
\hline Oscillaria-Filze. & Frei. & 1 Exempl. & Bettminger-Weiher. & 27. \\
Polycelis nigra. & Haut. & $/$ & Schusterinsel. & 26.2.
\end{tabular}

Die von Claparède und Lachmann (1858-59) als Trichodina steini beschriebene Form, wurde von den Autoren auf Planarien gefunden. Kent (1880-82) fand sie auf Planaria spec. Cattaneo (1888), Сhatton (1910) sammelten sie auf Planarien. Da die Peritriche sich morphologisch und anatomisch von Trichodina unterscheidet, hat FabreDomergue (1888) für sie das Genus Anhymenia geschaffen; er fand das Infusor auf Planarien, André (1909) auf Dendrocoelum lacteum. Freischwimmend oder an Steinen konnte es von Steinmanv und Surвеск (1918) beobachtet werden. Monard (1919) fand es auf Dendrocoelum lacteum.

Ich selbst habe Anhymenia steini sowohl freischwimmend als auch auf einem Träger beobachtet. Es schien mir, als löse sie sich leichter von diesem los als Urceolaria. Deshalb glaube ich, dass Anhymenia einer freien Lebensweise fähig ist. Diese Vermutung scheint mir in der äussern Erscheinung des Tieres eine Stütze zu finden. Während der Körper von Urceolaria plump, sackartig gebaut ist, ist derjenige von Anhymenia abgeplattet, fast scheibenförmig und von der grossen adoralen Wimperspirale überragt, für eine planktontische Lebensweise gestaltet. Was nun die Regel ist, das Leben auf der Turbellarienhaut oder im freien Wasser, wage ich nicht zu entscheiden. Die Menge des Beobachtungsmaterials scheint allerdings für ersteres zu sprechen. Der Haftring ermöglicht es der 
Peritriche, sich jedenfalls temporär auf Planarien aufzuhalten und, diese als Fahrzeug benutzend, neue Lokalitäten aufzusuchen.

Genus: Trichodina Ehrenberg.

Trichodina pediculus (O. F. Müller).

Die dritte Art der Urceolarien, deren Ortswechselvermögen den höchsten Grad erreicht, ist Trichodina pediculus, die nicht nur unsere Hydra-Arten, sondern die verschiedensten Tiere aufsucht. Ich fand sie auf folgenden Wirten :

\begin{tabular}{|c|c|c|c|c|}
\hline Träger. & Besetzte Teile. & Häıfigk. & Fundort. & Datum. \\
\hline Hydravulgaris. & K., Tentakeln. & + & Bot. Garten Basel. & 20.5 . \\
\hline$"$ & K., & + & Bottminger-Weiher & 27. 5 . \\
\hline$"$ & K. , & + & ” & 27.11 \\
\hline Hydra oligactis. & $"$ & ++ & Stauweiher Augst. & 13. 6. \\
\hline Hydra viridis. & K. & & Allschwil. & 6. 1. \\
\hline Phoxinus laevis. & Flossen, Haut. & $1-+$ & Zool. Institut. Basel & 7. 2 . \\
\hline $\begin{array}{l}\text { Gasterosteus } \\
\text { aculeatus. }\end{array}$ & 1 & & Lange Erl & 12 \\
\hline Triton-Larven. & Kiemen. & + & Margarethen-Park. & 8. 3. \\
\hline
\end{tabular}

Der umfangreichen Literatur, die Angaben über das Vorkommen von Trichodina enthält, entnehme ich folgendes:

WiLcke (1761) beabachtete seinen Volvox dimidiatus an Schwänzen von Anuren-Larven. Leuwenhock (1676), Trembley (1744), Bakek (1754), Sснӓғfer (1763), Resec (1755) auf den Armen von Hydra. O. F. Müller (1786) fand Vorticiella stellina und Vorticella discina (=-Trichodina pediculus) auf Hydra, Ehrenberg (1838) auf Hydra oulgaris, $H$. viridissima und Gyrodactilus coronatus in den Kiemen von Cyprinus und Carassius. Sehr oft, aber immer nur vereinzelt, konnte der Forscher die Peritriche freischwimmend feststellen. Dujardin (1841) auf Hydra fusca oder frei. v. Siebold (1848) machte die gleichen Angaben. Sters (1854) auf Hydra, an den Kiemen von Esox und an den Flossen von Gasterosterls. Davaine (1854) und Besch (1855) in der Harnblase von Triston cristatus; ersterer nannte das Infusor deshalb nach seinem Vorkommen "l'urcéolaire des tritons». Vulpian (1857) in der Kiemenhöhle von Cyprinus cephalus und der Kaulquappe, auf der Caudalflosse von Gasterosteus aculeatus und andern Fischen, und auf den äussern Kiemen von Triton-Larven. 
Quenerstedt (1865) auf Hydra und Fischen. James-Clake (1866) auf Hydra fusca und Hydra viridis. Wйgнт (1880) auf Kiemen und in der Harnblase von Nociurnus (= Menobranchus). Rosseten (1886) auf Hydra vulgaris und den Kiemen junger Tritonen, in den Exkretionsorganen von Triton cristatus. Fabre-Domergue (1888) gibt als Aufenthaltsort von Trichodina pediculus die Samenleiter und Kloake von Tritonen, Darm und Harnblase von Rana und die Kiemenhöhle von Gasterosteus aculeatus an. Monti (1899) auf Hydra spec., Тнí́baud (1908), Conv (1905) und Chatton (1910) auf Hydra-Arten. Dalla-Torré (1891) auf Hydra fusca. Svec (1897) auf Hydra fusca und Cristntelia. Hempel (1898) auf Hydra viridis. Roux (1901) auf Hydra, speziell auf Hydra fusca, auf den Kiemen von Triton-Larven und auf der Haut junger Leuciscus-Individuen. Als häufigen Planktonten beobachteten Seligo (1900), Zacharias (1900), Entz (1903), Krause (1907) und Steinmann und Surbeck (1918) das Infusor. Wesenberg-Lund (1904) auf Fischen, Spongillen, Planarien und Cristatella. Koford (1908), der Trichodina auf Hydra, Jungfischen und den Kiemen und der Haut von Amphibien beobachtete, bemerkt, dass das planktontische Leben nicht das gewöhnliche der Art sei. André (1912) fand es in der Kiemenhöhle von Eupomotis gibbosus.

Auf dieser mannigfaltigen Liste von Angaben fussend, möchte ich für Trichodina pediculus das Folgende feststellen: Die bevorzugten Träger scheint das Genus Hydra zu stellen. Gewisse Unterschiede treten uns da entgegen, indem Hydra vulgaris und andere Species viel eher aufgesucht werden, als Hydra viridis. Von den vielen Individuen letztgenannter Art, die ich im Verlaufe dieser Arbeit untersucht habe, erbeutete ich nur ein einziges, auf dem Trichodina zu finden war. Aus den bis jetzt gemachten Beobachtungen über die Besiedlung einzelner Organe von Fischen scheint hervorzugehen, dass immer gerne solche Teile von Trichodina aufgesucht werden, wo ein beständiger Wasserwechsel stattfindet. Diese Tatsache könnte auf einen oxyphilen Charakter von Trichodina schliessen lassen. hr stehen aber die ebenso zahlreichen Befunde aus dem Darm und den Exkretionsorganen von Fischen und Amphibien gegenüber. Ob tatsächlich die eine Art eine so grosse Anpassungsmöglichkeit besitzt, oder ob es sich vielleicht um zwei verschiedene Arten handelt, wage ich nicht zu entscheiden.

Auf alle Fälle kann festgestellt werden, dass Trichodina keinen specifischen Wirt besitzt, sie ist ein auf Vertretern der verschie- 
densten Tierklassen lebendes Infusor. Dieses Verhalten trennt sie biologisch scharf von Kerona, die sich viel strengeran Hydra hält.

Noch offen muss die Frage nach den Ursachen des oft massenhaften Auftretens von Trichodina im Plankton gelassen werden. Ob hier chemische oder physikalische Faktoren des Wassers mit im Spiele stehen, bedarf der nähern Untersuchung.

Unt.-Fam. Vorticellininae Bülschli.

Seklion: Scyphidinea.

Genus: Scyphidia Dujardin (Lachmann emend.).

Scyphidia limacina Lachmann.

Diese Peritriche stellt eine für die Infusorienfauna der Schweiz neue Art dar. Folgende Wirte fand ich von ihr besetzt :

\begin{tabular}{|c|c|c|c|c|}
\hline Träger. & Besetzte Teile. & Häufigk. & Fundort. & Dat. \\
\hline Planorbis contortus. & Ko. Fühler. & + & Schusterinsel. & 19. 7. \\
\hline$"$ & Ko. " " & $1-+$ & Niederholz. & $20 . \quad 1$. \\
\hline$n$ & Ko. & + & Zool. Institut Basel. & 29. 1 . \\
\hline$"$ & Ko. & $1-++$ & Schusterinsel. & 7. 3 . \\
\hline ") & Fuss, " & ++ & Niederholz. & 14. 5 . \\
\hline Pl. Planorbis. & - & + & - & 14. 5 . \\
\hline Limnaea ovata. & - & ++ & Schusterinsel. & 28. 2 . \\
\hline Lim. auricularia. & Ko. & + & Allschwil. & 6. 1. \\
\hline
\end{tabular}

O. F. MülLer (1786) fand Vorticella limacina (=Scyphidia limacina) auf Tentakeln und auf dem Mund junger Individuen von Planorbis contortus und Bulla (=Physa) fontinalis. Lachmann (1856) hat das Infusor neu beschrieben und seine Zugehörigkeit zum Genus Scyphidia nachgewiesen, er beobachtete dasselbe auf den nackten Teilen kleiner Planorbis-Arten. Kellicotт nach Stokes auf einer kleinen Planorbis.

Weitere Angaben über das Vorkommen von Scyphidia limacina konnte ich nicht finden. Doch zeigen meine Funde, dass das Infusor keinen specifischen Wirt hat. Wichtig ist, dass bei fast allen Citaten die Besetzung der Tentakeln oder des vordern Körperteiles hervorgehoben wird. Die Angabe von 
Müller glaube ich in der Weise deuten zu können, dass es sich bei dem Fund auf Physa wohl nicht um Scyphidia limacina gehandelt hat, sondern viel eher um Scyphidia physarum, die erst viel später von Claparède und Lachmann (1858-59) als selbständige Art beschrieben worden ist.

Auf den Fühlern der Schnecken, die bei jeder Berührung mit einem Fremdkörper eingezogen werden, ist es einer gestielten Vorticelline, die mit kleiner Basis der Unterlage aufsitzt, nicht möglich, sich festzusetzen. Nur eine stiellose Form, welche mit grosser Fixationsfläche sich halten kann, hat die Möglichkeit, diese Körperteile zu besiedeln.

Genus: Glossalella Bülschli.

Glossatella tintinnabulum. (Kent).

Angaben über die Verbreitung dieses Symphorionten finden sich ausserordentlich spärlich, sodass es scheinen möchte, dass dieses Infusor zu den Seltenheiten gehörte. Die scheinbare Seltenheit erklärt sich indessen wohl dadurch, dass die Wirtstiere wohl nur zufällig auf sesssile Infusorien hin untersucht werden. Ueberall da, wo ich Triton-Larven erbeuten konnte, fand ich ihre Kiemen mit Glossatella besetzt, wie dies folgende Tabelle veranschaulicht :

\begin{tabular}{|c|c|c|l|r|}
\hline Träger. & Besetzte Teile. & Häufigk. & \multicolumn{1}{|c|}{ Fundort. } & Datum. \\
\hline Triton-Larven. & Kiemen. & ++ & Margarethen-Park. & 8.3. \\
$" \prime$ & $"$ & $1-+$ & Bad Burg. & 5.10 \\
$" \prime$ & $"$ & + & Schusteriusel. & 7.3. \\
$" \prime$ & $"$ & ++ & Allschwil (Schiesstand). & 9.11. \\
& $n$ & + & Kloster Beinwil. & 29.10
\end{tabular}

Unter dem Namen Spirochona tintinnabulum wurde das Infusor von Kent (1880-82) in die Literatur eingeführt; er fand es auf der Epidermis und den Kienen von Triton cristatus-Larven. Kellicot (188j) auf den Kiemen von jungen Dimyctylus viredescens-Individuen. Bürschli (1887-89) trennt die Form von Spirochona und weist sie in die neue Gattung Glossatella. Roux (1901) und Mermod (1914) auf den Kiemen junger Triton-Larven. 
Mit diesen Beobachtungen stimmen auch meine Funde überein, und es kann mit Sicherheit gesagt werden, dass Glossatella tintinnabulum ein specifischer Symphoriont ist, dessen Vorkommen auf die Kiemen junger Tritonen beschränkt ist. Wirt und Ort der Festsetzung beeinflussen die Gestalt des Epizoons. Die schnellen, oft schnellenden Bewegungen der Tritonlarve machten es einer gestielten Peritriche nicht möglich, auf ihr Fuss zu fassen. Nur eine stiellose Art, deren hinteres Ende sich verjüngt, um dann saugnapfartig sich zu erweitern, hat die Möglichkeit, auf solchen Wirten sessil zu werden. Um einen Ersatz für die verlorene Eigenbewegung zu schaffen, ist eine grosse undulierende Membran ausgebildet worden, welche die Nahrungaus grossem Umkreise herbeizustrudeln im Stande ist.

Von Interesse scheint mir noch der negative Befund zu sein, dass ich die Kiemen von Anuren-Larven, welche aus den gleichen Lokalitäten wie die Tritonen stammten, nie mit Glossatella-Individuen besetzt fand.

Sektion: Contractilia Bütschli.

Genus: Vorticella Linné (Ehrenberg emend.).

Da, wie die nachfolgenden Zusammenstellungen zeigen werden, bei den Vorticellen mit ganz wenigen Ausnahmen von einem specifischen Symphorismus nicht mehr gesprochen werden kann, so halte ich es für zweckmässiger die Schlüsse, welche aus meinen Funden und den Literaturcitaten gezogen werden können, nach der Besprechung der einzelnen Arten zusammenzufassen.

Vorticella crassicaulis Kent.

Diese Art, die aus der Schweiz noch nicht bekannt war, scheint ein enges Verbreitungsgegiet zu besitzen, da sie vielleicht unter den Vorticellen der einzige specifische Symphoriont sein könnte und nach den bis jetzt gemachten Funden nur auf 
Asellus beobachtet wurde. Ich selbst fand das Infusor nur einmal und zwar :

\begin{tabular}{|c|c|c|c|c|}
\hline Träger. & Besetzte Teile. & Häufigk. & Fundort. & Datum. \\
\hline $\begin{array}{l}\text { Asellus } \\
\qquad \text { aquaticus. }\end{array}$ & Ko., Füsse, Borsten. & + & Margarethen-Park. & 8. 3. \\
\hline
\end{tabular}

Die einzigen Angaben, die über das Vorkommen von Vorlicella crassicaulis Aufschluss geben, finden sich bei KeNr (1880-82) und Richand (1899), die das Infusor auf Asellus aquaticus fanden.

Ich würde es für verfrüht halten, wollte man nach diesen wenigen Funden Asellus als den specifischen Wirt der Peritrichen ansehen. Vielmehr glaube ich auf Grund meiner Untersuchungen über den Symphorismus der übrigen VorticellaArten annehmen zu können, dass Vorticella crassicaulis nicht nur auf Asellus ihr Vorkommen beschränkt, sondern dass auch ihr in der Wahl der Wirte weitere Grenzen offen stehen. Die Ansicht von Entz (1903), dass Vorticella crassicaulis eine isoliert lebende Form einer bis jetzt noch nicht beschriebenen Carchesium-Art ist, konnte ich aus Mangel an Material nicht nachprüfen.

\section{Vorticella alba Fromentel.}

Vorticella alba, die allgemein als seltenes Infusor gilt, konnte ich in meinem Untersuchungsmaterial des öftern feststellen und zwar kamen folgende Wirte für sie in Betracht:

\begin{tabular}{|c|c|c|c|c|}
\hline Träger. & Besetzte Teile. & Häufigkf. & Fuudort. & Datum. \\
\hline \\
\hline natans. & Blatter. & + & Allschwil (Schiessland). & 6. 1. \\
\hline Spongilla fragilis & & 1 & Bottminger-Weiher & 7. 8. \\
\hline Cyclops albidus. & C. & + & Schusterinsel. & 20. 7 . \\
\hline$" \quad$ viridis. & Ventralfl. d. C & ++ & $"$ & 6. 11. \\
\hline$" \quad 1$ & Dorsalfl. d. C. & ++ & 》 & 6. 11. \\
\hline Gammarus pulex. & Ob. Teil d. Th. & ++ & $"$ & 6. 1. \\
\hline$"$ & ) & + & Münchenstein. & $22 . \quad 1$. \\
\hline ") & ) & ++ & Allschwil. & 20. 2 . \\
\hline$n$ & $"$ & + & $n$ & 6. 1. \\
\hline Chirotonetes jus. & K. & I & Schusterinsel. & 6. 11. \\
\hline
\end{tabular}


Die Arbeit von Fromentel (1874), in welcher Vorticella alba beschrieben und wahrscheinlich auch über ihr Vorkommen etwas ausgesagt wird, war mir nicht zugänglich. Die übrigen Angaben, die für mich Interessantes über den Aufenthalt von Vorticella alba bieten, sind die folgenden. André $(1912,1916)$ beobachtete sie im Moos einer Mauer und am Fusse eines Gammarus pulex. Gruber (1914) fand sie an den Blättern von Potamogeton.

\section{Vorlicella nebulifera O. F. Müller.}

Diese in allen Gewässern häufige Art konnte ich auf folgenden Wirten beobachten:

\begin{tabular}{|c|c|c|c|c|}
\hline Träger. & Besetzte Teile. & Hāuligk. & Fundort. & Datum. \\
\hline $\begin{array}{l}\text { Tote Pflanzenteile. } \\
\text { Algenfäden. } \\
\text { Spirogyra-Fäden. } \\
\text { Lemna minor. } \\
\text { Cyclops strenuus. } \\
\text { " viridis. } \\
\text { Planorbis contorlus. } \\
\text { Limnaea peregra. } \\
\text { Agrion puella juv. } \\
\text { Limnophilus } \\
\quad \text { rhombicus juv. } \\
\text { Stenophylax } \\
\text { concentricus j. } \\
\text { Agabus-Larve. } \\
\text { Cloeon juv. } \\
\text { Abgestreifte } \\
\text { Larveuhaut. }\end{array}$ & $\begin{array}{l}\text { Wurzeln. } \\
\text { C. } \\
\text { C. } \\
\text { Schale. } \\
\text { K. } \\
\text { Vord, K.teil. } \\
\text { Gehäuse. } \\
\text { K. } \\
\text { Rumpf u. Füsse. }\end{array}$ & $\begin{array}{l}+ \\
+ \\
1 \\
1 \\
++ \\
+ \\
++ \\
++\end{array}$ & $\begin{array}{l}\text { Bot. Garten Basel. } \\
\text { Bottminger-Weiher. } \\
\text { Allschwil (Schiesstand). } \\
\text { Schusterinsel. } \\
\text { Zool. Institut Basel. } \\
\text { Allschwil (Schiesstand). } \\
\text { Vord. Geissberg. } \\
\text { Schusterinsel. } \\
\text { Helgenmatt. } \\
\text { Stauweiher Augst. } \\
\text { Allschwil (Schiesstand). }\end{array}$ & $\begin{array}{rr}14 . & 5 . \\
13 . & 8 . \\
6 . & 1 . \\
7 . & 3 . \\
16 . & 10 . \\
6 . & 1 . \\
5 . & 11 . \\
29 . & 1 . \\
6 . & 1 . \\
29 . & 10 . \\
7 . & 3 . \\
29 . & 10 . \\
13 . & 6 . \\
6 . & 1 .\end{array}$ \\
\hline
\end{tabular}

Aus der grossen Menge der Angaben, die wir in der Literatur über das Vorkommen von Vorticella nebulifera finden, seien nur diejenigen herausgegriffen, die uns über die Wahl der verschiedenen Träger orientieren. Unger (1746) und Schäffer (1754) auf Lemna. Rasel (1755) auf einer Hydra, auf Schnecken und Wasserflöhen. Baker (1764) auf Froschlaich. Schrank (1777) auf einer Planarie. O. F. Müller (1786) an Conferven, Lemna, Ceratophyllum und Schnecken. Ehrenbers (1838) an Meerlinsenwurzeln und auf den Blättern von Ceratophyllum und der Hottonia palustris. STEIn (1854) an Lemna, Perty (1852) an Conferven und Lemna. Clapariède und Lachmann (1858-59) auf Hottonia und Lemna-Wurzeln, wo sie auch von Kent (1880-82) nachgewiesen werden konnte, Everts (1873) an 
den Schalen von Schnecken und den Wurzeln von Lemna. DallaTовве́ (1891) an Lemna und Ranunculıs. Aмвевg (1900) auf verschiedenen Planktonten, hauptsächlich auf Cyclopiden, Anabaena und Melosiren. Le Roux (1907) isolierte Vorticella nebulifera aus dem schlammigen Ueberzug der Ufersteine. Baumans (1910) auf faulenden Stengeln von Equisetum heleocharis oder auf Copepoden und Ostracoden. Steiner (1911) auf Cyclops serrulatus. Heuscher (1915) auf Chara und pelagischen Algen. Bourquin-Lindt (1918) auf Vaucheria und Moosen. Seligo nach Schröder, B. (1914) auf Anabaena, Tanner (1913) auf toten flottierenden Organismen.

\section{Vorticella campanula Ehrenberg.}

Wie die vorhergehende Art, so geniesst auch Vorticella campanula eine grosse Verbreitung. Die Träger, auf denen ich sie finden konnte, sind in der nachstehenden Liste zusammengestellt:

\begin{tabular}{|c|c|c|c|c|}
\hline Trä & Besetzte Teile. & iufigk. | & Fun & Datum. \\
\hline $\begin{array}{l}\text { Algenfilze. } \\
\text { Rhizzia. } \\
\text { Myriophyllum } \\
\text { demersum. } \\
\text { Elodea canadensis. } \\
\text { Ranunculus fluitans. } \\
\text { Cyclops viridis. } \\
\text { Gammarus pulex. } \\
\text { Planorbis contortus. } \\
\text { Pl. carinatus. } \\
\text { Nepa cinerea. } \\
\text { Ilybius-Larve. } \\
\text { Agabus-Larve. } \\
\text { Ilybius-Larve. } \\
\text { Chirotonetes juv. } \\
\text { Cloeon-juv. } \\
\text { Limnophilus } \\
\text { rhombicus juv. } \\
\text { Cyclops viridis. }\end{array}$ & $\begin{array}{l}\text { Blätter, Stengel. } \\
\text { Blätter. } \\
\text { Blätter, Stengel. } \\
\text { C. Ab., A. } \\
\text { oberer Teil d. Th. } \\
\text { Gehäuse. } \\
\quad \text { K. } \\
\text { K. } \\
\text { K. } \\
\text { K. } \\
\text { K. } \\
\text { Kiemen. } \\
\text { K. } \\
\text { K. } \\
\text { Beine. } \\
\text { Gehäuse. } \\
\text { A. }\end{array}$ & $\begin{array}{l}1 \\
+ \\
+ \\
++ \\
+ \\
1 \\
+ \\
1 \\
++ \\
++ \\
1 \\
1 \\
+ \\
+ \\
1-+ \\
+ \\
1\end{array}$ & $\begin{array}{l}\text { Helgenmatt. } \\
\text { Schusterinsel. } \\
\text { "” } \\
\text { Vord. Geissberg. } \\
\text { Seewener See. } \\
\text { Schusterinsel. } \\
\qquad, " \\
\quad \text { " } \\
\quad \text { " } \\
\text { Neuhüsli. } \\
\text { Schusterinsel. } \\
\text { Margarethen-Park. } \\
\text { Kloster-Beinwil. } \\
\text { Angenstein. } \\
\text { Arlesheim. } \\
\text { Allschwil (Schiesstand). } \\
\text { Margarethen-Park. }\end{array}$ & $\begin{array}{rr}29 . & 10 . \\
27 . & 8 . \\
12 . & 3 . \\
27 . & 2 . \\
29 . & 10 . \\
21 . & 10 . \\
11 . & 2 . \\
7 . & 3 . \\
11 . & 2 . \\
7 . & 3 . \\
16 . & 10 . \\
29 . & 10 . \\
7 . & 3 . \\
26 & 1 . \\
29 . & 10 . \\
9 . & 5 . \\
20 . & 11 . \\
6 . & 1 . \\
25 . & 1 .\end{array}$ \\
\hline
\end{tabular}

Ehrenberg (1838), dem wir die erste Beschreibung der Vorticella campanula zu verdanken haben, fand diese an Wasserpflanzen. Die von Dujardin (1841) beschriebene Vorticella lunaris, die mit der Eнrenberg'schen Form identisch sein dürfte, beobachtete der Autor ebenfalls an verschiedenen Wasserpflanzen. Sснмarda (1846) an 
Lemna. Pввту (1852), der in seinem Verzeichnis die Vorticella lunaris weiterführt, traf das Infusor häufig auf Conferven. FoneL (1884) auf Schlammpartikeln. Moniez (1889) auf Cladothrix. Zacharias (1902) auf dem Algenüberzug, der die Stengel von Phragmites communis bedeckt. Thiébaud und Favre (1906) auf Cyclops viridis. Le Roux (1907) auf den Blättern von Myriophyllum. Zsснокке (1911) auf Cyclops viridis, viel häufiger dagegen auf Fredericella. KLEIBer (1911) auf pflanzlichem Detritus der Torfgräben. STeinmann und Surbeck (1918) auf Pilzbüscheln der Abwässer und auf Perliden-Larven. Monard (1919) auf Cyclops serrulatus, lliocypris lacustris, Limnicythere Sancti-Patrici, auf einer nicht näher bestimmten Ephemeriden-Larve und auf Detritus. Emmonoson (1906) auf Steinen und Blättern. Gruber (1914) auf den Blättern von Potamogeton. Hempel (1898) auf Lemna. Pritchard (1852) und Sveg (1897) auf Wasserpflanzen.

Vorticella microstoma Ehrenberg.

Diese für Abwässer und stagnierende Tümpel charakteristische Form fand ich auf folgenden Substraten:

\begin{tabular}{|c|c|c|c|c|}
\hline Träger. & Besetzte Teile. & Häuligk. ! & Fundort. & Datum. \\
\hline Strohhalme. & & ++ & Allschwil. & 20.2 . \\
\hline Grashalme. & & ++ & Muttenz. & 17. 5 . \\
\hline Cyclops strenuus. & C. $\mathrm{Ab}$. & + & Sichusterinsel. & 16. 10. \\
\hline C. viridis. & C. $\mathrm{Ab}$. & i & $"$ & 16. 7. \\
\hline ") & C. $\mathrm{Ab}$. & + & $"$ & 16. 10. \\
\hline $\begin{array}{l}\text { Limnophilus } \\
\text { politus juv. }\end{array}$ & Gehäuse. & + & Helgenmatt. & 29. 10 . \\
\hline
\end{tabular}

Ehrenberg (1838) und Stein (1854) in Heuaufgüssen und übelriechenden Wässern. Perty (1849) an Moosen, Chara und Oscillarien. Vельоvsк (1882) auf organischen Abfällen. Zsснокке $(1890,1893)$ auf Chironomus-Larven, Hydrophilus piceus und Notonecta lutea, später (1900) kommt als neuer Wirt noch Corixa hinzu. Francé (1897) aut Cladothrix. Hempel (1898) auf Lemna. Steinmann und Surbeck (1918) auf Cyclops. FaUré-Frémiet (1906) in Aufgüssen aller Art.

Vorticella microstoma var. abreviata nov. var.

Auf den verschiedensten Crustaceen, die zur Untersuchung gelangten, fand ich zu wiederholten Malen eine Vorticella, welche sich ihrem Habitus nach an Vorticella microstoma 
anschloss. Von dieser Species unterscheidet sie sich aber durch die kleinern Dimensionen des Körpers und durch die

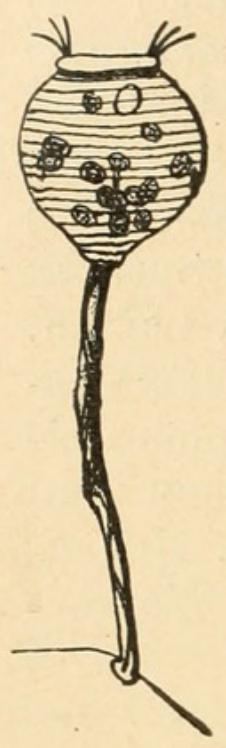

FIG. 1 . Kürze des Stieles. Der Stiel selbst erreicht selten die doppelte Länge des Körpers und erscheint daher ziemlich dick. Der Körper des Infusors hat eine eioder urnenförmige Gestalt, er ist in seiner Mitte am breitesten, verjüngt sich sowohl nach oben, als auch nach unten. Die Cuticula ist deutlich quergestreift. Der Rand des Peristoms ist nicht zurückgeschlagen, sondernbildet um das obere Körperende einen dicken, deutlich abgesetzten Wulst. Die Peristomoberfläche weist in ihrer Mitte eine kleine Erhebung auf. In der Nähe des Pharynx befindet sich die grosse

Vorticella microstoma var. abrecontractile Vakuole. Der Kern zeigt in Bezug auf viata n.var. Lage und Form die gleichen Verhältnisse wie bei Vorticella microstoma. Er ist hufeisenförmig und in der Längsrichtung des Körpers gelagert. Länge des Körpers : 31-39 $\mu$, Breite : 26-28 $\mu$. Hauptunterschiede gegenüber der Stamm-Art: Verkürzung der Längs- und Queraxe des Körpers und Reduktion der Stiellänge.

Dieses Infusor habe ich auf folgenden Wirten feststellen können :

\begin{tabular}{|c|c|c|c|c|}
\hline Träger. & Besetzte Teile. & Häufigk. & Fundort. & Datum. \\
\hline Alona intermedia & Schr. & 1 & Lange Erlen. & 26. 6 . \\
\hline simocephalus & & & & \\
\hline vetulus. & Schr. & I & Schusterinsel. & 25. 3 . \\
\hline $\begin{array}{l}\text { Chydorus } \\
\text { sphxricus. }\end{array}$ & Schr. & + & Lange Erle & 26. 6 . \\
\hline Cyclops strenuus. & C. A. Ab. & +-++ & Rheinfelden. & 11. 10 . \\
\hline C. viridis. & C. Ab. & & Böckten. & 16. 1. \\
\hline$"$ & C. A. & + & Benken. & 25. 3 . \\
\hline$"$ & C. & + & Niederholz/Basel. & 21. 3 . \\
\hline C. vernalis. & C. $\mathrm{Ab}$. & +-++ & Rheinfelden. & 11. 10 . \\
\hline 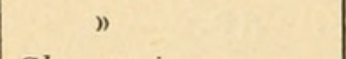 & C. Ab. A. & ++ & Augst. & 11. 10 . \\
\hline Cloeon juv. & hint. K.-Ende. & + & Schusterinsel. & 12. 5 . \\
\hline
\end{tabular}

Ob bei diesem Infusor Körper- und Stielverkürzung durch die Wahl des besetzten Substrates bedingt ist, kann ich nach 
dem jetzigen Stand meiner Beobachtungen noch nicht beurteilen. Auf die übermässig progressive oder regressive Entwicklung einzelner Organe, oder auf die gehemmte Entwicklung derselben bei den Infusorien hat Extz (1903) aufmerksam gemacht. Er fand, dass die Länge des Stieles der Vorticelliden im allgemeinen sehr veränderlich ist, und dass deshalb das Verhältnis zwischen Körper un Stiel keinen verlässlichen Artcharakter bildet. Auch konnte der Autor feststellen, dass bei Corthunia das besetzte Medium auf die Körpergrösse einen Einfluss ausübt.

\section{Vorticella putrinum O. F. Müller.}

Vorticella putrinum, die stark verschmutzte Gewässer den klaren vorzieht, in diesen aber auch häufig anzutreffen ist, besetzte nach meinen Funden folgende Wirte:

\begin{tabular}{|c|c|c|c|c|}
\hline Träger. & Besetzte Teile. & Häufigk. | & Fundort. & Dat. \\
\hline $\begin{array}{l}\text { Tote Pflanzenteile. } \\
\text { Faule Blätler. } \\
\text { Lemna trisulca. } \\
\text { L. minor. } \\
\text { Spirogyra. } \\
\text { Myriophyllum. } \\
\qquad " \text { " } \\
\text { Cyclops viridis. } \\
\quad " \\
\text { Chirotonetes-juv. } \\
\quad " \\
\text { " } \\
\text { Cloeon-juv. } \\
\text { " } \\
\text { Aeschna cyanea-juv. } \\
\text { Ilybius-juv. }\end{array}$ & $\begin{array}{l}\text { Blätter. } \\
\text { Wurzeln. } \\
\text { Blätter. } \\
\quad \text { » } \\
\text { C. } \\
\text { Eisäckchen } \\
\text { C. } \\
\text { K. } \\
\text { K. Kb. } \\
\text { K. B. Ko. } \\
\text { K. } \\
\text { Kb. } \\
\text { K. B. Ko. } \\
\text { B. } \\
\text { K. }\end{array}$ & $\begin{array}{l}+ \\
1 \\
+ \\
1-+ \\
+ \\
1 \\
++ \\
+ \\
+ \\
1 \\
1 \\
++ \\
1 \\
++ \\
++ \\
+ \\
1 \\
++ \\
+ \\
++\end{array}$ & $\begin{array}{l}\text { Bot. Garten Basel. } \\
\text { Lange Erlen. } \\
\text { Margarethen-Park. } \\
\text { Bot. Garten Basel. } \\
\text { Schusterinsel. } \\
\text { Lange Erlen. } \\
\text { Bot. Gaıten Basel } \\
\text { Zool Institut Basel. } \\
\text { Schusterinsel. } \\
\text { Margarethen-Park. } \\
\text { Kunzentalweiher. } \\
\text { Schusterinsel. } \\
\text { Margarethen-Park. } \\
\text { Neudorf. } \\
\text { Angenstein. } \\
\text { Margarethen-Park. } \\
\text { Schusterinsel. } \\
\text { Angenstein. } \\
\text { Schusterinsel. } \\
\text { Neuhüsli. }\end{array}$ & $\begin{array}{rr}\text { 4. } & 6 . \\
11 . & 12 . \\
8 . & 6 . \\
8 . & 12 . \\
27 . & 8 . \\
11 . & 12 . \\
29 . & 8 . \\
16 . & 8 . \\
12 . & 3 . \\
25 . & 1 . \\
11 . & 10 . \\
7 . & 3 . \\
25 . & 1 . \\
24 . & 9 . \\
9 . & 5 . \\
11 . & 6 . \\
7 . & 3 . \\
9 . & 5 . \\
7 . & 3 . \\
29 . & 10 .\end{array}$ \\
\hline
\end{tabular}

Alle Literaturangaben, die ich über Vorticella putrinum finden konnte, beziehen sich nur auf das Vorkommen dieser Peritrichen in den verschiedenen Gewässertypen, ohne dass 
die Substrate, auf denen sich die Infusorien-Familien angesiedelt haben, näher angegeben werden. Nur eine Angabe, die auf pflanzliche Träger schliessen lassen könnte, findet sich bei Roux (1901), der Vorticella putrinum in vegetabilischen Aufgüssen nachweisen konnte.

\section{Vorlicella convallaria Linné.}

Nicht wählerisch in Bezug auf die zu besetzenden Substrate ist, wie alle Vertreter dieses Genus, Vorticella convallaria, wie dies nachstehende Liste zeigt:

\begin{tabular}{|c|c|c|c|c|}
\hline Träger. & Besetzte Teile. & Häufigk. | & Fundort. & Datum. \\
\hline 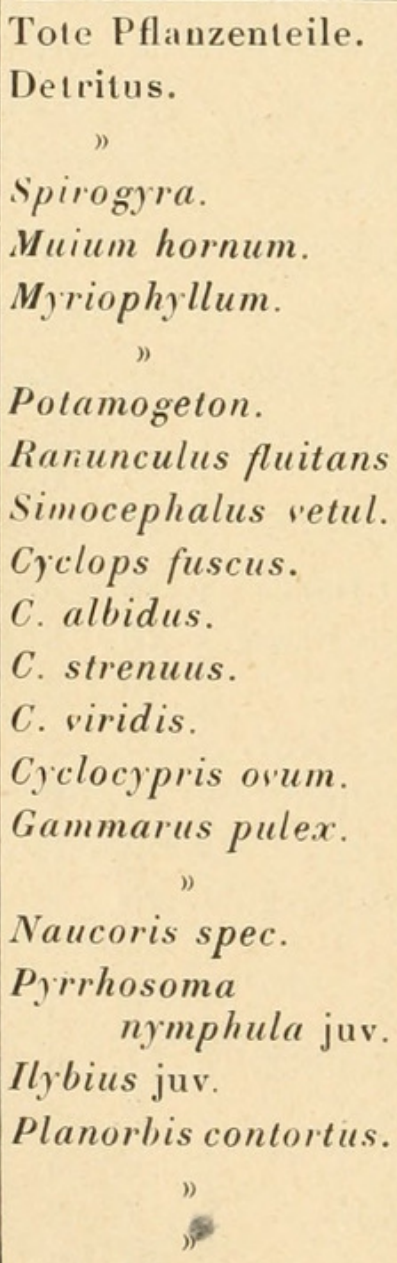 & $\begin{array}{l}\text { Blätter. } \\
\text { " , Stengel } \\
\text { Schr. } \\
\text { C. } \\
\text { Eisäckchen. } \\
\text { C. Ab. } \\
\text { C. } \\
\text { abgestreifte Schal. } \\
\text { ob. Teil d. Th. } \\
\text { B. } \\
\text { hinter d. Ko. . } \\
\text { K. } \\
\text { Gehäuse. } \\
\text { " , im Nabel }\end{array}$ & $\begin{array}{l}+ \\
++ \\
+ \\
1 \\
+ \\
+ \\
++ \\
++ \\
1 \\
1 \\
+ \\
1 \\
++ \\
++ \\
++ \\
++ \\
+ \\
1 \\
+ \\
+ \\
+ \\
+ \\
++\end{array}$ & $\begin{array}{l}\text { Bot. Garten Basel. } \\
\text { Bottmingcr-Weiher. } \\
\text { Lange Erlen. } \\
\text { Margarethen-Park. } \\
\text { Schusterinsel. } \\
\text { Seewagen. } \\
\text { Schusterinsel. } \\
\text { Zool. Institut Basel. } \\
\text { Kloster. Beinwil. } \\
\text { Schusterinsel. } \\
\quad \text { " } \\
\text { Liestal. } \\
\text { Schusterinsel. } \\
\quad \text { " } \\
\text { Zool. Institut Basel. } \\
\text { Schusterinsel. } \\
\text { Allschwil(Schiesstand) } \\
\text { Seewagen. } \\
\text { Görbelhofer Weiher } \\
\text { Benken. } \\
\text { Schusterinsel. } \\
\text { Niederholz/Basel. } \\
\text { Schusterinsel. }\end{array}$ & $\begin{array}{rr}24 . & 5 . \\
9 . & 8 . \\
7 . & 12 . \\
12 . & 6 . \\
7 . & 3 . \\
1 . & 10 . \\
7 . & 3 . \\
22 . & 6 . \\
29 . & 10 . \\
7 . & 3 . \\
27 . & 2 . \\
22 . & 5 . \\
9 . & 2 . \\
16 . & 1 . \\
28 . & 4 . \\
27 . & 2 . \\
6 . & 1 . \\
1 . & 10 . \\
& \\
11 . & 10 . \\
25 . & 3 . \\
16 . & 7 . \\
20 . & 1 . \\
7 . & 3 .\end{array}$ \\
\hline
\end{tabular}

Um das Bild über die Verbreitung der Vorticella convallaria auf Pflanzen und Tieren zu ergänzen, führe ich noch folgende Literaturangaben an. O. F. MüLler (1786) an Lemna und C'eratophyllum. Ehrenberg (1838) an Lemna. Perty (1852) an Lemna, Oscillaria, See- 
rosenblättern. Claparède und Lachmann (1858-59) auf Trümmern aller Art in stagnierenden Gewässern. Forel $(1877,1884,1904)$ auf Schneckengehäusen, Crustaceenpanzern, Anabaena circinalis und nach Chорат auf Sphaerocystis schroeteri. Iмноғ (1883, 1884, 1885-86, 1892 auf Algen. Duplessis (1885) fand Vorticella convallaria in der Tiefe der Seen auf Tieren, die einer raschen Bewegung unfähig sind; als Wirte werden von ihm angegeben: Arachniden, Bryozoen, Ostracoden und Cladoceren. Yung $(1885,1890)$ auf Cypris, Acanthopus und Lynceus. Heuscher (1890-1906) auf Diatomeen und Diaptomus. HoFer (1895) auf Cyclops viridis und Hygrobates longipalpis. Lozßron (1902) auf Fragillarla. Thí́baud und Favre (1906) auf Cyclops viridis. Le Roux (1907) auf Anabaena circinalis. Fentmann (1911) auf Limnaea profunda. Heuscher (1915) auf Anabaena crotonensis, Anabaena flos aquae und Asterionella gracillima.

\section{Vorticella monilatı Tatem.}

Dieses Infusor, das in unserm Untersuchungsgebiet selten zu sein scheint, fand ich auf folgenden Wirten :

\begin{tabular}{|c|c|c|c|c|}
\hline Träger. & Besetzte Teile. & Häufigk. & Fundort. & Datum. \\
\hline $\begin{array}{l}\text { Algenfäden. } \\
\text { Lemna minor. } \\
\text { Cyclops viridis. }\end{array}$ & $\begin{array}{l}\text { Wurzeln. } \\
\text { C. }\end{array}$ & $\begin{array}{l}1 \\
1-+ \\
+\end{array}$ & $\begin{array}{l}\text { Bottminger Weiher. } \\
\text { " } \\
\text { Schusterinsel. }\end{array}$ & $\begin{array}{ll}\text { 10. } & 8 . \\
15 . & 8 . \\
16 . & 1 .\end{array}$ \\
\hline
\end{tabular}

Die Peritriche, die von Tatem (1870) als Vorlicella consallaria var. monilata beschrieben wurde, wurde von ihrem Entdecker an Myriophyllum-Blättern gefunden. KEnt (1980-82) erhob die Varietät zur selbständigen Art. Anvandale (1906) begegnete ihr auf Hydra orientalis, Schröder (1906) auf Wasserpflanzen und faulenden Blättern.

\section{Der Symphorismus der Vorticellen.}

Ich versuchte für die einzelnen Arten der Vorticellen alles das zusammenzutragen, was für die Beurteilung ihres Symphorismus wichtig zu sein schien. Das Bild, das ich durch meine Untersuchungen schon erhalten hatte, wurde durch die Litteraturcitata erweitert und abgerundet, und so komme ich auf Grund des oft reichen Materials zum Schlusse, dass ein specifischer Symphorismus bei sämtlichen Vorticella-Arten nicht nachgewiesen werden kann. Steine, Detritus und organische 
Ueberreste werden ebenso häufig besiedelt, wie die aus den systematisch-verschiedensten Gruppen stammenden Pflanzen und Tiere. Nur wenige Süsswassertiere werden unter den Trägern vermisst, z. B. die Käfer. Den starken, hastigen Bewegungen dieser Tiere werden die dünnen Stiele der Vorticellen nicht gewachsen sein. Nur acontractile Vorticelliden, mit speziell angepasster Stielstruktur, können sich auf Coleoptern festsetzen. Wo ist nun aber der Grund für die weite Verbreitung der Vorticellen auf den verschiedensten Wirtsgruppen zu suchen? Ich erkenne ihn in der Contractilität des Stieles; sie ist es, die keine Vorticella zum specifischen Symphorionten werden lässt. Ganz ähnliche Verhältnisse werden uns bei den Genera Carchesium und Zoothamnium wieder begegnen. Eine Erklärung für die Erscheinung, dass wirklich die Contractilität des Stieles eine weite Verbreitung einer Infusorien-Art auf den verschiedensten Wirten sichert, wird weiter unten zu geben versucht.

Genus: Carchesium Ehrenberg.

Carchesium aselli Engelmann.

Carchesium aselli fand ich überall da, wo auch sein specifischer Wirt auftritt, nämlich an folgenden Orten:

\begin{tabular}{|c|c|c|c|c|}
\hline Träger. & Beselzte Teile. & Häufigk. | & Fundort. & Datum. \\
\hline Asellus aquaticus. & $\begin{array}{l}\text { Kb., Th. } \\
\text { Th. } \\
\text { A. Th. }\end{array}$ & $\begin{array}{l}+-++ \\
+ \\
+\end{array}$ & $\begin{array}{l}\text { Margarethen-Park. } \\
\text { Bot. Garten Basel. } \\
\text { " }\end{array}$ & $\begin{array}{ll}\text { 11. } & 6 . \\
12 . & 7 . \\
28 . & 8 .\end{array}$ \\
\hline
\end{tabular}

Das Infusor ist von Engelmane (1862) beschrieben und von ihm auf den Füssen, Fühlern und Seiten von Asellus aquaticus gefunden worden. Kent (1880-82) und nach Stokes (1888) auch Kellicott auf demselben Wirt. Richard (1899) und Roux (1899, 1901) begegneten der Peritrichen häufig auf den Füssen und ihren Anhängen vor Asellus. Roux bemerkt, dass die Kolonien immer zahlreich an den Gelenken zu finden waren.

Diese wenigen Angaben zeigen, dass Carchesium aselli ein specifischer Symphoriont von Asellus aquaticus ist. Zu seiner 
Besiedlung bevorzugt das Infusor die Bewegunsorgane des Isopoden, setzt sich zuweilen aber auch auf den Kiemen und Antennen fest. Obwohl Asellus gewöhnlich träge zwischen Wasserpflanzen herumkriecht, ist er doch auch einer raschschwimmenden Bewegung fähig, um seinen Feinden zu entwischen. An diese Bewegungsart ist sein Symphoriont angepasst durch den dicken, längs- und quergestreiften Stiel. Auf die Bedeutung der Stielstruklur für die Epizoen, die uns noch öfters beschäftigen wird, werde ich später zurückkommen.

\section{Carchesium polypinum (Linné).}

Diese weitverbreitete Art konnte von mir auf folgenden Substraten nachgewiesen werden:

\begin{tabular}{|c|c|c|c|c|}
\hline Träger. & Besetzle Teile. & Häufigk. & Fundort. & Datum. \\
\hline $\begin{array}{l}\text { Detritus. } \\
\text { Spongilla fragilis. } \\
\text { Limnaea peregra. }\end{array}$ & Gehäuse. & $\begin{array}{l}+ \\
+ \\
++\end{array}$ & $\begin{array}{l}\text { Bottminger Weiher. } \\
\text { Zool. Institut Basel. }\end{array}$ & $\begin{array}{l}\text { 7. } 8 . \\
\text { 7. } 8 . \\
\text { 1. } 11 .\end{array}$ \\
\hline
\end{tabular}

Gross ist die Zahl der Angaben, die wir in der Literatur über Carchesium polypinum finden, handelt es sich doch nicht nur um eine ausgesprochene Süsswasserform, sondern um eine Art, welche auch im Meere häufig angetroffen wird. Ich beschränke mich jedoch im folgenden auf die Daten, die ich über das Vorkommen der Peritrichen im Süsswasser finden konnte, da bei den marinen Funden ähnliche Verhältnisse in Bezug auf die Wahl der Wirte angetroffen worden sind.

Ehrexberg (1838) fand C'archesium polypinum an Lemna, C'eratophyllum und andern Wasserpflanzen. Seltener beobachtete er das Infusor auf lebenden Schnecken, Wasserflöhen und PhryganeenLarven. Stein (1854) an Lemnawurzeln. Claparède und Lachmann (1860-61) auf Callitriche. Fores (1884, 1904) auf Holzstückchen, Chara und Potamogeton. Moniez (1889) auf Gammarus puteanus-Leichen. Francé (1897) auf Entomostracen. Hempel (1897) auf Lemna. Godet (1900) auf Steinen. Roux (1901) auf Wasserpflanzen und Blättern. Edmondson (1906) auf Steinen und Blättern. Thí́baud und Favre (1906) auf den Gehäusen von Limnaea. Le Roux (1907) auf Myriophyllum-Blättern. Тнге́ваud (1908) auf C'yclops viridis. Zsснокке 
(1911) auf Holzstücken, Pflanzen und Mollusken-Schalen. André (1912) an einer Larve von Hydrophilus. Sternmann und Surbeck (1918) an Larven von Perla maxima.

Carchesium polypinum zieht, wie aus diesen Angaben ersichtlich ist, die ruhenden Substrate den beweglichen vor. Als die ursprünglichen Träger des Infusors sind wohl die Wasserpflanzen anzusehen. Doch dank der Contractilität des Stieles wird es ihm ermöglicht, auch auf Mollusken, Insekten-Larven und ausnahmsweise sogar auf Cyclopiden Fuss zu fassen.

\section{Carchesium epistylidis Claparède und Lachmann.}

Diese Art, welche ich in meinem Untersuchungsmaterial häufig zu beobachten Gelegenheit hatte, konnte ich auf folgenden Wirtstieren finden :

\begin{tabular}{|c|c|c|c|c|}
\hline Träger. & Besetzte Teile. & Häufigk. & Fundort. & Datum. \\
\hline Dero spec. & Ko. & + & Stauweiher Augst. & 18. 6. \\
\hline Cyclops viridis. & & + & Margarethen-Park. & 7. 6 . \\
\hline Chirotonetes juv. & K. in d. Nähe d. Kb. & ++ & Stauweiher Augst. & 18. 6. \\
\hline ") & & + & Allschwil. & 21. 7 . \\
\hline 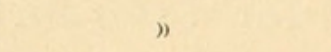 & $\mathrm{Kb}$. & & Schusterinsel. & 6. 11. \\
\hline ") & K. Kb. Füsse. & +-++ & Neudorf. & 24. 9. \\
\hline Cloeon juv. & $\mathrm{K}$. & & Bot. Garten Basel. & 12. 7. \\
\hline " & K. b. d. Kb. & + & Bottminger Weiher. & 10. 8. \\
\hline ) & & ++ & Schusterinsel. & 26. \\
\hline ) & $\mathrm{Kb}$. & + & " & 7. 3. \\
\hline $\begin{array}{l}\text { Limnophilus } \\
\text { rhombicus juv. }\end{array}$ & Beine, rord. K. teil. & ++ & Allschwil(Schiesstand) & 6. 1. \\
\hline Limnoph. spec. & K. Mt., Füsse. & + & Vord. Geissberg. & 29. 10 . \\
\hline ") & vord. K. teil. & / & Niederholz/Basel. & 21. 3 . \\
\hline $\begin{array}{l}\text { Stenophylax } \\
\text { concentricus juv. }\end{array}$ & ") & + & Schusterinsel. & 20. 1 . \\
\hline$"$ & Beine, hiut. K. ende. & + & Niederholz/Basel. & 7. 3. \\
\hline Perla & & & Kalub & $29 \quad 10$ \\
\hline Ilybius juv. & K. Beine. & ++ & Schusterinsel. & 16. 3. \\
\hline (101). & K. Beine. & 1 & ) & 16. 3. \\
\hline
\end{tabular}

Von Claparède und Lachmann (1858-59) ist Carchesium epistylidis zuerst beschrieben und auf Phryganiden-Larven und deren Gehäuse sowohl, als auch auf den Larven von Culex pipiens gefunden worden. Kent (1880-82) auf Plumatella repens. Roux (1901) auf EphemeraLarven. 'Thíbaud und Favre (1906) auf Cyclops strenuus, C. serru- 
latus und C' fuscus. Die Autoren versehen jedoch ihren Fund mit einem Fragezeichen. Ich glaube, dass es sich eher auf Zoothamnium parasita bezieht. Monard (1919) auf Iliocypris sordidus.

Đer Symphorismus von Carchesium epistylidis unterscheidet sich von dem der oben genannten Species dadurch, dass ruhende Substrate fast gänzlich gemieden und nur frei sich bewegende Tierformen besetzt werden. Anklänge an den primären Symphorismus auf Pflanzen finden sich noch. So weist der Befund von Kext deutlich auf die ursprüngliche Lebensweise hin, und auch in den meisten der oben angeführten Inseckten-Larven erkennen wir Tiere, die ein "wenig bewegtes Leben » führen.

\section{Der Symphorismus der Carchesien.}

In dem kleinen Genus macht sich bereits ein Anstieg 7.um specifischen Symphorismus bemerkbar. Während Carchesium polypinum auf den verschiedensten Substraten die nötigen Lebensbedingungen findet, zieht sich der Kreis der zu besetzenden Substrate bei Carchesium epistylidis immer enger. Aus seinem Bereich werden alle pflanzlichen Träger ausgeschieden und nur mehr oder weniger bewegliche Tierformen bilden den Bestand der zu besetzenden Wirte. Fast sprunghaft, ohne mit den beiden erstgenannten Arten durch eine Zwischenform biologisch verbunden zu sein, hat sich Carchesium aselli zum specifischen Symphorionten s. str. ausgebildet.

\section{Genus: Zoothamnium Ehrenberg (Stein emend).}

\section{Zoothamnium affine Stein.}

Ich konnte diese Peritriche auf nachfolgenden Wirten feststellen :

\begin{tabular}{|c|c|c|c|c|}
\hline Träger. & Besetzte T'eile. & Häufigk. | & Fundort. & Datum. \\
\hline $\begin{array}{l}\text { Gammarus pulex. } \\
\text { Chirotonetes juv. } \\
\text { Limnophilus } \\
\text { rhombicus juv. }\end{array}$ & $\begin{array}{l}\text { Th. } \\
\text { Kb. } \\
\text { vord. K. teil. }\end{array}$ & $\begin{array}{l}1 \\
1-+ \\
+\end{array}$ & $\begin{array}{l}\text { Allschwil. } \\
\text { Margarethen-Park. } \\
\text { Bökten. }\end{array}$ & $\begin{aligned} 21 . & 7 . \\
9 . & 6 . \\
16 . & 1 .\end{aligned}$ \\
\hline
\end{tabular}


STEIN (1854) macht über das Vorkommen von Zoothamnium affine auf Gammarus pulex die interessante Angabe, die ich bestätigen kann, dass die Kolonien fast ausnahmslos auf den Beinen des Krebses gefunden werden. Ganz selten konnte der Autor kümmerlich entwickelte Kolonien auch auf den Kiemenblättern des Amphipoden feststellen. Francé (1897) auf C'yclops und Diaptomus. Richard (1899) auf Gammarus und Entomostracen.

Aus diesen Angaben geht hervor, dass bei Zoothamnium affine von einem specifischen Symphorismus nicht gesprochen werden kann. Wie bei der nächsten Art, werden von den Kolonien dieser Species die verschiedensten Arthropoden besiedelt, ohne dass, wie ich aus den angeführten Litteraturcitalen und meinen Befunden schliesse, gewisse Arten bevorzugt werden.

\section{Zoothamnium parasita Stein.}

Diese Art scheint etwas häufiger als die vorige zu sein; sie konnte von mir auf folgenden Wirten beobachtet werden:

\begin{tabular}{|l|l|l|r|r|}
\hline \multicolumn{1}{|c|}{ Träger. } & Besetzte Teile. & Häufigk. & Fundort. & Dalum. \\
\hline Daphnialongispina. & Ko., Schr. & ++ & Bottminger Weiher. & 6.12. \\
Cyclops albidus. & C. & $\mid$ & $»$ & 29.10. \\
C. strenuus. & C., Ab., F., Biballen. & ++ & $»$ & 30.11. \\
Diaptomus vulgaris. & Eiballen. & ++ & $»$ & 2.12.
\end{tabular}

Zoothamnium ist ebenfalls von STEIN (1854) beschrieben und auf Kopf, Schwanzanhängen, seltener auf den Beinen von Asellus aquaticus beobachtet worden. Von seinem Entdecker wurde das Infusor auch auf Cyclops, auf den Kiemenblättern von Ephemeriden-Larven, auf Daphnia und Brachionen gefunden. Ehrenberg's C'archesium pygmaeum (1838) hat Stern mit seiner neuen Art identificiert. D'UDEKEM (186') auf Asellus aquaticus und Insekten-Larven. KenT (1880-82) auf Cylops quadricornis und andern Entomostraken. DADAY (1895) auf Cypris dispar. Richard (1899) auf Cyclops quadricornis. Godet (1900) auf dem Abdomen eines Cyclops. Daday (1908) nur auf Copepoden; später (1910) gibt er ganz allgemein Entomostraken als Wirte der Peritrichen an.

Auch bei Zoothamnium parasita kann von einem specifischen Symphorismus nicht die Rede sein. Wohl beschränkt 
sich das Vorkommen des Infusors auf Arthropoden; aber die Wirte, die von ihm besetzt werden, gehören systematisch sehr weit auseinanderliegenden Gruppen an. Die Entomostraken, und unter diesen speciell die Cyclops-Arten, werden von Zoothamnium parasita am häufigsten aufgesucht.

Zoothamnium aselli Claparède und Lachmann.

Das seltene Infusor kommt nicht nur, wie sein Name vermuten lässt, auf Asellus vor, sondern setzt sich auch auf andern Wirten fest, was folgende Tabelle zeigt: .

\begin{tabular}{|c|c|c|c|c|}
\hline Träger. & Besetzte Teile. & Iläufigk. | & Fundort. & Datum. \\
\hline Gammarus pulex. & Th. (Gelenke). & + & $\begin{array}{l}\text { Arlesheim. } \\
\text { Görbelhofer Weiher }\end{array}$ & $\begin{aligned} 6 . & 2 . \\
11 . & 10 .\end{aligned}$ \\
\hline $\begin{array}{l}\text { Niphargus puteanus } \\
\text { Asellus aquaticus. }\end{array}$ & Ko., Beine. & 1 & $\begin{array}{l}\text { Allschwil (Quelle). } \\
\text { Margarethen Park. }\end{array}$ & $\begin{aligned} 16 . & 6 . \\
9 . & 6 .\end{aligned}$ \\
\hline
\end{tabular}

Von Claparède und I,achmann (1858-59) ist Zoothamnium aselli auf Asellus aquaticus gefunden worden. KeNo (1880-82) gibt als Wirte "Asellus and various aquatic insects and Crustacea" an. FauréFrémiet (1906a) beobachtete die Peritriche nur auf dem Kopf von Asellus aquaticus.

Dies sind die einzigen Daten, die ich in der Literatur über das Vorkommen von Zoothamnium aselli finden konnte. Aus ihnen mag hervorgehen, dass das Infusor nicht allein an Asellus gebunden ist, wie aus der Angabe von Kent geschlossen werden kann. Auch meine eigenen Funde verweisen Zoothamnium aselli auf verschiedene Wirte.

\section{Der Symphorismus der Zoothamnien.}

Ueber den Symphorismus der Vertreter des Genus Zoothamnium lässt sich kurz folgendes sagen. Wie bei der Gattung Carchesium, finden sich auch hier noch keine specifischen Symphorionten. Die drei beobachteten Arten konnten von mir auf den verschiedensten Arthropoden festgestellt werden, nie sind 
aber Pflanzen oder tote Substrate als Träger der einen oder andern Species nachgewiesen worden. Nur Zoothamnium arbuscula Ehrenberg steht als auf Wasserpflanzen beobachtete Zoothamnium-Art da. Während beim Genus Carchesium noch starke Anklänge an Vorticella in Bezug auf die Wahl der Träger sich vorfanden, leitet Zoothamnium über zu den acontractilen Peritrichen, bei denen der specifische Symphorismus sich stark ausgeprägt hat.

\section{Sektion: Acontractilea Bütschli. \\ Genus: Epistylis Ehrenberg. \\ Epistylis steini Wrzesniowsky.}

Diese Art, die aus der Schweiz nur aus dem Genfer-See bekannt ist, konnte ich in der Umgebung von Basel öfters finden und zwar immer auf Gammarus, wie dies folgende Zusamenstellung zeigt :

\begin{tabular}{|c|c|c|c|c|}
\hline Träger. & Besetzte Teile. & Häufigk. & Fundort. & Datum. \\
\hline Gammaruspulex & Kb. (Fläche). & $T$ & Münchenstein. & 22. 1 . \\
\hline$n$ & $n$ & $1-+$ & Arlesheim. & 6. 2 . \\
\hline ") & $"$ & + & Schusterinsel. & 11. 2 . \\
\hline 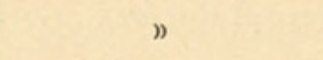 & ) & +-++ & 》) & 27. 6 . \\
\hline$”$ & ” & & Görbelhofer Weiher. & 10. 10 \\
\hline ) & ) & $1 /$ & Allschwil (Schiesstand). & 6. 1. \\
\hline
\end{tabular}

Epistylis steini wurde von Wrzesniowsky (1877) als Epizoon von Gammarus pulex beschrieben. Kent (1880-82), Forel (1904), Richard (1889), Fauré-Frémiet (1906a), André (1915) haben das Infusor auf den Kiemenblättern desselben Krebses gefunden.

Diese Angaben und meine Funde zeigen deutlich, dass Epistylis steini ein specifischer Symphoriont von Gammarus pulex ist. Sein Verbreitungsgebiet deckt sich mit demjenigen des Amphipoden. Das von Fauré-Frémiet (1906a) gewonnene Resultat, dass ein Wasserinsekt nur von seinem oder seinen spe- 
cifischen Symphorionten besiedelt werde, oder aber von einer Besiedlung verschont bleibe, kann auf alle Wirte ausgedehnt werden, denen specifische Symphorionten zukommen, besonders aber auch auf Gammarus. Nie habe ich auf den Kiemen von Gammarus andere Epizoen finden können als Spirochona gemmipara, Epistylis sleini, Lagenophrys ampulla und Dendrocomeles paradoxus. Aus der ganzen Litteratur sind mir nur zwei Fälle bekannt geworden, wo die Regel nicht zutraf. Im ersten Fall setzte sich Zoothamnium affine auf den Respirationsorganen des Amphipoden fest. Stein (1854) bemerkt aber selbst zu seinem Befund, dass die Kolonien nur kümmerlich entwickelt waren. Ich bin geneigt, dieses Zoothamnium auf den Kiemen von Gammarus mit Epistylis steini zu identificieren; denn auch bei dieser sind die Stöcke klein und individuenarm. Im zweiten Falle handelt es sich um eine Angabe von Richard (1899), der Epistylis anastatica auf den Kiemen von Gammarus gefunden haben will. Auch die Richtigkeit dieses Befundes scheint mir sehr fraglich zu sein.

Der Ort, auf dem sich die Epistylis-Kolonien festsetzen, ist nicht der freie Kiemenrand, sondern stets die Fläche. Ich konnte die Beobachtung machen, dass die Kolonien sich mit Vorliebe in der Mitte des Kiemenblattes aufhielten und gegen die Ansatzstelle zu sich concentrierten. In diesem Verhalten erkenne ich eine Anpassung an die fortwährende Bewegung der Kiemenblätter. An den genannten Anheftungsstellen ist, da sie näher dem Bewegungscentrum gelegen sind, die Wucht der Bewegung kleiner als am freien Ende. Hier, und nur hier, kann sich infolge dessen eine gestielte Vorticellide halten. Alle übrigen Symphorionten der Atmungsorgane von Gammarus vermögen, da sie mit einer breiten Basisfläche der Unterlage aufliegen, die freien Kiemenränder zu besiedeln.

Epistylis digitalis Ehrenberg.

Die in unserm Untersuchungsgebiet weit verbreitete Art konnte auf folgenden Wirten festgestellt werden: 


\begin{tabular}{|c|c|c|c|c|}
\hline Träger. & | Besetzte Teile. & Häufigk. | & Fundort. & Datum. \\
\hline Cyclops fuscus. & F. & l & Lange Erlen Basel. & 2. 7 . \\
\hline$"$ & $\mathrm{Ab}$. & I & Schusterinsel. & 27.2 . \\
\hline ” & $\mathrm{Ab}$. & i & Bottminger Weiher. & 29. 11 . \\
\hline C. serrulatus. & 4. Th. & + & Stauweiher Augst. & 19. 6. \\
\hline$"$ & 4. Th. & + & Schusterinsel. & 19. 7. \\
\hline$"$ & $\mathrm{Ab}$. & l & ") & 19. 7. \\
\hline » & 4. Th C. Ab. & ++ & ” & 25. 8 . \\
\hline$"$ & 4. Th. & ++ & ) & $\begin{array}{rr}16 . & 10 . \\
16 . & 1 .\end{array}$ \\
\hline ” & 4. Th. & + & Arlesheim. & 5. 2 . \\
\hline ” & 4. Th. & ++ & Alschwil. & 20. 2 . \\
\hline$»$ & 4. Th. & ++ & Bogental. & 25. 11 . \\
\hline$n$ & $\mathrm{Ab}$. & + & Mariastein. & 5. 10. \\
\hline ") & 4. Th. & ++ & Rheinfelden. & 11. 10 . \\
\hline$n$ & 4. Th. & + & Seewener-See. & 21. 10 . \\
\hline ” & 4. Th. & ++ & Kaltbrunnental. & 29. 10 . \\
\hline$"$ & 4. Th. & + & Niederholz/Basel. & 14. 5. \\
\hline C. bisetosus & C. & 1 & Allschwil (Schiesstand). & 13. 2 . \\
\hline
\end{tabular}

Von O.F. Mǘler (1786) istVorticella digitalis (=Epistylis digitalis) auf Cyclops quadricornis gefunden worden. Schrank (1803) auf Stratiomys-Larven und Ceratophyllum. Ehrenberg (1830-31) hat die Species dem Genus Epistylis einverleibt, er beobachtete sie häufig auf Cyclops quadricornis (1838). Perty (1852) auf Lemna und Cyclops quadricornis. Pntchard (1852) und Stein (1854) auf C'yclops quadricornis. Letzterer gibt über das Vorkommen auf diesem Crustaceen an, dass die Kolonien sich an der Furka, dem Abdomen und der Rückenseite festsetzen und oft in solcher Menge auftreten, dass die Wirte teilweise oder ganz wie in einem schimmelartigen Gewebe stecken. Kent (1880-82) auf verschiedenen Arten von Cyclops und andern Entomostraken. Richard (1899), Francé (1897), Svec (1897) und Roux (1901) auf Cyclops spec. Monard (1919) auf Cyclops serrulatus.

Aus diesen Daten, die ich über das Vorkommen von Epistylis digitalis finden konnte, scheint mit Sicherheit ein specifischer Symphorismus auf Cyclopiden sich zu ergeben. Der von Schrank gemachte Befund der Peritrichen auf Ceratophyllum ist schon von Ehrenberg angezweifelt worden, und ebenso möchte ich die von Penty gemachte Angabe über das Vorkommen auf Lemna in Frage stellen. Bei beiden Angaben mag es sich vielleicht um eine Verwechslung mit Epistylis anastatica handeln. 
Wie aus meiner obigen Zusammenstellung zu ersehen ist, setzt sich der Symphoriont mit grosser Regelmässigkeit am vierten Thoracalfuss von Cyclops serrulatus fest, oder dann, wie dies die Angaben von Stern bestätigen, am Abdomen und der Furka von andern Cyclops-Arten. Die Besetzung von einem der drei ersten Thoracalfüsse von Cyclops serrulatus ist deshalb unmöglich, da diese eng aneinander liegen und kein freier Raum zwischen ihnen vorhanden ist. Der vierte Fuss ragt dagegen frei ins Wasser hinaus und gibt den Kolonien Gelegenheit, sich auf ihm festzusetzen. Nach den Resultaten, die Fauré-Frémiet $(1906$ b) aus einer Versuchsserie erhalten hat, ist die Bewegung des Wirtes die alleinige Lebensbedingung, welche die Epizoen von ihm verlangen. Sie erklärt aber nicht die Specifität des Symphorismus, da vielleicht noch andere, weniger wichtige Faktoren, sie beeinflussen. Wenn wir also Epistylis digitalis auf zwei verschiedenen Körperteilen von zwei oder mehreren Cyclops-Arten antreffen, so muss angenommen werden, dass beide Körperteile in ihrer Bewegung. dieselbe Wirkung auf das Epizoon ausüben. Mit andern Worten, an dem Abdomen oder der Furka von Cyclops fuscus findet die Peritriche die gleichen biologischen Verhältnisse wieder, wie auf dem vierten Thoracalfuss von Cyclops serrulatus. Ein Uebergang der Kolonien von Epistylis digitalis auf den Cephalothorax der Cyclopiden findet nach meinen Beobachtungen nur dann statt, wenn die gewöhnlich besetzten Teile übervölkert sind. Dass in diesem Falle der neue Ort den Ansprüchen des Infusors nicht genügt, glaube ich an der geringen Höhe und Individuenzahl der Kolonien an solchen Stellen zu erkennen. Es kommt zu einer Art von Degeneration.

An die starke Bewegung des vierten Thoracalfusses von $C y-$ clops serrulatus hat sich das Infusor durch eine starke Querringelung des Stieles angepasst. Diese Erscheinung, die bei Carchesium aselli schon zu constatieren war, tritt uns in der Sektion der Acontractilea in erhöhtem Masse noch entgegen, und zwar mit steter Regelmässigkeit bei den Epizoen, die lebhaft sich bewegende Wirte oder Körperteile derselben besiedeln.

Revue Suisse de Zoologie T'. 28. 1921. 
Eine Erklärung dieser Erscheinung soll im folgenden Teile dieser Arbeit gegeben werden.

\section{Epistylis diaptomi Fauré-Frémiet.}

Bei meinen Untersuchungen musste des öftern constatiert werden, dass sich auf Diaptomiden selten sessile Infusorien finden. Nur zwei Species, Epistylis lacustris und Zoothamnium parasita, konnte ich auf Vertretern dieses Genus nachweisen. Umso auffallender war es, dass fast alle DiaptomusExemplare aus einem Altwasser des Rheins dicht mit einer Epistylis-Art besetzt waren, die mit der von Fauré-Frémiet (1906e) beschriebenen Epistylis diaptomi identificiert werden konnte. Meine Funde für das Infusor sind die folgenden:

\begin{tabular}{|c|c|c|c|c|}
\hline Träger. & Besetzte Teile & Häufigk. | & Fundort. & Datum. \\
\hline Diaptomus ,ulgaris. & $\begin{array}{l}\text { Ab., C., A. } \\
\text { Ab., A. }\end{array}$ & $\begin{array}{l}++ \\
++\end{array}$ & $\begin{array}{c}\text { Schusterinsel. } \\
\Downarrow\end{array}$ & $\begin{array}{rr}6.11 . \\
16 . \quad 1 .\end{array}$ \\
\hline
\end{tabular}

Fauré-Frémiet hat die Kolonien dieser Peritrichen auf Diap-

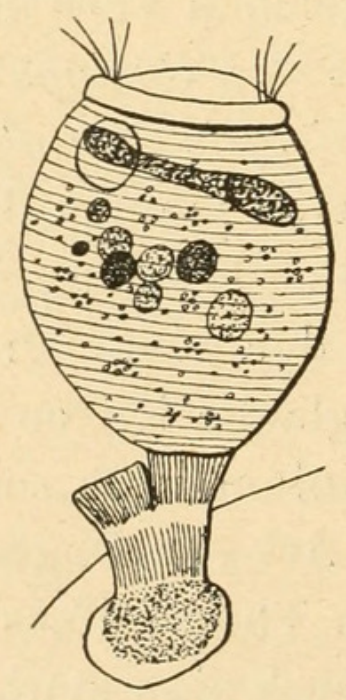

FIG. 2 .

Epistylis diaptomi Fauré. Einzeltier einer Kolonie.

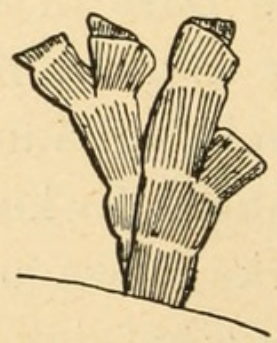

FIG. 3. Epistylis diaptomi Fauré. Stiel einer Kolonie.

tomus castor beobachtet. Da die Art nur kurz von ihm charakterisiert ist und in der gesamten neuern Literatur nirgends 
erscheint, so glaube ich, dass eine erweiterte Diagnose hier am Platze ist.

Epistylis diaptomi: Der Körper hat eine eiförmige oder elliptische Gestalt. In seinem mittleren Teile ist die grösste Breite. Die Cuticula ist quergestreift, das Peristom ziemlich eng, sein Rand springt nur wenig vor und ist nicht zurückgeschlagen. Die Peristomoberfläche ist stark gewölbt und erhebt sich deutlich über dem Peristomrand. Der hufeisenförmige Kern liegt quer im obern Drittel des Körpers in der Nähe des Peristomrandes. Eine grosse contractile Vakuole ist vorhanden. Der Stiel zeichnet sich durch seine Dicke und oft geringe Höhe aus. Er ist dichotom verzweigt und deutlich längsgestreift. An den Bifurkationsstellen fällt ein heller Ring auf, dem jegliche Längsstreifung fehlt. Die Kolonien sind individuenarm bis sehr individuenreich.

Länge des Körpers : $49 \mu$. Breite : $43 \mu$.

Der specifische Symphorismus hat auch hier eine Anpassung des Infusors an Bewegungseigentümlichkeiten des Wirtes hervorgerufen. Es ist wieder der Stiel, der den Anforderungen, welche die sprunghafte Fortbewegung der Diaptomiden an das Epizoon stellt, Stand halten muss. In seiner beträchtlichen Dicke und seiner oft geringen Höhe ist ein Weg gefunden, der seine Festigkeit erhöht. Doch darf in der Verdickung und Verkürzung des Stieles nicht die alleinige Erklärung für eine Anpassung an die Bewegungen des Trägers gesucht werden. Vielen andern acontractilen Epizoen, welche ebenfalls heftige Bewegungen ihrer Wirte auszuhalten haben, kommt eine solche Ausbildung des Stieles nicht zu, wohl aber besitzen sie eine Längsstreifung des Fixationsorganes, die für diese Symphorionten hinsichtlich der Möglichkeit der Besetzung gewisser Wirte von grösster Bedeutung ist, und auf die ich weiter unten eingehender zu sprechen kommen werde.

\section{Epistylis plicatilis Ehrenberg.}

Diese zu allen Jahreszeiten sich häufig findende Species 
konnte ich auf den verschiedensten Wirten feststellen, wie das die folgende Zusammenstellung zeigt:

\begin{tabular}{|c|c|c|c|c|}
\hline Träger. & Besetzte Teile. & Häufigk. & Fundort. & Datum. \\
\hline Tote Pflanzen. & & + & Bottminger Weiher. & 10. 8. \\
\hline spirogyra. & & + & (n) & 10. 8. \\
\hline Lemna minor. & Wurzeln. & ++ & Schusterinsel. & 27.11 \\
\hline Cyclops fuscus. & & + & Bot Garten Basel. & 5. 7 . \\
\hline ) & $\mathrm{Ab}$. & 1 & Schusterinsel. & 6. 11. \\
\hline ) & C. & + & Neudorf. & 24. 9 \\
\hline ") & $\mathrm{F}$. & l & Arlesheim. & 20.11 . \\
\hline C. strenuus. & C., $\mathrm{Ab}$. & $1-+$ & Schusterinsel. & 19. 2. \\
\hline C. vernalis. & C. & & Helgeumatt. & 29. 10 . \\
\hline C. serrulatus. & C. & $1-+$ & Mariastein. & 5. 10 . \\
\hline$"$ & C. Ab. & + & Kaltbrunnental. & 29. 10 . \\
\hline () & C. & I & Arlesheim. & 20.11 . \\
\hline Gammarus pulex. & Th. & 1 & Schusterinsel. & 19. 2. \\
\hline Chirotonetes juv. & Ko., Beine. & + & Mariastein. & 5. 10 . \\
\hline $\begin{array}{l}\text { Platambus } \\
\text { maculatus. }\end{array}$ & Ko. & 1 & Allschwil. & 22. 7 . \\
\hline Physa fontinalis. & Gehäuse. & + & Mariastein. & 510. \\
\hline Planorbis contortus. & ” & + & Schusterinsel. & 12. 3. \\
\hline
\end{tabular}

O. F. Müller (1886) beschrieb eine Vorticella pyraria, Vorticella anularis, die er auf Ceratophyllum fand, die nach Ehrenserg mit Epistylis plicatilis identisch sind. Epistylis plicatilis erscheint in der Literatur zum ersten Male bei Ehrenberg (1838), er fand sie auf kleinen Wasserschnecken. Dujardin (18'1) auf Ceratophyllum. Perty (1852) auf Lemna. STEIN (1854) sah Epistylis plicalilis weissliche schimmelartige Ueberzüge auf den Gehäusen von Paludina vivipara bilden, dann konnte er sie auch auf Paludina impura, Planorbis spirorbis und Limnaea palustris feststellen. Claparède und I.ACHManN (1858-59) auf den Gehäusen von Paludina achatina. Engelmann (1876) auf Paludina vivipara, Kent (1880-82) auf Limnaea stagnalis und Wasserpflanzen. Moniez (1889) auf den Cadavern von Lumbricus. Zsснокке (1890) in grossen Kolonien auf den meisten Exemplaren von Gammarus pulex. Hempel (1898) auf lnsekten-Larven, den Gehäusen von Wasserschnecken, wie Physa, und Paludina vivipara. Roux (1900, 1901) auf Typha, Limneus und Cyclops. Emondson (1906) auf Steinen und Blättern. Le Roux (1907) auf Cyclops und Nais. Daday (1908) auf Pflanzenresten und Entomostraken, später (1910) auf Cyclops leuckarti. André (1912) und Ḧ̈мpeL (1917) auf Cyclops spec. Меrмod (1914) auf den Gehäusen von Planorben. Bourquin-Lindt (1918) auf Nais. Heberli (1918) auf Copepoden. Monand (1919) auf Tanitarsus, seltener auf Tubifex velutinus. 
Aus diesen Angaben ergibt sich, dass Epistylis plicatilis keine specifischen Wirte besiedelt. Die verschiedensten Organismen werden besetzt; unter diesen nehmen aber die Mollusken einerseits und die Wasserpflanzen andererseits den ersten Rang ein. Auf eine Tatsache, die für die spätern Betrachtungen von Wichtigkeit werden wird, soll hier kurz hingewiesen sein. Sie betrifft das Vorkommen auf den Cyclopiden. Wie meine Zusammenstellung zeigt, wird in erster Linie der Cephalothorax von den Kolonien besetzt, viel seltener sind Infusorienbäumchen auf dem Abdomen, sie fehlen fast ganz auf der Furka und den Füssen. Auf die Gründe, die diese Erscheinung bedingen, soll später zurückgekommen werden.

\section{Epistylis umbilicata Claparède und Lachmann.}

Diese Peritriche konnte ich nur viermal finden und zwar auf:

\begin{tabular}{|c|c|c|c|c|}
\hline Träger. & Besetzte Teile. & Häufigk. & Fundort. & Datum. \\
\hline Nais spec. & $\mathrm{K}$. & ++ & Schusterinsel. & 16. 10. \\
\hline Tubifex spec. & $\mathrm{K}$. & l & 》 & 27. 3 . \\
\hline Cyclops fuscus. & $\mathrm{Ab}$. & & Bot. Garten Basel. & 5. 7. \\
\hline C. albidus. & C. & + & Schusterinsel. & 16. 10. \\
\hline
\end{tabular}

Epistylis umbilicata wurde von ihren Entdeckern, Claparède und Lachmann (1858-59), auf den Larven von Culex pipiens gefunden. Parona (1880) auf Nais elinguis. Roux (1901) auf Insekten-Larven. Fehlmann (1911) auf Tubifex tubifex. André (1916) auf einer Hydrachnide. Bouroun-Lindt (1918) auf Tubifex tubifera und Nais. Monard (1919) auf Chironomiden-Larven.

Ein specifischer Symphoriont kann Epistylis umbilicata nach diesen Angaben und meinen Funden nicht sein, da sie systematisch sehr verschiedene Wirte besiedelt. Eine Vorzugsstellung nehmen die Oligochaeten und Insektenlarven ein, aber keineswegs bleibt der Symphorismus auf diese beiden Gruppen beschränkt. Immerhin glaube ich, dass meine Befunde auf den Cyclopiden zu den Ausnahmefällen zu rechnen sind. 


\section{Epistylis branchiophila Perty.}

Diese Species, die aus der Schweiz nur von wenigen Orten her bekannt ist, wurde von mir auf folgenden Wirten gefunden :

\begin{tabular}{|c|c|c|c|c|}
\hline Träger. & Besetzte Teile. & Häufigk. | & Fundort. & Datum. \\
\hline $\begin{array}{l}\text { Phryganea grandis. } \\
\text { Ph. spec. } \\
\text { Limnophilus spec. } \\
\text { L. rhombicus. } \\
\text { " } \\
\text { Glyphothaelius } \\
\text { pellucidus. } \\
\text { Stenophylax } \\
\text { concentricus. }\end{array}$ & $\begin{array}{l}\text { Kb., B. vord. K. teil. } \\
\text { Kb., B. } \\
\text { Kb. K. i. d. Kb. region. } \\
\text { Kb. } \\
\text { Kb. } \\
\text { Kb. } \\
\text { Kb. }\end{array}$ & $\begin{array}{l}++ \\
+ \\
++ \\
++ \\
++ \\
++ \\
++\end{array}$ & $\begin{array}{l}\text { Helgenmatt. } \\
\text { Oberwil. } \\
\text { Arlesheim. } \\
\text { Allschwil (Schiesstand). } \\
\text { Böcktcn. } \\
\text { Allschwil (Schiessland). } \\
\text { Schusterinsel. }\end{array}$ & $\begin{array}{rr}29 . & 10 . \\
25 . & 3 . \\
20 . & 11 . \\
6 . & 1 . \\
16 . & 1 . \\
6 . & 1 . \\
7 . & 3 .\end{array}$ \\
\hline
\end{tabular}

Von Perty (1852) ist Epistylis branchiophila beschrieben und auf den Kiemen von Phryganeen-Larven gefunden worden, wo sie auch Stern (1854) nachweisen konnte. Du Plessis (1885) hat Kolonien dieser Peritrichen auf Diptern-Larven festgestellt. Monard (1919) fand sie auf den Larven von Molanna und auf den Borsten von Tanytarsus.

Ich wäre geneigt gewesen, Epistylis branchiophila nach meinen Funden und nach dem grössten Teile der Literaturangaben als specifischen Symphorionten der Trichoptern-Larven anzusprechen. Nie habe ich sie auf andern Wirtstieren, welche dieselben Lokalitäten bewohnten, feststellen können. Ephemeriden-und Libellen-Larven fand ich nie mit Kolonien dieser Peritrichen besetzt. Doch scheinen die Befunde von Duplessis und Monard zu zeigen, dass Epistylis branchiophila auf andere Insekten-Larven überzugehen im Stande ist. Diesen Angaben kommt grosse Wichtigkeit zu, denn sie zeigen, dass es nicht die stete Wasserbewegung in der Kiemengegend der Trichoptern-Larven ist, die das Infusor veranlasst, auf diesen Organen sich festzusetzen. Vielmehr müssen es andere Faktoren sein, welche hier in Frage kommen. Sie sollen weiter unten berücksichtigt werden. Nebenbei sei bemerkt, dass die 
Kolonien auch auf dem Kopf, den Beinen und dem Hinterende des Körpers der Larven sich häufig ansiedeln und sich hier wohl fühlen.

\section{Epistylis anastatica (Linné).}

Als Wirte dieser häufigen Art sind folgende anzugeben :

\begin{tabular}{|c|c|c|c|c|}
\hline Träger. & Besetzte Teile. & Häufigk. & Fundort. & Datum. \\
\hline Spirogyra. & & & Schusterinsel. & 16. 1. \\
\hline Lemna minor. & Wurzeln. & + & Bottminger Weiher. & 9. 8 . \\
\hline Phragmites. & Stengel. & ++ & Schusterinsel. & 13. 5 . \\
\hline Simocephalus & & & & \\
\hline $\begin{array}{r}\text { vetulus. } \\
\text {. }\end{array}$ & Schale. & $\begin{array}{l}++ \\
+\end{array}$ & Vord. Geissberg. & 29. 10 . \\
\hline $\begin{array}{l}\text { Cyclops fuscus. } \\
\text { C. albidus. }\end{array}$ & C. $\mathrm{Ab}$. & $\begin{array}{l}+ \\
++\end{array}$ & $\begin{array}{l}\text { Arlesheim. } \\
\text { Schusterinsel. }\end{array}$ & $\begin{aligned} 20 . & 11 . \\
6 . & 11 .\end{aligned}$ \\
\hline$"$ & $\mathrm{Ab}$. & & Vord. Geissberg. & 29. 1 . \\
\hline , & C. $A$. & ++ & Allschwil (Schiesstand). & 6. 1. \\
\hline ") & C. A. & 1 & Liestal. & $22 . \quad 5$. \\
\hline C. strenuus. & $\mathrm{Ab}$. & + & Schusterinsel. & 11. 2 . \\
\hline$"$ & C. & $1-+$ & Vord. Geissberg. & 29. 1 . \\
\hline C. serrulatus. & C. & $1--+$ & Sitauweiher Augst. & 21. 6 . \\
\hline 》 & C. & +-++ & Margarethen-Park. & 25. 1 . \\
\hline 》 & C. & + & Bad Burg. & 5. 10. \\
\hline 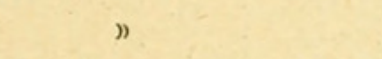 & $\mathrm{Ab}$. & & Kloster Beinwil. & 29. 10 . \\
\hline ” & C. & + & Arlesheim. & 20. 11 . \\
\hline$"$ & C. & & Allschwil (Schiesstand). & 6. 1 . \\
\hline$n$ & C. & ++ & Schusterinsel. & 12. 5 . \\
\hline » & C. Ab. & $1-+$ & Oberwil. & 25. 3 . \\
\hline C. vernalis. & C. & $+-t+$ & Helgenmatt. & 29. 10 . \\
\hline , & C. A. & & Schusterinsel. & 12. 5 . \\
\hline$"$ & C. & ++ & Oberwil. & 25. 3 . \\
\hline$C$. viridis. & A. & 1 & Helgenmatt. & 29. 10 . \\
\hline - & $\mathrm{Ab}$. & l & Niederholz/Basel. & 21. 3 . \\
\hline Copepoditen. & C. & + & Liestal. & 22. 5. \\
\hline Chirotonetes juv. & B., K. & + & Margarethen-Park. & 25. 1 . \\
\hline
\end{tabular}

de Geer (1746) hat die Peritriche mit Carchesium gemischt auf Cyclopiden gefunden. Röser (1755) hat den "arlessbeerförmigen Affterpolyp" auf Cyclops quadricornis beobachtet. O. F. Müller (1786) begegnete der Vorticella anastatica, Vorticella crataegaris und Vorticella ringens, die alle mit Epistylis anastatica identisch sind, auf Pflanzen und Tieren. Schrank (1803) fand seine Vorticella acinesa (=Epistylis anastatica) auf den Köpfen der Larven von Stratiomys chamaeleon. Bов y (1824) beschrieb ein Infusor, Digitalina anastatica, 
das er von einem alten Karpfen abgelöst hatte, und das mit Epistylis anastatica identificiert werden könnte. Ëhrenberg (1838) stellte Kolonien der Epistylis anastatica auf Ceratophyllum und Entomostraken fest. Dusardin (1841) auf Wasserpflanzen, hauptsächlich auf Ceratophyllum. Pritchard (1852) ebendaselbst und auf kleinen Wassermollusken. Perty $(1849,1852)$ an Fliegenköpfen im Wasser, auf Cyclops und an der Unterseite der Blätter von Nuphar luteum. Claparède und Lachmane (1858-59) auf Cyclops. Kent (1880-82) allgemein auf Entomostraken und Wasserpflanzen. Richard (1899) nicht nur auf Cyclops, sondern auch auf den Kiemen von Gammarus pulex. Amberg (1900) auf Cyclopiden. Daday (1910) auf Copepoden. Zsснокке (1911) auf Cyclops viridis, C. strenuus und Hygrobates albinus. Monard (1919) auf Cyclops fimbriatus, C. serrulatus und C. piridis.

Als primäre Träger von Epistylis anastatica muss ich aus Gründen, die später erörtert werden sollen, die Wasserpflanzen ansehen. Von diesen ausgehend, hat sich das Infusor weitere Wirte erobert. Namentlich von den Cyclopiden hat es Besitz ergriffen. Dass in der neuern Literatur die Cyclops-Arten an erster Stelle der Wirte dieser Peritrichen stehen, darf uns nicht täuschen, da in der jetzigen Zeit der Erforschung der Fauna unserer Gewässer grosse Aufmerksamkeit geschenkt wird. Daher vermehrt sich die Zahl der tierischen Träger, während die ursprünglichen Wirte in den Hintergrund gedrängt und unberücksichtigt bleiben. Auch ich habe speciell den animalischen Trägern besondere Aufmerksamkeit geschenkt.

Von Wichtigkeit ist der Festsetzungsort der Epistylis anastatica auf den Cyclopiden. Aus der obigen Zusammenstellung ist zu ersehen, dass in den weitaus meisten Fällen der Cephalothorax der Kruster besiedelt wird; viel seltener findet man die Kolonien auf dem Abdomen, und über das Vorkommen auf Furka und Füssen fehlen die Daten gänzlich.

\section{Epistylis nympharum Engelmann.}

Als Symphoriont von Insekten-Larven geniesst dieses Infusor eine weite Verbreitung. Es wurde von mir auf folgenden Wirten festgestellt: 


\begin{tabular}{|c|c|c|c|c|}
\hline Träger. & Besetzte Teile. & | Häufigk. | & Fundort. & Datum. \\
\hline Cyclops albidus. & A., C., Th. & $1-+$ & Schusterinsel. & 6. 11. \\
\hline Chirotonetes juv. & A. & & Margarethen-Park. & 25. 1 . \\
\hline 》) & Ht., B., Kb., gegend. & ++ & Neuhüsli. & 29. 10 . \\
\hline Cloeon juv. & Mt. & + & Arlesheim. & 20. 11 . \\
\hline$n$ & Mt. & + & Schusterinsel. & 7. 3 . \\
\hline ” & Mt., A., B. & + & Oberwil. & 25. 3 . \\
\hline Chironomus spec. & Mt. & + & Allschwil (Schiesstand). & 6. 1 . \\
\hline ) & Mt. & + & Böckten. & 16. 1. \\
\hline Limnophilus & & & & \\
\hline centralis. & B. & + & Svaviella See. & 1. 11. \\
\hline Limn. spec. juv. & $\mathrm{K}$. & ++ & Schusterinsel. & 7. 3 . \\
\hline$"$ & hint. K. teil. & ++ & ” & 12. 3 . \\
\hline Phryganea grandis. & ) $\mathrm{Kb}$. & + & Benken. & 25. 3 . \\
\hline
\end{tabular}

Engelmann (1862) fand Epistylis nympharum in wenig zahlreichen Stöcken auf Diptern-Larven. Roux (1899) auf dem Kopfe einer CulexLarve. Thí́baud und Favre (1906) auf Cyclops strenuus, C.serrulatus und C. fuscus. Zsснокке (1911) auf Kopf und letztem Segment von Chironomiden-Larven, hauptsächlich von Tanytarsus gmundensisdives, seltener von Tanytarsus clorens. Auch Asellus cavaticus, Gammarus pulex und Cyrnus trimaculatus fand der Autor von ihnen befallen. Sehr fraglich ist der Befund Bourouin-Lindts (1918, von Epistylis nympharum auf Nais. Mosard (1919) auf Cyclops fimbriatus, Limnicythere Sancti-Patrici und ChironomidenLarven.

Es kann nach diesen Angaben und in Berücksichtigung: meiner Funde für Epistylis nympharum gesagt werden, dass ihr Symphorismus nicht so specifisch ist, wie bisher angenommen wurde. Ihr Vorkommen beschränkt sich nicht allein auf Insekten-Larven, sondern erweitert sich vielmehr auf den ganzen Stamm der Arthropoden. Obwohl die Crustaceen in der Reihe der Träger der Peritrichen einen grossen Raum einnehmen, glaube ich trotzdem, dass die eigentlichen Wirte unter den Insekten-Larven zu suchen sind.

Epistylis lacustris Imhof.

Als Wirte dieser Art sollen folgende angegeben werden: 


\begin{tabular}{|c|c|c|c|c|}
\hline Träger. & Besetzte Teile. & gk. & Fundort. & Datum. \\
\hline $\begin{array}{l}\text { Simocephalus } \\
\quad \text { vetulus. } \\
\text { Cyclops fuscus. } \\
\text { C. albidus. } \\
\text { C. viridis. } \\
\text { C. serrulatus. } \\
\quad " \\
\text { C. leucliarti. } \\
\text { Diaptomus gracilis. }\end{array}$ & $\begin{array}{l}\text { Schr. } \\
\text { Ab. F. C. } \\
\text { C. A. Ad. Th. } \\
\text { C. A. Ab. } \\
\text { C. } \\
\text { Ab. } \\
\text { C. Ab. } \\
\text { C. }\end{array}$ & $\begin{array}{l}1 \\
++ \\
++ \\
++ \\
+ \\
1 \\
++ \\
++\end{array}$ & $\begin{array}{l}\text { Bot. Garten Basel. } \\
\text { Bottminger Weiher. } \\
\text { Angenstein. } \\
\text { Seewener See. } \\
\text { Neuhüsli. } \\
\text { Niederholz/Basel. } \\
\text { Mauensee. } \\
\quad \text { " }\end{array}$ & $\begin{array}{rr}10 . & 7 . \\
22 . & 11 . \\
9 . & 5 . \\
21 . & 10 . \\
29 . & 10 . \\
20 . & 1 . \\
1 . & 10 . \\
1 . & 10 .\end{array}$ \\
\hline
\end{tabular}

Epistylis lacustris erscheint in der Literatur zuerst beі Імноғ (1883). Eine genaue Beschreibung des Infusors lieferte der genannte Autor später (1885). Er gibt als Wirte Cyclops und Diaptomus an (1885, 1885-86). Du Plessis (1885) auf Fredericella sultanea, auf den Füssen von Hygrobates longipalpis und auf den Schalen verschiedener Ostracoden. Forel $(1885,1904)$ auf Crustaceen. Yung (1887, 1890) auf den Füssen von Hygrobates und den Kolonien von Fredericella. Steck (1893) auf Cyclopiden. Heuscher (1895) auf Diaptomus gracilis. Francé (1897) auf Leptodora hyalina. Hofer (1899) auf Cyclops viridis und Hygrobates longipalips. Mermod (1914) auf C'yclopsArten. Heuscher (1915) auf Cyclops strenuus. Monard (1919) auf Candona neglecta, Cyclops fimbriatus und Cyclops serrulatus.

Der specifische Symphorismus der Epistylis lacustris erleidet durch die Befunde von Du Plessis, Hofer und Monard eine Einbusse. Die Angaben zeigen, dass nicht nur die Copepoden oder die Entomostraken im allgemeinen als die eigentlichen Träger angesehen werden dürfen, sondern dass zu ihnen sich noch die Hydrachniden gesellen. An dieser Stelle soll darauf hingewiesen werden, und das bezieht sich auf alle Befunde von sessilen Infusorien auf den Milben, dass es nicht die freischwimmenden Arten sind, die von Kolonien besetzt werden, sondern stets die langsam sich bewegenden Bodenformen. Die continuierliche, ruhelose Bewegung der meisten Wassermilben lässt eine Festsetzung irgendwelcher Peritrichen-Arten nicht zu. Auf den vielen Hydrachniden, die ich untersucht habe, konnte nie ein sessiles Infusor festgestellt werden. Nach persönlicher Mitteilung des Hydrachnologen Dr. Ch. Walter (Basel) ist auch ihm diese Erscheinung aufgefallen. Nicht näher 
bestimmte Epizoen, fand er nur auf Milben, die den Tiefen der Seen entstammten oder solchen, die im Moos der Quellen ihr Dasein fristen, nie aber auf den freischwimmenden Arten.

\section{Der Symphorismus im Genus Epistylis.}

Es mögen hier die Ergebnisse über den Symphorismus, die wir bei den einzelnen Epistylis-Arten gewonnen haben, kurz zusammengestellt werden. Ganz allgemein lässt sich sagen, dass er gegenüber dem Symphorismus im Genus Vorticella und den beiden andern contractilen Genera Carchesium und Zoothamnium an Specifität zugenommen hat, ohne aber den spezifischen Grad des Symphorismus der Opercularien zu erreichen.

Ich teile die Epistylis-Species auf Grund ihrer symphoriontischen Eigenschaften in folgende drei Gruppen :

A. Symphorionten s. l. Darunter verstehe ich diejenigen Symphorionten, welche sowohl Pflanzen áls auch Tiere der systematisch verschiedensten Abteilungen befallen. An die Basis dieser Reihe möchte ich Epistylis anastatica stellen, die ihre Träger im Pflanzenreich und im grossen Stamm der aquatilen Arthropoden und ihrer Jugendformen findet. Spezialisierter in ihrem Vorkommen ist Epistylis plicatilis, sie wählt ihre Wirte nur noch unter den Cyclopiden und den Mollusken, und kann ebenso häufig auf Wasserpflanzen beobachtet werden. Mit Epistylis umbilicata verlassen die Epistyliden die vegetabilischen Substrate; die Art setzt sich auf Oligochaeten und den verschiedensten Gliederfüsslern fest. Nur noch Insekten-Larven und Crustaceen besiedelt Epistylis nympharum. An die oberste Reihe wäre Epistylis lacustris zu stellen, die haupsächlich auf Entomostraken und hin und wieder auf Hydrachniden gefunden werden kann.

B. Specifische Symphorionten s. 1. Unter diesem Begriff fasse ich alle diejenigen sessilen Infusorien zusammen, die pflanzliche Substrate verlassen haben und ihr Vorkommen nur auf tierische Träger beschränken. Diese finden sie aber in syste- 
matisch eng umschriebenen Gruppen, wie Familien oder Gattungen. An erster Stelle steht hier Epistylis branchiophila, die Insekten-Larven besetzt, sich aber mit grosser Vorliebe auf Trichoptern-Larven aufhält. Specifischer ist die Wahl der Träger bei Epistylis digitalis und Epistylis diaptomi geworden, indem diese nur Diaptomiden, jene nur Cyclopiden befällt. Mit Epistylis digitalis erreicht diese Gruppe ihren Gipfelpunkt, denn es wurde früher schon gezeigt, dass sie sich auf den Cyclopiden regelmässig an ganz bestimmten Körperteilen festsetzt. Diese Art verbindet die erste Gruppe mit der nächsten.

C. Specifische Symphorionten s. str. nenne ich die sessilen Infusorien, die sich nur auf einem einzigen Wirt und bei diesem sich gewöhnlich auf ganz bestimmten Organen festsetzen. Das Genus Epistylis hat nur eine hierher gehörige Art aufzuweisen, nämlich Epistylis steini, die nur auf den Atmungsorganen von Gammarus pulex zu finden ist.

Aus dieser Zusammenfassung ist zu ersehen, dass die Gruppe der Symphorionten s. l. am stärksten vertreten ist, während die specifischen s. str. nur eine Art stellen. Dieses Verhältnis wird sich bei den nächsten Genera wesentlich zu Gunsten der dritten Gruppe verschieben. Der Fortschritt, der dieses Genus vor den vorherbehandelten auszeichnet, besteht in der Bildung: der specifischen Symphorionten s. 1. Als Grund der weiten Verbreitung der Epistyliden im allgemeinen darf eine grosse Anpassungsfähigkeit an die verschiedensten Wirtstiere angeführt werden. Wie die Versuche von Fauré-Frémiet (1906 c) gezeigt haben, kann die specifische Opercularie eines Wasserinsekts ebenso gut auf einem andern leben, das nicht ihr specifischer Wirt ist. Wie die obigen Ausführungen zeigten, lässt sich der Satz auch für dieses Genus anwenden.

Genus: Rhabdosiyla Kent.

Rhabdostyla ovum Kent.

Diese kleine, in ihrer Organisation an Epistylis erinnernde Art, hatte ich während meiner Untersuchungen sehr oft Gele- 
genheit zu beobachten, wie das die nachstehende Zusammenstellung zeigen soll:

\begin{tabular}{|c|c|c|c|c|}
\hline Träger. & Besetzle Teile. & gk. ! & Fundort. & Dalum. \\
\hline $\begin{array}{l}\text { Cyclops fuscus. } \\
\text { C. strenuus. } \\
\text { C. albidus. } \\
\text { C. viridis. } \\
\quad \text { " } \\
\text { C. serrulatus. } \\
\quad \text { " } \\
\text { C. vernalis. } \\
\text { C. bisetosus. } \\
\text { C. leuckarti } \\
\text { Ceriodaphnia } \\
\quad \text { reticulata. } \\
\text { Candona neglecta. } \\
\text { C. candida. } \\
\text { C. rostrata. } \\
\text { Cypridopsis } \\
\text { C. vidua. elongata. } \\
\text { Cyprois marginata. } \\
\text { Cyclocypris ovum. } \\
\text { Cyprinotus } \\
\quad \text { incongruens. } \\
\text { " } \\
\text { Eucypris virens. } \\
\text { Potamocypris }\end{array}$ & $\begin{array}{l}\text { A. } \\
\text { Ab., C. } \\
\text { Ab., C. } \\
\text { C. } \\
\text { C. } \\
\text { Ab., C. } \\
\text { C., Eiballen. } \\
\text { Ab., } \\
\text { C., Ab. } \\
\text { C.. Ab. } \\
\text { Schr. } \\
\text { Schr. } \\
\text { Schr. } \\
\text { Schr. } \\
\text { Schr. } \\
\text { Schr. } \\
\text { Schr. } \\
\text { Schr. } \\
\text { Schr. } \\
\text { Schr. } \\
\text { Schr. } \\
\text { Schr. }\end{array}$ & $\left\{\begin{array}{l}1 \\
++ \\
++ \\
+ \\
1 \\
++ \\
+ \\
++ \\
+ \\
++ \\
1 \\
+ \\
1 \\
1 \\
+-++ \\
+ \\
++ \\
++ \\
1 \\
+-++ \\
1 \\
+\end{array}\right.$ & 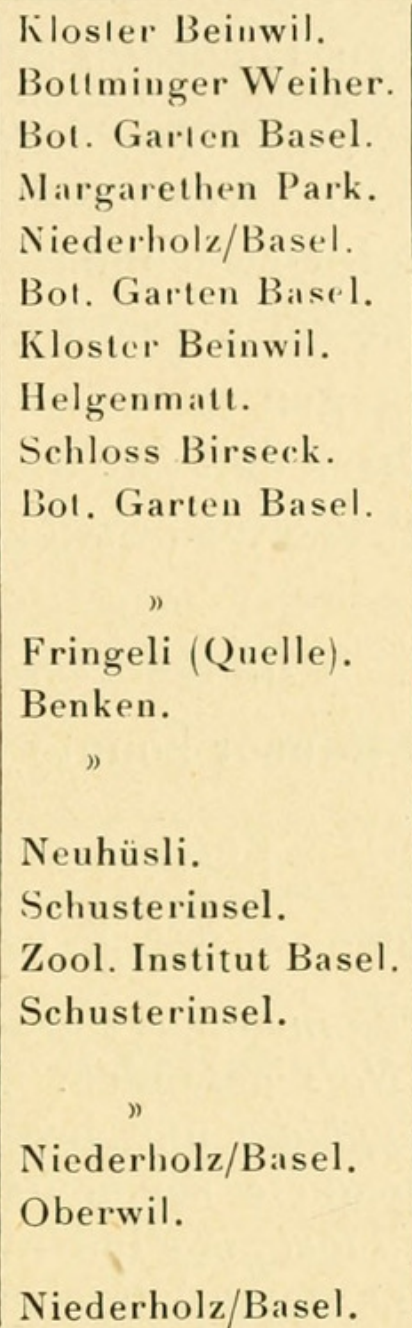 & $\begin{array}{rr}29 . & 10 . \\
10 . & 5 . \\
20 . & 5 . \\
25 . & 1 . \\
14 . & 5 . \\
20 . & 5 . \\
29 . & 10 . \\
29 . & 10 . \\
20 . & 1 . \\
20 . & 5 . \\
& \\
3 . & 7 . \\
1 . & 11 . \\
25 . & 3 . \\
26 . & 4 . \\
& \\
29 . & 10 . \\
12 . & 5 . \\
5 . & 11 . \\
6 . & 11 . \\
& \\
12 . & 5 . \\
14 . & 5 . \\
25 . & 3 . \\
14 . & 5 . \\
14\end{array}$ \\
\hline
\end{tabular}

Rhabdostyla ovum wurde zuerst von Kent (1880-82) beschrieben. Roux (1901) begegnete ihr auf Pflanzen und Ostracoden. Linder (190't) hat sie auf Fragillaria und Asterionella angetroffen. Тни́́вAud und Favre (1906) beobachteten die Peritriche auf Daphnia und Cyclops viridis, und Bourour-Lindt (1918) auf einem Ostracoden.

Wie aus meiner obigen Fundliste zu ersehen ist, habe ich Rhabdostyla ovum nie auf Pflanzen finden können; stets wurde sie von mir nur auf tierischen Trägern beobachtet. Es will mir scheinen, als ob alle Fälle von Vorkommen auf vegetabilischen Trägern Ausnahmen sind. Besonders die Angaben von Linder möchte ich stark bezweifeln. Wie mir Prof. ANdré (Genf) mitteilte, fand er bei seinen Planktonuntersuchungen regelmässig auf Anabaena, Fragillaria und andern pelagischen Algen eine 
kleine kurzgestielte Vorticelle, die mit einer der bis jetzt bekannten Arten noch nicht identificiert werden konnte. Es wäre deshalb denkbar, dass das von Linder als Rhabdostyla ovum bestimmte Infusor nicht in das Genus Rhabdostyla, sondern vielmehr zu Vorticella zu stellen wäre.

Wenn wir unter den animalischen Trägern Umschau halten, so erkennen wir, dass diese fast ausnahmslos unter den Cyclopiden und Ostracoden zu finden sind. Bei den Cyclopiden ist der Festsetzungsort nicht genauer bestimmt, bei den Ostracoden dagegen ist es nur der Schalenrand, der von den Peritrichen besiedelt wird. Auf diese auffallende Erscheinung: werde ich weiter unten zurückommen.

\section{Rhabdostyla inclinans (D'Udekem).}

Dieses Infusor konnte ich einmal finden und zwar auf:

\begin{tabular}{|c|c|c|c|}
\hline Träger. & Besetzte Teile. | Häufigk. & Fundort. & Datum. \\
\hline Nais spec. & vord. K. teil. $\mid+$ & Schusterinsel. & 7. 3.
\end{tabular}

Als Gerda inclinans wurde die Art von d'Uрекем (1864) beschrieben und auf Nais gefunden. Kent (1880-82) stellte die Peritriche zum Genus Scyphidia und beobachtete sie auf demselben Wirt. Sтокеs (1888) begegnete seiner Rhabdostyla chaeticola, die von Roux mit Rabdostyla inclinans indentificiert wurde, auf Nais. Auf dem Körper und an den dorso-lateralen Borsten desselben Oligochaeten haben Roux (1901) und Bourquin-Lindt (1918) das Infusor beobachtet. Erst Roux hat seine Zugehörigkeit zum Genus Rhabdostyla erkannt.

Diese Daten und mein Fund zeigen, dass Rhabdostyla inclinans ein specifischer Symphoriont von Nais ist. Welchen Grad der Höhe er aber erreicht, kann aus diesen Angaben nicht entnommen werden, da eine genaue Determination des Oligochaeten nicht vorgenommen worden ist.

Genus: Opercularia Goldfuss (Stein emend.).

Opercularia coarctata (Claparède und Lachmann).

Kolonien dieser Peritrichen konnte ich in meinem Material nur zweimal finden und zwar auf: 


\begin{tabular}{|l|l|c|c|c|}
\hline Träger. & Beselzte Teile. & Häufigk. & Fundort. & Datum. \\
\hline Spirogyra. & & $/$ & Bottminger Weiher. & 11. \\
Rhizzia fluitans. & & + & Bot. Garten Basel. & 7. 12.
\end{tabular}

Claparède und Lachmann (1858-59) haben diese Form unter dem Namen Epistylis coarctata beschrieben und auf Molluskenschalen und pflanzlichen Abfällen beobachtet. Francé (1897) will die Peritriche auf Cyclops und Diaptomus gefunden haben. Roux (1901) wies sie auf Grund der morphologischen und anatomischen Charaktere zum Genus Opercularia. Er konnte sie zu wiederholten Malen in Heuaufgüssen feststellen.

Aus diesen wenigen Angaben ergibt sich für den Symphorismus von Opercularia coarctata, dass er insofern specifisch ist, als von den Kolonien nur Vegetabilien besetzt werden. Jedenfalls steht hier der Symphorismus auf der niedersten Stufe. An eine Besiedlung von tierischen Wirten hat sich das Infusor nicht angepasst.

\section{Opercularia berberina (Linné).}

Diese Species konnte ich nur einmal finden und zwar auf:

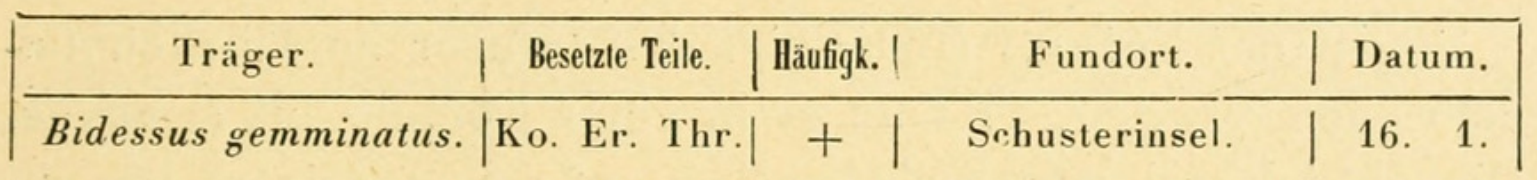

Die Art ist schon vou Rösel beobachtet und unter dem Namen "Berbersbeerförmiger Afterpolyp " beschrieben worden. Fundort: After eines Wasserkäfers. Enrenberg (1840) begegnete der Peritriche auf Cybister roeselii (= laterimarginalis) und benannte sie Epistylis berberiformis. Erst STEIN (1854) erkannte in ihr einen Vertreter des Genus Opercularia; er konnte Opercularia berberiformis häufig auf Noterus crassicornis, Laccophilus minutus (= hyalinus) finden, seltener begegnete er ihr auf Hydroporus (= Hygrotus) inaequalis, Hydroporus palustris und Haliplus impressus (=flavicollis). Bei allen diesen Wirten konnte Sters beobachten, dass die Kolonien an den Hinterleibs- oder den Flügeldeckenspitzen sassen. Ganz ungenügend ist die Angabe über das Vorkommen dieser Art bei Kent (1880-82), der als Träger "various aquatic insects» ohne nähere Bestimmung angibt.

Von einer Specifität des Symphorismus kann bei dieser Art 
noch nicht gesprochen werden. Von den von Kolonien der Opercularia berberina besetzt gefundenen Wasserkäfern fällt uns auf, dass es speziell die Grosskäfer sind, die in der Liste der Wirte erscheinen. Die kleinen Hydrophiliden werden nur spärlich oder gar nicht besiedelt. Ebenso auffallend ist die Tatsache, dass nie an den Beinen der Wirte Kolonien gefunden worden sind. Wohl hat sich die Peritriche an die starke Bewegung der Wasserkäfer angepasst; aber die Anpassung ist nicht so weit ausgebaut worden, dass auch Organe der Träger, welche Eigenbewegung haben, und wo die Stärke der Bewegung durch diese vergrössert wird, besetzt werden können.

Opercularia gracilis Fauré-Frémiet.

Opercularia gracilis scheint eine noch wenig bekannte und seltene Peritriche zu sein. Es gelang mir, sie einmal in einer Kolonie zu beobachten und zwar auf:

\begin{tabular}{|c|c|c|c|c|}
\hline Träger. & Besetzte Teile. & Hàufigk. & Fundort. & Datum. \\
\hline Planorbis contortus. & Gehäuse. & $/$ & Niederholz/Basel. & 20. \\
\hline
\end{tabular}

Von Fauré-Frémiet (1904a) ist das Infusor ausführlich beschrieben worden; er fand es in einer Kolonie auf Limnaea. Obwohl ich viele Wasserschnecken auf dieses Epizoon hin untersucht habe, blieb es doch bei diesem einzigen Fund. Käfer, Cyclopiden und Wasserpflanzen, die derselben Lokalität entstammten, waren nicht besetzt, so dass es scheint, als sei Opercularia gracilis ein Symphoriont von Süsswasser-Gastropoden. Wie weit dies zutrifft und welchen Grad die Specifität des Symphorismus erreicht, kann nach nur so spärlich vorliegenden Daten nicht entschieden werden.

\section{Opercularia arliculata (Ehrenberg).}

Diese schöne Opercularie geniesst in unsern Gewässern eine grosse Verbreitung. Sie konnte in meinem Material auf folgenden Wirten festgestellt werden: 


\begin{tabular}{|c|c|c|c|c|}
\hline Träger. & Besetzte T'eile. & lläufigk. & Fundort. & Datum. \\
\hline Asellus aquaticus. & K. anhänge. & / & Margarethen Park. & 11. 6 . \\
\hline Gammarus pulex. & Th. & t & Schusterinsel. & 24. 8 . \\
\hline$"$ & Th. Ab. beine. & ++ & " & 11. 2 . \\
\hline ") & Th. Ab. beine. & ++ & Arlesheim. & 20. 11 . \\
\hline Limnophilus spec. & & + & Böckten. & 16. 1. \\
\hline Agabus sturmi. & Cg. Er. & ++ & Schusterinsel. & 7. 3 . \\
\hline A. didymus. & Cg. Er. & ++ & $"$ & 7. 3 . \\
\hline A. undulatus. & $\mathrm{Cg}$. & l & $"$ & 7. 3 . \\
\hline Rhantus punctatus. & $\mathrm{Cg}$. & + & ) & 7. 3 . \\
\hline ” & Er. & 1 & Niederholz/Basel. & 14. 5. \\
\hline $\begin{array}{l}\text { Platambus } \\
\text { maculatus. }\end{array}$ & 2 vord. B. paare. & 1 & Allschwil & 22. 7 . \\
\hline Dytiscus marginalis. & Ab., Er., C.g. & + & Vessy b/Genève. & 10. 10. \\
\hline
\end{tabular}

Von Ehrenberg (1838) wurde Opercularia articulata am Hinterleib und den Schenkeln von Dytiscus marginalis und Hydrophilus piceus gefunden, wo sie auch Рriтchard (1852) nachweisen konnte. Ansehnlich ist die Trägerliste, die von Sters (1854) angegeben wird.

Er beobachtete die Peritriche hauptsächlich auf den beiden vordern Beinpaaren, der Vorder- und Mittelbrust von Dytiscus marginalis, Colymbetes fuscus, Ilybius fenestratus, Agabus bipustulatus, A. $1=$ Platambus) maculatus, Cybister laterimarginalis und Dytiscus punctulalus. Frixcé (1897) auf C'yclops und Diaptomus. Roux (1901) auf Dytiscus. Emmondos (1906) an Steinen. Vivrieux (1909-10) auf den Mundgliedmassen und vordern Beinen von Dytiscus. André (1917) auf C'lepsine bioculata und Notonecta glauca. Monard (1919) auf Hellobdella stagnalis.

Nach diesen Angaben, sowie nach meinen eigenen Funden ergibt sich für Opercularia articulata folgendes. Das Infusor ist nicht an einen specifischen Wirt gebunden, sondern sucht seine Träger in systematisch ganz verschiedenen Gruppen der aquatilen Fauna auf. Nicht nur Malacostracen, Coleoptern und Hemiptern werden von ihm befallen, sondern auch InsektenLarven, Copepoden und Hirudineen. Selbst auf totem Substrat können seine Kolonien angetroffen werden. Meine Befunde, die durch Literaturcitate noch ergänzt wurden, zeigen, dass die Käfer in der Reihe der Wirte eine bevorzugte Stellung einnehmen, und zwar sind es nicht die Kleinkäfer, sondern wieder die Grosskäfer, auf denen die Peritriche zu finden ist (wie bei Opercularia berberina). Beachtung verdient die Angabe von

Revue Suisse de Zoologie T. 28. 1921. 
Stein, die ich bestätigen kann, dass die Kolonien sich nie an den Schwimmbeinen festsetzen, sondern nur an den beiden vordern Beinpaaren. Nach meiner Ansicht ist es ihnen nicht möglich, auf den energisch arbeitenden Gliedmassen genügend Halt zu finden. Infolge der Höhe des Stiels sind die Kolonien durch die Bewegungen der Extremitäten stark gefährdet. Wir finden die Schwimmbeine deshalb nur mit kurzgestielten Suctorien besetzt.

In den Wirten der Opercularia articulata erkennen wir fast ausnahmslos Tiere, die mehr oder weniger eine lebhafte Schwimmbewegung aufweisen. An diese hat sich das Epizoon anpassen müssen, wenn es ihr Stand halten will. Wie bei Epistylis digitalis, allerdings nicht in demselben hohen Masse, findet auch hier durch Bildung von Querlinien eine Auflösung des Stieles in kürzere Glieder statt, welche eine Stärkung des ganzen Organes im Gefolge hat. Als neue Erscheinung tritt uns noch die Längsstreifung entgegen, die, mit der Querstreifung kombiniert, die Festigkeit des Stieles erhöht und dadurch der Peritriche die Besetzung von lebhaften Wirten erlaubt.

\section{Opercularia lichtensteini Stein.}

Diese in der Schweiz noch wenig hekannte Art konnte ich in meinem Untersuchungsgebiet nur einmal nachweisen :

\begin{tabular}{|c|c|c|c|c|}
\hline Träger. & Besetzte Teile. $\mid$ Hauligk. & Fundort. & Datum. \\
\hline Asellus aquaticus. & B. & $|+|$ Margarethen Park. & 8. 3.
\end{tabular}

Opercularia lichtensteini wurde von STEIN (1854) beschrieben und an den Beinen von Hyphydrus ovatus (=ferrugineus), Hydaticus transversalis, Agabus (= Platambus) maculalus, A. bipustulatus und llybius spec. gefunden. DaDAY (1895) regelmässig und sehr häufig auf Cyprois dispar. Die Kolonien des Infusors beselzten die Antennen und andern Extremitäten und den Schalenrand dieses Ostracoden. Richard (1899) auf verschiedenen Entomostracen. Mermod (1914) hat das Infusor einer Neubeschreibung unterzogen ; er fand dasselbe auf den Köpfen von Chironomus spec. André (1916) auf den Beinen von Gammarıs und, nach Mегмор, ebenfalls auf dem Köpfen der oben genannten Diptern-Larven. 
Opercularia lichtensteini ist kein specifischer Symphoriont. Im Kreis der Arthropoden sind ihrem Vorkommen weite Grenzen gezogen. Die besetzten Träger oder Organe derselben sind lebhafter Bewegungen fähig. Als neue Anpassungserscheinung des Stieles an die Bewegungen der Träger tritt uns hier neben der Längsstreifung noch die Verkürzung des Fixationsorganes entgegen. Dieser Modus der Anpassung wird von den Suctorien übernommen.

\section{Opercularia nulans (Ehrenberg).}

Meine wenigen Funde für Opercularia nutans beziehen sich auf folgende Wirte :

\begin{tabular}{|c|c|c|c|c|}
\hline Tr: & Besetzte Teile. & Häı & Fundort. & Datum \\
\hline $\begin{array}{l}\text { Lemna minor. } \\
\text { Gammarus pulex. } \\
\text { Laccobius nigriceps. }\end{array}$ & $\begin{array}{l}\text { Wurzeln. } \\
\text { Th. } \\
\text { Er. }\end{array}$ & $\begin{array}{l}1-+ \\
+-++ \\
+\end{array}$ & $\begin{array}{l}\text { Bottminger Weiher. } \\
\text { Schusterinsel. } \\
\text { " }\end{array}$ & $\begin{aligned} 11 . & 8 . \\
16 . & 1 . \\
7 . & 3 .\end{aligned}$ \\
\hline
\end{tabular}

Von Ehrenberg (1838) ist der Infusor als Epistylis nutans beschrieben worden. Dem Entdecker erschien aber schon damals die systematische Stellung dieser Peritrichen im Genus Epistylis fraglich. Er machte die Bemerkung, dass die Art wohl richtiger zu Opercularia gezählt, oder für sie in ein neues Genus aufgestellt werde. Von Ehrenberg ist die Peritriche an Myriophyllum, Hottonia palustris und Ceratophyllum gefunden worden. Sters (1854) an Lemna-Wurzeln. Kent (1880-82) stellte das Infusor zum Genus Opercularia und gibt als Träger Wasserpflanzen und -Tiere an. Die Funde von Kellicott $(1884,1887)$ waren mir nicht zugänglich. Dalla Torre (1891) an Moosen. Zschoкke $(1893,1895,1900,1911)$ auf Chironomus-Larven, Corixa, Hydroporıs, Agabus, Sialis-Larven, Gammarus und Hydrachniden. Henpel (1898) auf Planorbis. Richard (1899) auf verschiedenen Entomostracen. Koford (1908) auf Alona affinis und Cyclops. DadAY (1910) auf Copepoden und Microcystis. Steiner (1911) auf Cyclops serrulatus und Canthocamptus. Monard (1919) auf Chironomus-Larven.

Die Liste der Träger von Opercularia nutans ist nach meinen Befunden und obigen Literaturcitaten in ihrer Zusammensetzung äusserst heterogen. Pflanzen und Tiere der verschiedensten Gruppen werden von der Art behaftet gefunden.

Noch kurz möchte ich auf den durch Querlinien abgeteilten 
Stiel zu sprechen kommen. Einen solchen haben nach dem oben Gesagten diejenigen Epizoen aufzuweisen, die auf sehr beweglichen Wirten oder Organen derselben sich ansiedeln. Auch bei Opercularia nutans sind in der Reihe der Träger Formen zu finden, die einer lebhaften Bewegung fähig sind. Die Bildung der Querlinien erhöht die Stärke des Stieles, und durch sie wird dem Infusor eine Besetzung von sehr beweglichen Trägern ermöglicht.

\section{Opercularia cylindrata Wrzesniowky.}

Opercularia cylindrata stellt für die Schweiz eine neue Art dar. Sie wurde von mir auf folgenden Trägern beobachtet:

\begin{tabular}{|c|c|c|c|c|}
\hline Träger. & Besetzte Teile. & Häufigk. | & Fundort. & Datum. \\
\hline $\begin{array}{l}\text { Cyclops fuscus. } \\
\text { Potamocypris villosa. } \\
\text { Cyprinotus incongruens. }\end{array}$ & $\begin{array}{l}\text { Th. } \\
\text { Schr. } \\
\text { Schr. }\end{array}$ & $\begin{array}{l}1 \\
1 \\
+\end{array}$ & $\begin{array}{l}\text { Allschwil (Schiesstand). } \\
\text { Niederholz/Basel. } \\
\text { „ }\end{array}$ & $\begin{array}{ll}14 . & 2 . \\
20 . & 1 . \\
21 . & 3 .\end{array}$ \\
\hline
\end{tabular}

Opercularia cylindrata wurde von ihrem Entdecker Wrzesniowsky (1870), auf Cyclops quadricornis gefunden. Von Kent (1880-82) und Richard (1899) wird derselbe Wirt citiert.

Meine Funde zeigen aber, dass von Opercularia cylindrata nicht nur Copepoden, sondern auch Ostracoden besetzt werden können. Ob aber der Symphorismus nur auf Vertreter dieser beiden Crustaceen-Gruppen beschränkt bleibt, kann ich nach diesen wenigen Daten nicht mit Sicherheit entscheiden.

\section{Opercularia corethrae nov. spec.}

Bei der Untersuchung des aus einem Weiher in der Nähe von Liestal stammenden Materials, das sehr reich an Larven von Corethra plumicornis war, konnte an diesen Tieren ein Epizoon beobachtét werden, das dem Genus Opercularia angehört. Eine Identifizierung mit einer der bis jetzt bekannten Arten war nicht möglich, und daher habe ich das Infusor als neue Species beschrieben und sie nach ihrem Träger benannt. 
Artdiagnose:

Die äussere Körperform erinnert an diejenige von Opercularia articulata, sie ist länglich-oval, in der Mitte am breitesten, nach vorn und hinten sich verjüngend. Die Körperoberfläche ist quergestreift. Der Discus erhebt sich hoch über den Peristomrand, ist aber nicht nach rückwärts gelegt. Die undulierende Membran ist hoch und breit, erreicht aber in der Höhe den Discus nicht. Der Pharynx ist ziemlich kurz, gelangt nicht bis zur Körpermitte und weist in seinem mittleren Teile eine grosse, mit Cilien versehene Ausbuchtung auf. Der Kern ist hufeisenförmig, transversal in der Mitte des Körpers gelegen. Der Stiel ist kurz und dick, mit starken Querfurchen versehen, die

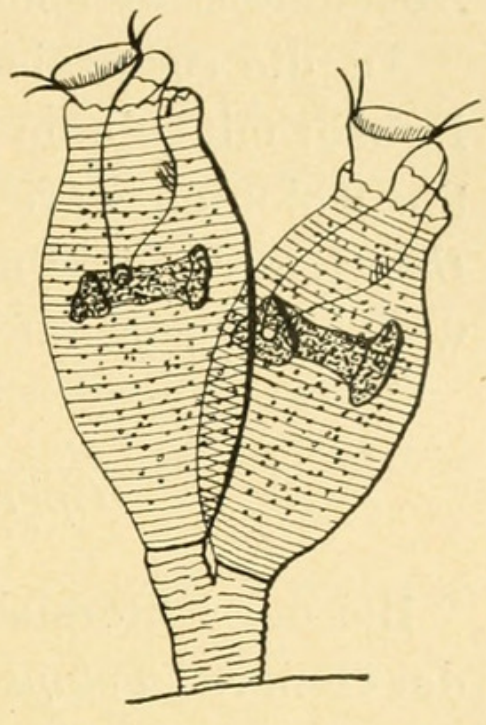

Fig. 4 .

Opercularia corethrae n. sp. dicht gedrängt und in unregelmässigen Abständen einander folgen. Die Kolonien sind klein, bestehen aus zwei, höchstens fünf Individuen.

Länge des Körpers : 75-78 $\mu$, Breite des Körpers : $32-33 \mu$.

Meine Funde für diese Peritriche sind :

\begin{tabular}{|c|c|c|c|c|}
\hline Träger. & Besetzte Teile. & Häufigk. | & Fundort. & Datum. \\
\hline $\begin{array}{l}\text { Corethra } \\
\qquad \text { plumicornis-juv. }\end{array}$ & im Schwanzfächer. & $\begin{array}{l}+-++ \\
+\end{array}$ & $\begin{array}{c}\text { Liestal. } \\
\text { " }\end{array}$ & $\begin{array}{rr}21 . & 10 . \\
22 . & 5 .\end{array}$ \\
\hline
\end{tabular}

Opercularia corethrae steht in ihrer äussern Körperform der Opercularia articulata am nächsten. Unterschiede zwischen beiden Arten sind kurz folgende:

Opercularia articulata: Der Discus ist sehr schräg, die undulierende Membran ist sehr hoch, Körperoberfläche glatt. Der Kern ist ein kurzes gebogenes Band. Der Stiel ist hoch, längsgestreift, mit weit auseinander liegenden Querlinien.

Opercularia corethrae: Der Discus ist nicht schräg, die un- 
dulierende Membran erreicht seine Höhe nicht. Körperoberfläche quergestreift. Der Kern ist hufeisenförmig. Der Stiel ist kurz, nicht längsgestreift, aber mit Querfurchen, die in kurzen Abständen aufeinander folgen.

An die ruckweisen Bewegungen der Larven hat sich das Infusor mit seinem kurzen dicken Stiel angepasst. Langgestielten Kolonien wäre ein Aufenthalt am Schwanzende der Corethra-Larven nicht möglich, da sie durch die schnellenden Bewegungen von der Unterlage abgerissen würden.

\section{Opercularia zschokkei nov. spec.}

Bei der Untersuchung von Süsswasser-Cructaceen, speziell der Genera Cyclops und Canthocamptus auf sessile Infusorien fielen mir oft kleine Kolonien auf, die an den verschiedensten

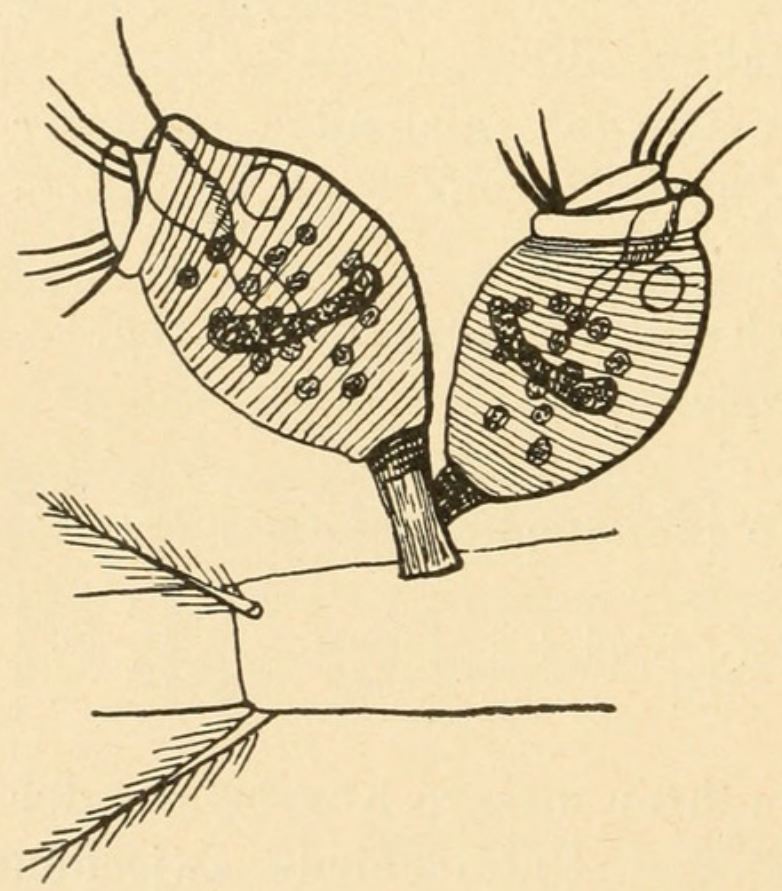

FIG. 5 .

Opercularia zschokkei n. sp. Körperteilen ihrer Träger sassen. Da die Peritrichen mit keiner bekannten Art in Uebereinstimmung gebracht werden konnten, sehe ich mich genötigt, sie als eine neue Species zu beschreiben und sie als Opercularia zschokkei, zu Ehren meines verehrten Lehrers, in die Literatur einzuführen. Folgende kurze Artdiagnose soll aufgestellt werden :

\section{Artdiagnose:}

Der Körper hat elliptische Gestalt, ist breit in der Mitte, verjüngt sich nach vorn und hinten etwas. Die Körperoberfläche ist deutlich quergestreift. Der Discus ist nur wenig über den Peristomrand erhoben, aber schräg nach hinten gebogen. Der Peristomrand selbst ist wulstig. Die unduluriende Membran überragt den Discus. Der 
Pharynx ist lang und reicht bis über die Körpermitte. In seiner Nähe liegt die contractile Vacuole. Der Macronucleus ist schwach gebogen und transversal in der Mitte des Körpers gelegen. Der Stiel ist kurz, so dass die Kolonien oft den Eindruck von Häufchen sitzender Einzelindividuen erwecken. Seine maximale Länge beträgt höchstens die Hälfte der Körperlänge. Dieser kurze Stiel zeigt eine Längsstreifung; an seinem obern Ende treten einige Querfurchen auf. Die Kolonien sind wenig zahlreich; sie bestehen aus 2-7 Individuen; oft können auch nur Einzeltiere beobachtet werden. Länge des Körpers : $50 \mu$. Breite des Körpers : $26 \mu$ (Durchschnittswerte).

Opercularia zschokkei konnte ich auf folgenden Wirten feststellen :

\begin{tabular}{|c|c|c|c|c|}
\hline Träger. & Besetzte Teile. & Häufigk. | & Fundort. & Datum. \\
\hline Cyclops fuscus. & C. 1. Th. & +-++ & Schusterinsel. & 16. 1. \\
\hline$"$ & C. 1. Th. & + & Angenstein. & 9.5 . \\
\hline C. strenuus. & C. (Ventralfl.). & + & Allschwil. & 19. 3. \\
\hline C. viridis. & C. & + & Schusterinsel. & 16. 1. \\
\hline C. serrulatus. & 1. Th. & $1-+$ & Niederholz/Basel. & 14. 5. \\
\hline C. fimbriatus. & Zw. d. F.ästen. & + & Allschwil (Quelle). & 16. 6 . \\
\hline $\begin{array}{c}\text { Canthocamptus } \\
\text { staphvlinus. }\end{array}$ & Ab A Th Bis & + & & 193. \\
\hline ) & F. Th. & + & Schusterinsel. & 7. 3 . \\
\hline 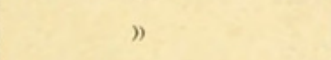 & F.Spermatophor & + & Oberwil. & 25. 3 . \\
\hline$"$ & F. & + & Benken. & 4. 4. \\
\hline $\begin{array}{l}\text { C. microsta- } \\
\text { phylinus }\end{array}$ & C. Ab. Th. & +-++ & Seewagen. & 1. 10. \\
\hline
\end{tabular}

Opercularia zschokkei unterscheidet sich von allen Opercularien durch ihre geringe Körpergrösse und die Kürze ihres Stieles.

Wie aus meinen Funden hervorgeht, besetzt das Infusor unter den Copoden nur Cyclopiden und Canthocamptus-Arten. Der specifische Symphorismus s. I. steht hier auf der Vorstufe zum specifischen s. str.

\section{Der Symphorismus der Opercularien.}

Die Ergebnisse, die wir bei der Betrachtung der einzelnen 
Arten des Genus Opercularia über den Symphorismus gewonnen haben, sollen hier in kurzer Zusammenfassung nochmals dargestellt werden. Der Grad des Symphorismus der einzelnen Formen bildet eine aufsteigende Reihe.

A. Symphorionten s. l. - An die Basis dieser Gruppe ist Opercularia coarctata zu stellen, deren Kolonien ausnahmslos Wasserpflanzen besiedeln. Höher steht schon Opercularia nutans, die Pflanzen und Tiere, die systematisch und biologisch sehr verschiedenen Gruppen angehören, besetzt.

$B$. Specifische Symphorionten s. 1. - An die eben genannte Art schliesst sich Opercularia articulata an, die pflanzliche Träger fast ganz aus ihrem Wirtskreis ausgeschlossen hat. Etwas weiter ist Opercularia lichtensteini gegangen; sie beschränkt ihr Vorkommen auf Arthropoden. Opercularia cylindrata sucht ihre Wirte nur noch in zwei, allerdings systematisch weit auseinander gelegenen Crustaceen-Ordnungen (Gyclopiden und Ostracoden). Der Wirtskreis zieht sich bei Opercularia berberina und Opercularia glomerata immer enger, von diesen zwei Species werden nur Coleoptern befallen. Auf zwei systematisch nahestehenden Copepoden-Genera setzt sich Opercularia zscholkei fest (Cylops und Canthocamptus). Die gleiche Stufe in symphoriontischer Hinsicht scheint auch Opercularia gracilis einzunehmen, wie aus den bis jetzt gemachten beiden Funden hervorgeht.

Die. Gruppe zeigt also deutlich die Verkleinerung der Zahl der zu besetzenden Träger-Arten und dadurch in aufsteigender Linie die Entwicklung zum specifischen Symphorismus s. str.

C. Specifische Symphorionten s. str. Hierhin gehören Opercularia corethrae, O. notoneclae, O. dytisci, O. acilii, $O$. ilybii, O. corixae, O. cypris. Sie alle beschränken ihr Vorkommen auf den durch den im Speciesnamen genannten Wirt. Mit den verschiedensten Formen dieser Arten hat Fauré-Fréмieт (1906a, b, $c, 1907$ ) Versuche angestellt, die ihn zum Schlusse führten, dass in ihnen nicht Variationen oder Mutationen einer einzigen oder einer Zahl von Species von Oper- 
cularien zu erblicken sind, die durch die Eigentümlichkeiten des Wasserinsekts, auf welchem das Infusor vorkommt, bedingt sein könnten. Vielmehr nimmt Fauré-Frémiet an, dass es sich um gut definierte Arten handelt, die sich genau an ihre Wirte angepasst haben. Die morphologischen Differenzen, welche die einzelnen Infusorien von einander unterscheiden, sind gering, aber constant.

Genus: Pyxidium Kent.

Pyxidium cothurnoides Kent.

Diese in ihrer Gestalt und innern Organisation an eine Opercularia erinnernde Art konnte ich auf folgenden Wirten feststellen :

\begin{tabular}{|c|c|c|c|c|}
\hline Träger. & Besetzte T€ile. & Iläufigk. & Fundort. & Datum. \\
\hline $\begin{array}{l}\text { Cypridopsis vidua. } \\
\text { Cyclocypris ovum. } \\
\text { Candona candida. }\end{array}$ & $\begin{array}{l}\text { Schr. } \\
\text { Schr. } \\
\text { Schr. }\end{array}$ & $\begin{array}{l}++ \\
++ \\
+\end{array}$ & $\begin{array}{l}\text { Schusterinsel. } \\
\text { " } \\
\text { Lange Erlen. }\end{array}$ & $\begin{array}{ll}\text { 7. } & 3 . \\
14 . & 8 . \\
21 . & 3 .\end{array}$ \\
\hline
\end{tabular}

Für die Vorticelliden von opercularienartigem Bau, die keine Kolonien bilden, stellte Kent (1880-82) ein besonderes Genus Pyxidium auf und beschrieb es als neue Art Pyxidium cothurnoides, das er auf Entomostraken gefunden hatte. Richard (1899) auf Cypris spec. Roux (1901) auf Cyclops spec. Henderson (1905) auf C'yclops und Cypris. Zschoкke (1911) auf Candona neglectr. ANdßÉ (1912) und Mermod (1914) auf den Schalen von Cypris. Monard (1919) auf Cyclops fimbriatus, Cyclops viridus, Canthocamptus staphylinus, und hauptsächlich auf Cypria ophthalmica. Francé (1897) auf Cyclops und Canthocamptus.

Auf Grund der Literaturangaben und speziell gestützt auf meine eigenen Funde möchte ich Pyxidium cothurnoides zu den specifischen Symphorionten der Ostracoden zählen, da doch diese Tiergruppe in der Wirtsreihe an erster Stelle steht. Es erhebt sich aber die Frage, wie es sich mit den Befunden auf den Copepoden verhält. Ich bin der Ansicht, dass es sich, wenn tatsächlich Pyxidium cothurnoides auf Copepoden beobachtet wurde, nur um vereinzelte Fälle handeln kann. Viel 
grösser scheint mir aber die Wahrscheinlichkeit zu sein, dass in diesen Fällen nicht Pyxidium cothurnoides, sondern eine andere Peritriche hätte nachgewiesen werden sollen, nämlich Pyxidium henneguyi. Eine Verwechslung der beiden Arten ist bei conserviertem Material erklärlich. Da der Discus eingezogen wird, die feinere Körperstruktur verschwunden ist, und Einzelheiten im Bau nicht mehr erkannt werden können, wird ein genaues Auseinanderhalten der beiden Arten sehr erschwert.

\section{Pyxidium henneguyi Fauré-Frémiet.}

Bei der Untersuchung von Cyclops serrulatus(Weibchen und Männchen) fielen mir am ersten Abdominalsegment dieses Copepoden dichte Infusorienkolonien auf, die ich zu Beginn meiner Studien als Pyxidium cothurnoides? bezeichnete. Die Funde für diese Peritriche waren :

\begin{tabular}{|c|c|c|c|c|}
\hline Träger. & Besetzte Teile. & Häufigk. & Fundort. & Datum. \\
\hline Cycl. serrulatus. & 1. Ab. segment. & ++ & Allschwil. & 15. 2. \\
\hline 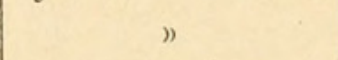 & $"$ & ++ & Burg Bad. & 5. 10 . \\
\hline$n$ & $n$ & + & GörbelhoferWeiher & 11. 10 . \\
\hline " & $"$ & & Kaltbrunnental. & 29.10 . \\
\hline , & ") & +-++ & Niederholz/Basel. & 20. 1 . \\
\hline$n$ & ) & & Flüelaseen. & 8. 8. \\
\hline ). & $"$ & ++ & Schusterinsel. & 27. 4. \\
\hline
\end{tabular}

Im Verlaufe des Literaturstudiums stiess ich auf eine Arbeit von Fauré-F́némiet $1904 a$ ), in der eine Opercularia henneguyi als neue Art beschrieben wurde und mit der ich meine fragliche Pyxidium-Art identificieren konnte. Fauré fand das Infusor nur auf dem ersten Abdominalsegment von Cyclops spec., wo es, wie der Entdecker sich ausdrückt, "des colonies encroûtantes » bildet. Diese für die Art typische Koloniebildung konnte auch von mir beobachtet werden, und sie kann schon als äusseres Merkmal der Species gelten. Solche Kolonien konnten in der ganzen Ordnung der Peritricha nicht wieder nachgewiesen werden. Der kurze Stiel der Einzelindividuen ist nie verzweigt. Nach der Teilung bleibt das eine Tochterin- 
dividuum auf dem von der Mutter gebildeten Fixationsorgan sitzen. Das andere wird mit einem neuen Stiele ausgerüstet und setzt sich direkt neben dem Orte seiner Enstehung fest. Auf diese Weise entstehen die dichtgedrängten Kolonien, welche wie ein zusammenhängender Ring das erste Segment des Abdomens des Cyclopiden umgeben.

Ueber die Stellung des Infusors im System der Peritricha möchte ich das Folgende bemerken. Fauré-Frémiet hat die von ihm neubeschriebene Art auf Grund der anatomischen Charaktere zum Opercularia gestellt. Vom Entdeckerwird besonders stark die Unverzweigtheit des Stieles betont. Zu einer echten Koloniebildung wie bei Carchesium, Epistylis u. a., wobei die Einzeltiere zeitlebens durch morphologische Bande miteinander verbunden bleiben, kommt es bei dieser Art nicht. Vielmehr treten die Infusorien in Gruppen oder Familien auf wie sie bei den meisten Vorticella-Arten beobachtet werden können. Auf Grund dieser Erscheinung glaube ich nicht fehlzugehen, wenn ich die Fauré'sche Art ins Genus Pyxidium versetze, das von KEnt (1880-82) für die Peritrichen von opercularienartigem Bau geschaffen wurde, welche keine Kolonien bilden.

Unterschiede von Pyxidium cothurnoides und Pyxidium henneguyi sind kurz folgende:

Bei Pyxidium cothurnoides ist die Körperoberfläche glatt, der Stiel ist dünn, nicht gestreift, der Kern hat bandförmige Gestalt und liegt longitudinal im Körper.

Die Körperoberfläche von Pyxidium henneguyi ist quergestreift, der Stiel ist kurz und mit Querfalten versehen, der Kern ist kurz bis hufeisenförmig und liegt quer in der obern Körperhälfte.

Angaben in der Literatur, die uns über das weitere Vorkommen dieses Infusors Aufschluss geben könnten, fehlen gänzlich. Und doch will mir scheinen, dass diese Peritriche nicht zu den Seltenheiten gehört. Das geht aus meinen Funden hervor. In der vorgehenden Art, Pyxidium cothurnoides, haben wir einen Symphorionten der Ostracoden kennen gelernt. 
Allerdings werden unter seinen Trägern auch Cyclopiden aufgeführt. Wie ich aus meinen Beobachtungen schliesse, ist Pyxidium henneguyi ein specifischer Symphoriont von Cyclops serrulatus. Daher glaube ich, dass alle Befunde der nachstehenden Autoren, welche Pyxidium cothurnoides auf Cyclops spec. gefunden haben, zu Pyxidium henneguyi zu stellen sind. Von grosser Wichtigkeit zur Entscheidung dieser Frage wäre natürlich die genaue Angabe des Vorkommens der Infusorien auf den Wirten, da, wie meine Funde zeigen, nur ein bestimmtes Segment ihres Körpers besetzt wird. Folgende Forscher geben Pyxidium cothurnoides auf Cyclopiden an: Henderson (1905), Roux (1901), Francé (1897), Kent (1880-82) und MONARD (1919).

\section{Sektion: Cothurnea Bütschli.}

Genus: Cothurnia Ehrenberg Claparède und Lachmann emend.).

\section{Cothurnia crystallina (Ehrenberg).}

Das als häufige Art bekannte Infusor konnte ich nur einmal finden und zwar auf:

\begin{tabular}{|c|c|c|c|c|}
\hline Träger. & Besetzte Teile. & Hänfigk. & Fundort. & Datum. \\
\hline spirogyra. & $\mid$ & $\mid$ Bottminger Weiher. & 13. & 8.
\end{tabular}

Recht unsicher sind die Angaben über Cothurnia crystallina in der ältern Literatur. Ehrenberg $(1830,1831,1838)$ fand seine I'aginicola crystallina, die mit Cothurnia crystallina identisch ist, an Meerlinsen, Conferven und Ceratophyllum. Unter dem gleichen Namen wurde das Infusor von Dujardin (1841), Stein (1849) und Pritchard (1852) beschrieben. Dujardin an Wasserpflanzen, Stein an Lemna-Wurzeln, Vaucherien und Conferven, Pritchard an Lemna. Perty (1852) beobachtete seine Vaginicola grandis, die synonym mit Cothurnia crystallina ist, an Wasserpflanzen. In einer spätern Arbeit (1852) verzeichnet er die Vaginicola crystallina an Conferven und Polamogeton natans. Stein (1854) behält die beiden von Perty beschriebenen Arten bei und konnte sie an Confervenfäden und Lemna-Wurzeln feststellen. Clapakède und Lachmanv (1858-59) haben 
die beiden Genera Cothurnia Ehrenberg und Vaginicola Schrank einer Revision unterzogen und sie auf Grund morphologischer Unterschiede neu umschrieben. Zum Genus Cothurnia werden alle die Formen gestellt, welche mit dem hintern Gehäuserand oder mit einem kurzen Stiel dem Substrat aufsitzen. So wurde die EhrenBerG'sche Vaginicola crystallina identisch mit Cothurnia crystallina, und in der Perty'schen Vaginicola grandis erkennen die beiden Autoren eine schlecht beobachtete Form dieser Species. QuennerStEDT (1867) an Lemna. Kent (1880-82), der in seinem Werke die Peritriche immer noch unter dem Namen Vaginicola crystallina weiterführt, begegnete ihr auf Lemna und Myriophyllum. Francé (1897) auf Oedogonium, Dalla-Torré (1891) auf Süsswasserpflanzen, Roux (1901) auf Spirogyra, ENTz (1903) an Algenfäden.

Mit Hilfe dieses reichen Beobachtungsmaterials fällt es nicht schwer, sich ein Bild über den Symphorismus von Cothurnia crystallina zu machen. Aus den Angaben kann entnommen werden, dass die Peritriche nur pflanzliche Träger besiedelt. Dass das Epizoon nur auf ruhenden Wirten sich festsetzten kann, lässt sich vielleicht aus seinen morphologischen Eigenschaften erklären. Das ohne Stiel direkt dem Substrat aufsitzende Gehäuse scheint nicht für sich bewegende Träger vorteilhaft zu sein. Die Fixationsfläche ist zu klein und daher die Befestigung zu wenig solide, um den Bewegungen der Wirte stand halten zu können. Diese würden eine Loslösung des Epizoons von der Unterlage veranlassen.

Die Bildung eines Stieles kommt einer ganzen Reihe von Gehäuse tragenden Peritrichen zu. Durch seine Ausbildung wird aber die Bewegung der Wirte in ihrer Wirkung abgeschwächt. Deshalb finden wir die Arten, die durch ein gestieltes Gehäuse charakterisiert sind, meistens auf Tieren, seltener auf Wasserpflanzen.

Zur Illustration des oben gesagten möchte ich noch einige Fälle des Vorkommens anderer Cothurnia-Species anführen, sie dienen zum Beweise meiner Annahme. So findet man Cothurnia truncata (Fromentel) am Grunde der Gewässer auf Schlammpartikeln. Cothurnia ovata Dujardin wurde von Kent (1880-82) auf Conferven und andern Wasserpflanzen beobachtet. Die mit einem sehr dünnen Stiel, der den Anforderungen 
eines auf tierischen Wirten sich festsetzenden Epizoons nicht genügen kann, ausgestattete Cothurnia pyxidiformis D'Udekem, wurde von ihrem Entdecker an einem Blatt von Nuphar, von andern Forschern an andern Wasserpflanzen gefunden. Nirgends finden sich aber unter ihren Trägern Tiere irgendwelcher Art.

Genus: Vaginicola Lamarck (Claparède und Lachmann emend.). Vaginicola longicollis Kent.

Diese Peritriche, die aus der Schweiz erst aus dem Marais de Noirvaux (Ste-Croix) bekannt ist, konnte an verschiedenen Orten und aufverschiedenen Wirten von mir gefunden werden:

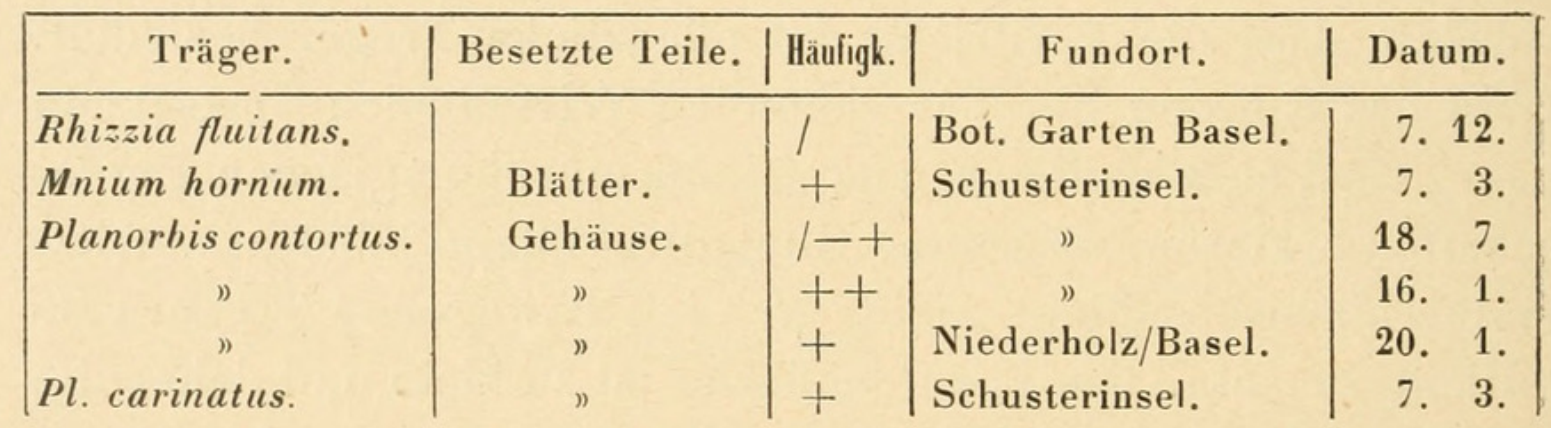

Von Claparède und Lachmann (1858-59) wurden zum Genus Vaginicola alle die Formen gezählt, deren Gehäuse mit einer abgeplatteten Seitenfläche dem Substrate aufliegen. Schon Ehrenberg (1838) muss der Vaginicola longicollis begegnet sein, denn er beschrieb und bildete eine Peritriche ab, die er Vaginicola decumbens nannte und an Lemna-Wurzeln und auf Conferven fand. Dieses Infusor wurde von Penard (1914) mit der Vaginicola longicollis identificiert. Pritchard (1852) fand seine Vaginicola decumbens auf Zygnema decimum. Steın (1854) auf den Gehäusen kleiner Planorbis-Arten und junger Limnaeen und an Lemna-Wurzeln. Die gleichen Fundorte gaben auch Claparède und Lachmane (1858-59) an. Kent (1880-82) hat die Peritriche unter dem Namen Platycola longicollis neubeschrieben. Dalla-Torré (1891) fand seine Platycola decumbens, welche ich mit Vaginicola longicollis identificieren konnte, an Süsswasserpflanzen aller Art.

Vaginicola longicollis ist nach meinen Funden, die durch Literaturnachweise bestätigt werden, zu schliessen, eine Peritriche, die pflanzliche Träger ebensogut wie tierische besetzt. 
Bei den letztern muss allerdings eine starke Einschränkung gemacht werden, in dem Sinne, dass nur langsam sich bewegende Tiere, wie es die Mollusken sind, besiedelt werden. Ich sehe in diesem Symphorionten eine biologische Uebergangsform, die vom Genus Cothurnia zum Genus Cothurniopsis leitet. In den Vertretern von Cothurnia haben wir Epizoen von Pflanzen kennen gelernt, und in den Cothurniopsis-Arten treten uns fast ausnahmslos Peritrichen entgegen, deren Vorkommen sich nur auf tierische Wirte beschränkt. Die Möglichkeit, nicht nur auf Pflanzen, sondern auch auf Tieren sich festsetzen zu können, erhält Vaginicola longicollis durch die Art der Fixation, da bei ihr das Gehäuse mit einer Breitseite der Unterlage aufliegt, wodurch die Anheftungsfläche vergrössert und somit die Gefahr abgelöst zu werden, verkleinert wird.

\section{Genus: Cothurniopsis Entz. \\ Cothurniopsis vaga Schrank.}

Cothurniopsis vaga konnte ich nur dreimal beobachten und zwar auf :

\begin{tabular}{|c|c|c|c|c|}
\hline Träger. & Besetzte Teile. & Häufigk. & Fundort. & Datum. \\
\hline $\begin{array}{l}\text { Sperogyra. } \\
\text { Lemna minor. } \\
\text { Cyclops albidus. }\end{array}$ & $\begin{array}{l}\text { Wurzeln. } \\
\text { An., F. }\end{array}$ & $\frac{1}{1-+}+$ & $\begin{array}{l}\text { Bottminger Weiher. } \\
\text { Schusterinsel. }\end{array}$ & $\begin{array}{ll}\text { 11. } & 8 . \\
11 . & 8 . \\
16 . & 1 .\end{array}$ \\
\hline
\end{tabular}

Schon Schrank (1776) hat das Infusorgekannt, er nannte es Tubularia vaga und traf dasselbe freischwimmend an. O. F. Müller (1886) fand seine Vorticella folliculata, die mit Cothurniopsis vaga identisch ist, auf Cyclops quadricornis. Mit unserm Infusor ist auch die von Соцомво (1793) beschriebene und an Lemna-Wurzeln beobachtete Rotifera ad astuccio synonym. Ehrenberg (1838) begegnete seiner Cothurnia imberbis, die sich mit Cothurniopsis paga deckt, nie anders als auf Cyclops quadricornis. Stein (1854) beobachtete Cothurnia imberbis auf Beinen, Fühlern und Furkalborsten von Cyclopsine (= Canthocamptus) staphylinus. Рвгтchaвd (1852) auf Cyclops quadricornis. Clapárède und Lachmann (1858-59) auf Canthocamptus spec.' Perty (1852) besonders am Schwanz von Cyclops- 
Arten. Kent (1880-82) gibt als Träger von Colhurnia imberbis Entomostraken und Wasserpflanzen an. Kellicott (1883a) an den Schwimmfüssen von Astacus. Vejoovsky (1882) auf Bruchstücken organischer Stoffe; er bezeichnete die Infusorienart in seiner Arbeit als Cothurnia; nach der vom Autor mitgegebenen Abbildung muss die Peritriche mit Cothurniopsis vaga identisch sein. Extz (1884) teilte das alte Genus Cothurnia von Ehrenberg in zwei selbständige Genera, wobei er für die Formen, deren Gehäuse von quergerunzelten dicken Stielen getragen werden, das Genus Cothurniopsis schuf. Zsснокке (1900) auf Chironomus spec., Ostracoden und Linceiden. Roux (1901) auf Cyclops spec. und Gammarus. Henderson (1905) und Steinmann (1907) auf Cyclops. Ebmondson (1906) fand seine Cothurnia imberbis an Wasserpflanzen. DaDAY (1968) meldet eine Cothurniopsis imberbis, die er auf Pflanzenresten und Cyclops gefunden hatte. Koford (1908) auf Canthocamptus. Bourouin-I,ind (1918) auf Candona. HжвеrLi (1918) auf dem Cephalothorax von Canthocamptus staphylinus.

Gegenüber den beiden vorherbehandelten Arten aus der Sektion der Cothurnia erkennen wir bei dieser Peritrichen eine Aenderung in der Wahl der Wirte. Wohl treten in der Liste der besetzten Substrate noch öfters pflanzliche Träger auf, aber sie sind im Hinblick auf die tierischen in den Schatten gestellt. Auch in der Auslese der aus dem Tierreich gewählten Wirte ist eine Aenderung zu verzeichnen, indem von diesem Infusor die langsam sich bewegenden Formen verlassen und durch lebhaft sich bewegende ersetzt werden. Von einem specifischen Symphorismus kann aber nicht gesprochen werden, rekrutieren sich doch die Träger aus den systematisch verschiedensten Klassen der aquatilen Fauna. Ein solcher wird aber erreicht bei der folgenden Art.

\section{Cothurniopsis plectostyla Stokes.}

Von Monard (1918) wurde für das Genus Cothurniopsis eine neue Art aufgestellt, die der Autor nach ihrem Träger Cothurniopsis canthocampti benannte. In seiner Dissertation (1919) gibt er in einer Fussnote bekannt, dass das Infusor nach der Ansicht von Penard (Genf) mit der von Stokes (1885) beschriebenen Cothurnia plectostyla identisch sein könnte. Nach per- 
sönlicher Rücksprache mit Herrn Penard und auf Grund meiner eigenen Erfahrung komme ich dazu, die beiden Arten als identisch zu erklären, da die von Stokes und Monard gegebenen Abbildungen miteinander übereinstimmen, und auch in den Diagnosen grosse Differenzen nicht zu finden sind.

Ich konnte Cothurniopsis plectostyla auf folgenden Wirten feststellen :

\begin{tabular}{|c|l|l|l|r|}
\hline Träger. & Besetzte Teile. | läufigk. & \multicolumn{1}{|c|}{ Fundort. } & Datum. \\
\hline \begin{tabular}{c|l|l|r} 
Canthocamptus \\
staphylinus.
\end{tabular} & Th. Ab. F. C. & ++ & Seewen. & 21.10. \\
$"$ & C. & + & Schusterinsel. & 7.3. \\
$"$ & C. Ab. & + & Oberwil. & 25.3. \\
$"$ & C. & ++ & Benken. & 25. \\
C. microstaphylinus. & C. Th. F. & + & Seewagen. & 1.10. \\
Th. F. Ab. C. & ++ & Schusterinsel. & 16. & 1.
\end{tabular}

Auf Grund der von Evtz (1884) gegebenen Charakteristik für das Genus Cothurniopsis muss das mit einem kurzen dicken Stiel, der zudem noch Querfalten aufweist, und mit einem ovalen Kern ausgestattete lnfusor in dieses Genus gestellt werden. Von Sтокеs (1885, 1888) wurde die Peritriche auf Canthocamptus minutus gefunden. Monard $(1918,1919)$ beobachtete seine Form auf Canthocamptus crassus, Canth. staphylinus, Canth. echinatus und Canth. schmeili, und zwar setzte sie sich am Abdomen, an den Beinen und an der Furka dieser Copepoden fest.

Der Symphorismus ist bei diesem Infusor specifisch s. l. geworden. Pflanzen sind ganz aus der Liste der Träger ausgeschaltet, und die Besetzung tendiert nach einer einzigen Tiergruppe. Der dicke kurze Stiel erlaubt es der Peritriche, die Harpacticiden zu besiedeln, und verhütet durch seine Stärke, dass die Infusorien von der Unterlage abgestreift werden.

Gleiche Stielstrukturen finden wir bei zwei auf verschiedenen Körperteilen von Astacus fluviatilis lebenden Symphorionten, nämlich bei Cothurnia astaci Stein und Cothurnia sieboldi Stein, welche beide nach ihrer morphologischen und anatomischen Beschaffenheit ins Genus Cothurniopsis gehören. Bei ihnen hat der specifische Symphorismus seinen Höhepunkt erreicht. Nicht nur ein einziger Wirt, sondern sogar nur be-

Revue Suisse de Zoologie T. 28. 1921. 
stimmte Organe und Körperanhänge werden von den zwei Arten besetzt. So setzt sich nach Stern (1854) Cothurniopsis astaci auf den Borsten der Abdominalfüsse und auf den Borsten in der Kiemenhöhle fest, auf die Kiemen selbst geht indessen das Infusor nicht über. Diese Organe sind ganz der Cothurniopsis sieboldi zur Besiedlung überlassen.

Unter-Fam. : Lagenophryininae Bütschli.

Genus: Lagenophrys Stein.

Lagenophrys labiata Wallengreen (non Stokes).

Dieses Infusor konnte ich während meiner Untersuchungen zu wiederholten Malen beđ̋bachten. Ueber sein Vorkommen und seine Träger mögen die folgenden Angaben Aufschluss geben :

\begin{tabular}{|c|c|c|c|c|}
\hline Träger. & Besetzte Teile. & Häufigk. & Fundort. & Datum. \\
\hline Cyclocypris ovum. & Schr. & $+-t+$ & Seewen (Seeboden). & 21. 10 . \\
\hline ") & n & ++ & Schusterinsel. & 6. 11 . \\
\hline ) & 1) & +-++ & ) & 7. 3 . \\
\hline ) & ) & & ” & 12. 5 . \\
\hline Candona neglecla. & ) & ++ & Fringeli (Quelle). & 1. 11 . \\
\hline Cypridopsis vidua. & ” & +-++ & Schusterinsel. & 7. 3 . \\
\hline
\end{tabular}

Es bestehen über das Vorkommen und die Systematik dieser Species in der Literatur noch einige Zweifel. Stokes (1887) hat auf den Beinen und Körperanhängen von Gammarus spec. eine Lagenophrys beobachtet und als Lagenophrys labiata nov. spec. beschrieben. Später wurde von Wallengreen (1900) eine Art des Genus entdeckt, die der Autor ebenfalls Lagenophrys labiata nannte. Obwohl beide Arten ähnliche Mundöffnungen besitzen, so können sie nach von Uвisch (1913) nicht als identisch aufgefasst werden, da sie sich in biologischer Hinsicht unterscheiden. Während die Lagenophrys labiata von Sтокеs auf Gammarus sich festsetzt, hält sich die Wallengreensche Form "auf der Aussenseite der Schale kleiner grünlicher Cypriden ») auf. 
Die übrigen wenigen Daten, die mir über das Vorkommen dieser Art bekannt geworden sind, beziehen sich alle auf Ostracoden. So fanden Roux (1901) und ANdré (1912) Lagenophrys labiata auf Cypris spec. Candona candida wurde von Bouroun-Lindt (1918) mit ihr besetzt gefunden.

Da, wie später gezeigt werden soll,- die Lagenophryden auf bestimmte Träger specialisiert sind, so wäre an die Möglichkeit zu denken, ob die Stokessche und Wallengreensche Art nicht durch eine neue Namengebung zu trennen wären, um Verwechslungen und Irrtümer aus dem Wege zu räumen. Die Lagenophrys labiata von Walengreen ist ein specifischer Symphoriont, der seine Träger nur unter den Ostracoden auswählt, und zwar werden auch von ihr, wie den andern Epizoen dieser Crustaceen, die freischwimmenden Formen bevorzugt. Nicht der Schalenrand der Muschelkrebse wird von dieser Art aufgesucht, sondern die freie Schalenfläche.

\section{Lagenophrys ampulla Stein.}

Diese zu allen Jahreszeiten vorkommende Art konnte ich an folgenden Orten erbeuten :

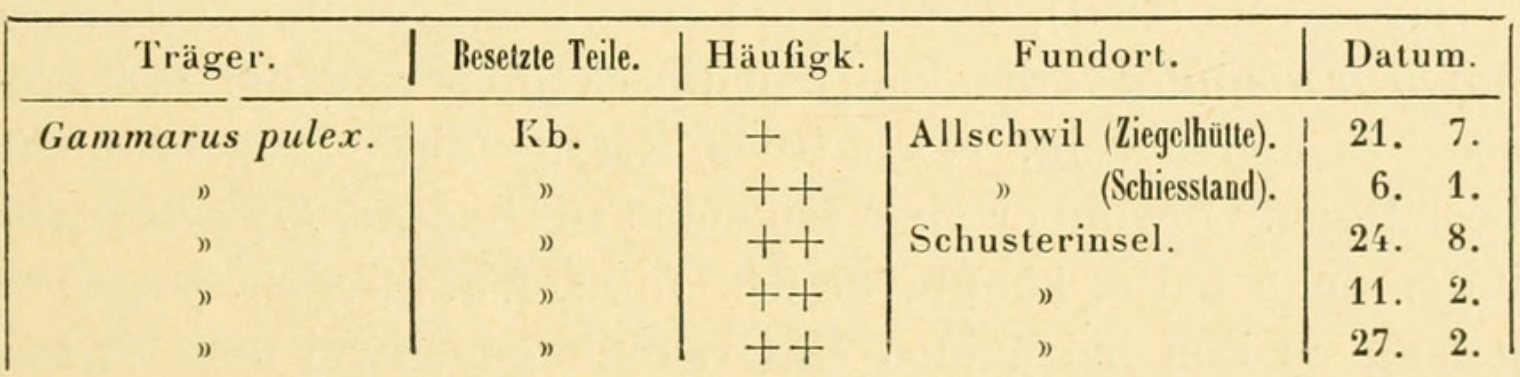

Lagenophrys ampulla wurde zuerst von Stein (1851) beschrieben. Ër fand sie $(1851,1854)$ auf den Kiemendeckeln und Kiemenblättern der Wasserassel und auf den Kiemenblättern von GammarusArten. Iмноғ (1885, 1885-86) auf Cypris spec. Plate (1886) auf den Atmungsorganen von Gammarus pulex, wo sie auch Bütschlı (1886) vorfinden konnte. Richard (1899), Wallengreen (1900), von Ubisch (1913) auf Kiemendeckeln und -blättern desselben Amphipoden. Monard (1919) sehr häufig auf Cypria ophtalmica, viel weniger häufig auf Candona.

Wenn wir dieses Beobachtungsmaterial näher betrachten, so fällt uns auf, dass Lagenophrys ampulla zwei so sehr verschie- 
dene Krebsgruppen, Amphipoden und Ostracoden, besetzen soll. Wie meine verschiedenen Trägerlisten zeigen, kommt es bei einigen Infusorien-Arten vor, dass oft systematisch weit auseinanderliegende Wirte besiedelt werden. Aber gerade für die Lagenophryden trifft das nicht zu. In der Wahl der Träger sind ihnen, mit einer Ausnahme, enge Grenzen gezogen. Es liegt daher die Vermutung nahe, dass es sich auch in diesem Falle um verschiedene Arten handelt. Die Angabe von Імноғ ist früher schon von ANDré (1912) angezweifelt worden; er glaubt, dass es nicht Lagenophrys ampulla war, welche Імног auf Ostracoden fand, sondern dass es vielmehr die Art Lagenophrys labiata gewesen sein muss, die allerdings in damaliger Zeit noch nicht bekannt und beschrieben war. Ich möchte an dieser Stelle darauf hinweisen, dass bei Zsснокке (1900, 1910, 1911), der die Funde von Iмноғ citiert, die betreffenden Angaben zu berichtigen wären. Die Funde von Monard, der Lagenophrys ampulla auf zwei Ostracoden-Arten gefunden haben will, möchte ich stark bezweifeln.

\section{Lagenophrys aselli Plate.}

Nach Stein (1851), dem wir die erste Beschreibung der Lagenophrys ampulla verdanken, soll dieses Infusor auf der Wasserassel zu finden sein. Plate (1889) konnte diese Angabe nicht bestätigen. Obwohl er viele Isopoden auf Lagenophrys ampulla untersucht hatte, konnte er das Infusor nie finden. Dagegen gelang es ihm bei seinen Untersuchungen, zwei neue Arten des Genus Lagenophrys zu entdeçken. Der Autor spricht die Vermutung aus, dass beide Formen von Stein schon gesehen wurden, jedoch irrtümlicher Weise für identisch mit der auf dem Flohkrebs lebenden Lagenophrys ampulla gehalten wurden. Die beiden neuen Arten Plates sind Lagenophrys aperta und L. aselli. Letztere hatte ich einmal zu beobachten Gelegenheit :

\begin{tabular}{|c|c|c|c|c|}
\hline Träger. & Besetzte Teile. & Häufigk. & Fundort. & Datum. \\
\hline Asellus aquaticus. & Kb. & ++ & Margarethenpark. & 8. 3.
\end{tabular}


Ueber das Vorkommen dieser Peritrichen finden sich bei Plate einige interessante Bemerkungen, die voll und ganz von mir bestätigt werden können. Plate beobachtete Lagenophrys aselli nur auf der untern Seite der Kiemenblättchen. Diese Organe sind oft so dicht mit den Infusorien besetzt und erscheinen wie mit den Gehäusen gepflastert. In diesen Fällen fällt auf, dass fast alle Individuen der Peritrichen gleich orientiert sind. Schalenöffnung und Wimperapparat sind gegen den hintern äussern Rand des Kiemenblattes gekehrt. Der Autor glaubt, diese Orientierung auf den, Einfluss der Richtung des über die Kiemen gleitenden Wasserstromes zurückführen zu müssen.

Auf den Kiemenblättern von Gammarus und Asellus gibt Richard (1899) als Symphorionten die Lagenophrys ampulla an; es wäre also wohl auch hier die Scheidung in die beiden specifischen Epizoen, Lagenophrys ampulla für Gammarus und L. aselli oder aperla für Asellus, durchzuführen. Wallengreen (1900) und von Ubisch (1913) auf den Respirationsorganen von Asellus aquaticus.

Nicht nur morphologische und anatomische Unterschiede trennen die Lagenophrys ampulla von Lagenophrys aselli, sondern auch, wie aus den oben angeführten Angaben ersichtlich ist, biologische. Beide Species haben ihre specifischen Wirte, welche sie bewohnen, sind also specifische Symphorionten s. str. Hier tritt uns nun eine neue Tatsache entgegen. In ihrer Specifität sind Lagenophrys aselli und L. aperta sogar so weit gegangen, dass nur ganz bestimmte Organe des Trägers von ihnen besetzt werden. Während Lagenophrys ampulla beide Seiten der Gammarus-Kiemen bewohnt, besiedelt Lagenophrys aselli stets nur die untere Seite, Lagenophrys aperta nur die obere der Asellus-Kiemen. Ein Uebergreifen der einen oder andern Art auf die entgegengesetzte Fläche, sodass also gemischte Kolonien entstünden, konnte weder von einem der genannten Autoren noch von mir nachgewiesen werden.

\section{Lagenophrys vaginicola Stein.}

Die in unserm Untersuchungsgebiet seltene Art, konnte nur einmal gefunden werden und zwar auf: 


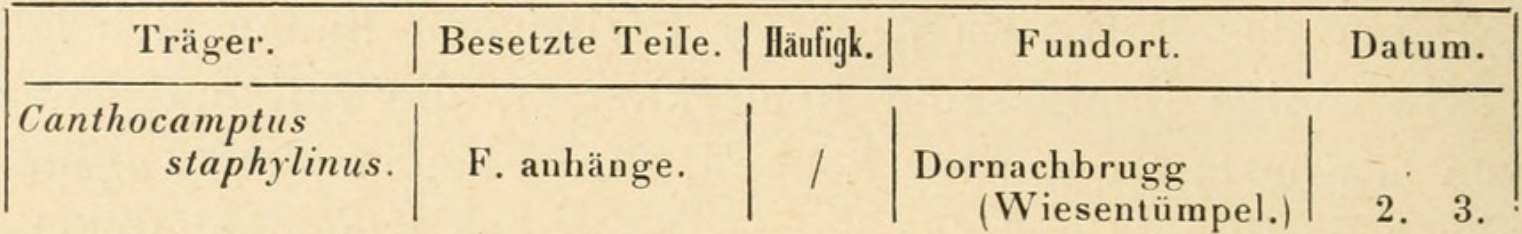

Stein (1848), der Entdecker von Lagenophrys vaginicola, fand das Infusor auf den Beinen und Schwanzborsten von Cyclopsine (=Canthocamptus staphylinus. KeNT (1880-82) auf Canthocamptus minutus. Richard (1899) auf demselben Copepoden. Zschoкke (1900), Roux (1901) und Henderson (1905) auf Cyclops spec. Penard (1917) sehr häufig auf den Caudalborsten von Canthocamptus spec. Monard (1919) auf den Furkalborsten von Canthocamptus staphylinus.

Aus diesen Daten scheint hervorzugehen, dass Lagenophrys vaginicola in specifisch-symphoriontischer Hinsicht nicht denselben Höhepunkt erreicht hat, wie ihre nächsten exklusiven Verwandten. Sie sucht ihre Träger unter den Copepoden aus, beschränkt aber ihr Auftreten allein auf die beiden Genera c'yclops und Canthocamptus. Wenigstens sind mir.Befunde, bei denen Vertreter anderer Copepoden-Genera mit dem Infusor behaftet gefunden wurden, nicht bekannt. Die oben angeführten Beobachtungen lassen indessen eine gewisse Vorliebe für Canthocamptus deutlich erkennen. An den vielen Cyclopiden, welche mein Mikroskop passiert haben, konnte ich diese Species oder auch nur leere Gehäuse von ihr, nie finden. Der specifische Symphorismus s. l. steht wohl hier nicht mehr ganz auf seiner Anfangsstufe. Zwei systematisch verschiedene Wirtsgruppen werden von Lagenophrys vaginicola besetzt, wobei die eine vor der andern einen Vorzug zu haben scheint.

\section{Lagenophrys nassa Stein.}

Lagenophrys nassa ist in ihrem Vorkommen streng an Gammarus pulex gebunden und zwar fand ich folgende Körperteile des Wirtes von ihr besetzt:

\begin{tabular}{|c|c|c|c|c|}
\hline Träger. & Besetzte Teile. & Häufigk. | & Fundort. & Datum. \\
\hline $\begin{array}{c}\text { Gammarus pulex. } \\
\text { " } \\
" \\
" \\
"\end{array}$ & \begin{tabular}{|} 
Th. Ab. anhänge. \\
Th. Cg. u. Femur. \\
” \\
"
\end{tabular} & $\begin{array}{l}+ \\
+ \\
+ \\
1-+ \\
++\end{array}$ & $\begin{array}{l}\text { Allschwil (Ziegelh) } \\
\text { Schusterinsel. } \\
\text { ") } \\
\text { Allschwil (Schiesst.) } \\
\text { Schusterinsel. }\end{array}$ & $\begin{array}{ll}21 . & 7 . \\
11 . & 2 . \\
27 . & 2 . \\
14 . & 2 . \\
16 . & 1 .\end{array}$ \\
\hline
\end{tabular}


Stein (1851) beobachtete die Peritriche auf den Beinen von Gammarus pulex, namentlich auf den Schenkeln und Hüften. Die Beobachtung Sterss, dass die Art niemals auf die benachbarten Kiemenblätter übergehe, kann von mir, wie aus obiger Tabelle ersichtlich ist, bestätigt werden. Fentmann (1911) auf Gammarus spec. und Candona candida. Richard (1899) und von Ubisch (1913) auf den Beinen von Gammarus pulex.

Meine Funde und die Angaben aus der Literatur zeigen deutlich den specifischen Symphorismus von Lagenophrys nassa. Die typische Lage der Gehäuse, bei der die Gehäusemündung stets nach der Spitze der Extremität gerichtet ist, erklärt von Uвisch als Anpassung, die den Tieren erlaubt, den Wasserstrom, der Nahrung und Sauerstoff bringt, besser aufnehmen zu können. Auf einem Bestimmungsfehler wird wohl die Angabe FenLmans beruhen, der Lagenophrys nassa auf Candona gefunden haben will, ich glaube viel eher dass es sich hier um die Lagenophrys labiata handeln dürfte.

\section{Der Symphorismus der Lagenophryininae.}

Zuzammenfassend möchte ich über den Symphorismus der Arten des Genus Lagenophrys, der in aufsteigender Reihe zunı specifischen s. str. sich entwickelt hat, das Folgende feststellen. Um das Bild zu vervollständigen, beziehe ich noch die beiden andern bekannten Species, Lagenophrys platei und L. aperta, in den Kreis der Betrachtungen ein.

Specifische Symphorionten s. I. An die Basis der Reihe stelle ich die beiden auf Entomostraken vorkommenden Formen, nämlich Lagenophrys labiata und L. vaginicola. Zur Wahl der Wirtstiere sind ihnen ziemlich weite Möglichkeiten gegeben. Immerhin muss betont werden, dass sie ihre Wirte in systematisch engbegrenzten Gruppen finden. Lagenophrys labiata besetzt nur Ostracoden, Lagenophrys vaginicola nur Copepoden.

Specifische Symphorionten s. str. sind Lagenophrys ampulla, L. aselli, L. aperta, L. nassa und L. platei. Bei L. ampulla und L. nassa beschränkt sich das Vorkommen auf 
Gammarus pulex, und zwar werden von den Infusorien nur spezielle Körperteile des Krebses besetzt. Ein Zusammenleben der beiden Arten auf demselben Organ findet nicht statt, obwohl beide Arten auf demselben Wirtsindividuum vorkommen können. (Vergl. die Listen bei den betr. Arten). Eine Parallelform zu L. ampulla und nassa ist L. platei, sie besetzt nur die Respirationsorgane von Asellus aquaticus und zwar ohne Unterschied der Flächen. Am differenziertesten ist wohl der specifische Symphorismus bei L. aperta und L. aselli, ausgeprägt. Beide bewohnen die Kiemenblättchen von Asellus aquaticus, aber sie beschränken ihr Vorkommen auf bestimmte Seiten dieser Organe. So findet man nach von Üisch (1913) Lagenophrys aperta stets nur an der Aussenseite und L. aselli nur auf der Innenseite der Kiemen. Diese beiden Formen können aber nie auf einem Asellus-Individuum gefunden werden, dessen Atmungsorgane schon mit Lagenophrys platei besiedelt sind. Auch ist ein Uebergang von $L$. aperta auf die Innenseite, oder ein solcher von L. aselli auf die Aussenseite der Kieme nicht beobachtet worden. Die auf diese Art entstehenden gemischten Kolonien konnten also nicht nachgewiesen werden.

Diese Feststellungen geben uns das Bild einer biologisch scharf spezialisierten Infusoriengruppe. Ausnahmefälle sind mir mit Sicherheit nicht bekannt geworden und die oben erwähnten sind wohl mehr scheinbar und lassen sich wahrscheinlich auf Bestimmungsfehler zurückführen.

Mit diesen Peritrichen schliesst die aufsteigende Reihe, die wir im Symphorismus der Loricata oder gehäusetragenden Peritrichen beobachten konnten. Die auf Pflanzen vorkommenden Epizoen aus der Gattung Cothurnia sind durch eine biologische Uebergangsform, Vaginicola longicollis, mit den immer mehr specifisch werdenden Symphorionten der Genera Cothurniopsis und Lagenophrys verbunden. Der biologischen Reihe geht eine morphologische parallel. Die stiellosen Arten der Gattung Cothurnia, bei denen das Gehäuse direkt mit dem hintern Pole dem Substrate aufsitzt, können infolge dieser Eigentümlichkeit nur ruhende Träger befallen. In 
Vaginicola und den Lagenophrys-Arten sehe ich Cothurnien, die, da sie auf tierische Wirte übergegangen sind, gezwungen waren, sich niederzulegen, um auf diese Art und Weise eine grössere Anheftungsfläche zu erhalten. Die Cothurniopsis-Arten endlich haben die äussere Form von Cothurnia beibehalten. Die Wahl der sehr lebhaft sich bewegenden Wirte erfordert aber von ihnen eine solide Fixierung, die durch die Ausbildung eines starken kurzen Stieles erreicht worden ist.

\section{Unterkl. SUCTORIA VEL TENTACULIFERA}

Fam. Acinetidae Bütschli.

Genus : Tokophrya Bütschli (Collin emend.).

Tokophrya quadripartita Claparède und Lachmann.

Dieses Infusor konnte von mir auf folgenden Wirten festgestellt werden :

\begin{tabular}{|c|c|c|c|c|}
\hline Träger. & Besetzte Teile. & Häuligk. | & Fundort. & Datum. \\
\hline $\begin{array}{l}\text { Spirogyra. } \\
\text { Epistylis plicatilis. } \\
\text { Agabus-juv. } \\
\text { Agrion puella-juv. }\end{array}$ & $\begin{array}{l}\text { Stiele. } \\
\text { Ko. B. K. } \\
\text { Ko. K. }\end{array}$ & $\begin{array}{l}+ \\
1 \\
1-+\end{array}$ & $\begin{array}{l}\text { Bottminger Weiher. } \\
\text { Allschwil (Schiesst.) }\end{array}$ & $\begin{aligned} 10 . & 8 . \\
27 . & 9 . \\
6 . & 1 . \\
6 . & 1 .\end{aligned}$ \\
\hline
\end{tabular}

Stein (1854) beobachtete Tokophrya quadripartita auf Epistylis plicatilis und nannte sie nach ihrem Träger "Acinete der Epistylis plicatilis». Später beschrieb er die Form als Tokophrya quadriloba (1859) und 1867 gab er ihr den jetzigen Namen. Claparède und Lachmann (1858-59) fanden Podophrya quadripartita auf Epistylis plicatilis, auf den Gehäusen von Paludina und anderer Wassermolluscen. Francé (1897) auf Cyclops. Kellicott (1885) an den Stielen verschiedener Vorticelliden. Hemper (1898) auf Epistylis plicatilis, Opercularia irritabilis, Cambarus diogenes und einer HexageniaLarve. Kent (1880-82) auf Epistylis plicatilis, Wasserpflanzen, Paludina und andern Wassermollusken. Colins (1906) auf einem Cyclops. EDmondson (1906) auf Epistylis plicatilis und andern Epistylis-Arten. 
Aus diesen Angaben und meinen Funden ist zu schliessen, dass Tokophrya quadripartita an keine specifischen Wirte gebunden zu sein scheint. Von den Wasserpflanzen ausgehend, hat sie auch auf tierischen Trägern Fuss fassen können. Dieses Vermögen, ihren Wirtskreis zu vergrössern, verdankt Tokophrya quadripartita wohl der Längsstreifung ihres Stieles, wodurch seine Zugfestigkeit erheblich erhöht wurde. In der Wirtsreihe fehlen allerdings die rasch sich bewegenden Tiere. Für ihre Besiedlung ist der Stiel des Suctors zu schwach, er ist den heftigen Bewegungen der Träger nicht gewachsen.

Tokophrya cyclopum (Claparède und Lachmann).

Tokophrya cyclopum konnte von mir auf folgenden Crustaceen beobachtet werden :

\begin{tabular}{|c|c|c|c|c|}
\hline Träger. & Besetzte Teile. | & Häufigk. & Fundort. & Datum. \\
\hline Cyclops fuscus. & |A. vord. Th. Mt. & ++ & Schusterinsel. & 26. 8 . \\
\hline$"$ & A. " Th. Mt. & ++ & Allschwil (Schiesst). & 14. 2. \\
\hline$n$ & A. 1. Th. & ++ & Schusterinsel. & 27. 2. \\
\hline ) & A. Mt. & + & $"$ & 16. 10. \\
\hline$"$ & A. & & ) & 6. 11. \\
\hline$"$ & vord. Th. & ++ & $"$ & 7. 3. \\
\hline$"$ & letztes C. segm. & $1-+$ & Arlesheim. & 20.11 . \\
\hline C. albidus. & $4 \mathrm{Th}$. & 1 & Neudorf. & 24. 9 . \\
\hline$"$ & Th. & + & Liestal. & 22. 5 . \\
\hline$"$ & A. Mt. & + & Schusterinsel. & 16. 11. \\
\hline ) & Mt. & + & $n$ & 12. 5. \\
\hline C. strenuus. & C. & l & ) & 9. 2 . \\
\hline ” & A. Mt. & + & " & 16. 11. \\
\hline C. bisetosus. & vord. Th. & + & Allschwil. & 14. 2. \\
\hline C. viridis. & A. Mt. & ++ & Margarethen Park. & 25. 1. \\
\hline C. serrulatus. & A. $\mathrm{Mt}$. & ++ & $"$ & 25. 1. \\
\hline$"$ & A. & ++ & Schusterinsel. & 9. 2 . \\
\hline$"$ & A. Mt. vord. Th. & ++ & Allschwil. & 15. 1. \\
\hline ” & A. 1. Th. & ++ & Schusterinsel. & 27. 2. \\
\hline C. fimbriatus. & A. & & Kaltbrunnental. & 20. 11 . \\
\hline Gammarus pulex. & Th. & & Arlesheim. & 7. 2 . \\
\hline
\end{tabular}

Als "Acinete des C'yclops quadricornis" wurde das Suctor von STEIN (1854) beschrieben und auf Cyclops quadricornis beobachtet. STEın bemerkt, dass die auf dem Rücken, am Abdomen oder an den 
Antennen lebenden Individuen nur kleine bis mittelgrosse Tiere sind, während die grossen Individuen auf den Beinen vorkommen. Es gab Fälle, wo ich diese Grössenunterschiede auch beobachten konnte, doch scheinen Ausnahmen von der Regel nicht zu den Seltenheiten zu gehören. Claparède und Lachmanx (1858-59) haben Podophrya cyclopum auf Cyclops quadricornis gefunden und wollen sie auch an Lemna gesehen haben. Ueber die Verteilung der Suctorien auf dem Cyclopidenkörper machten die genannten Autoren die Beobachtung, dass von den Infusorien alle Körperteile des Krebses besetzt werden. Mit Vorliebe setzen sich die Individuen von Tokophrya cyclopum aber an den Orten fest, wo sie, wie ClapaRÈDE und Lachnans annehmen, vor schädigenden Einflüssen geschützt sind, also zwischen den Füssen und an der Basis der Antennen (1860-61). Dieser Ansicht kann ich, gestützt auf meine Befunde, nicht restlos beipflichten, da von mir auch häufig der Cephalothorax der Cyclopiden von dem Infusor besetzt gefunden wurde. Weitere Funde sind folgende: Kent (1880-82) auf (yclops quadricornis und Wasserpflanzen, Mosiez (1889) auf verschiedenen Cyclops-Arten, Kellicotт, nach Sтокеs (1888) auf C'yclops quadricornis. Auf Cyclops spec. wurde das Suctor nachgewiesen von Hemper (1888), Daday (1910), Francé (1897), Kofold (1908), Schröder, B. (1914). Richand (1889) auf Cyclops quadricornis, Cyclops phaleratus, Gammarus pulex und Gammarus puteanus. Sтеск (1893) auf Cyclops phaleratus, Voigt (1902) auf Diaptomus gracilloides, Thancwitz (1903) auf $C y c l o p s$ fimbriatus, Thí́BAud und F AVRe (1906) auf $C y c l o p s$ viridis. Zsснокке (1911) auf Cyclops viridis, Hygrobates albinus, Gammarus, Eischura, Diptern- und Phryganiden-Larven und Wasserpflanzen. Fehlanan (1911) auf Cyclops viridis und Hygrobates micromaculatus. Daday (1908) an den Schalen von Ostracoden. Coltin (1911) auf Cyclops quadricornis und andern Cyclopiden.

In Tokophrya cyclopum erkenne ich nach meinen Befunden einen specifischen Symphorionten der Cyclopiden. Selten habe ich die Art auf andern Wirten als auf diesen feststellen können. Wie auch aus der Literatur zu entnehmen ist, ist die Specifität der Art für bestimmte Wirte noch sehr klein. Die verschiedensten Krebse, auch Milben und Insekten-Larven werden von Tokophrya cyclopum befallen. Die Funde des Suctors auf Pflanzen scheinen mir zweifelhaft, ich glaube, dass es sich in diesen Fällen um Tokophrya lemnarum gehandelt hat. Wie Claparède und Lachmann, so fand auch ich die Suctorien gewöhnlich in der Umgebung des Mundes der Cyclopiden 
angesiedelt, an der Antennenbasis oder am Grund der ersten Thoracalfüsse. In der Besetzung dieser Körperstellen mag das Bedürfnis nach Schutz mitgespielt haben, aber ich sehe in dieser Erscheinung vielmehr einen Vorteil, der darin besteht, dass die Suctorien Anteil an der Nahrung des Wirtes haben. Der gewöhnliche Symphorismus geht hier über in einen Commensalismus, der allerdings noch nicht sehr ausgeprägt zu Tage tritt. (Vide den Abschnitt über die Biologie der sessilen Infusorien und Suctorien im 3. Teil der Arbeit).

\section{Tokophrya cyclopum var. actinostyla Collin.}

Die von Collin (1908) beschriebene Varietät der Tokophrya cyclopum, die durch eine typische Ausbildung des obern Teiles des Stieles charakterisiert ist, fand ich in meinem Untersuchungsgebiet nur an einer Lokalität, wo sie neben der Stammform in grossen Mengen auftrat. Ihre Wirte sind die folgenden :

\begin{tabular}{|c|c|c|c|c|}
\hline Träger. & | Besetzte Teile. & Häufigk. | & Fundort. & Datum. \\
\hline Cyclops fuscus. & A. & +-++1 & Schusterinsel. & 16. 10. \\
\hline$"$ & A. & $+t$ & ) & 16. 1. \\
\hline " & A. & I & ”) & 3. 3 . \\
\hline C. albidus. & A. & $+-t+$ & $n$ & 16. 10. \\
\hline ") & A. & 1 & ” & 3. 3 . \\
\hline , & A. & + & $"$ & 6. 11 . \\
\hline ” & A. & ++ & ) & 12. 5. \\
\hline C. strenuus. & A. & +-++ & ) & 16. 10. \\
\hline C. viridis. & A. & +-++ & ") & 16. 10. \\
\hline ) & A. & & ) & 6. 11. \\
\hline$"$ & A. & ++ & ) & 16. 1. \\
\hline C. serrulatus. & A. & + & ” & 12. 5. \\
\hline
\end{tabular}

Von Collin (1908) wurde dieses Suctor auf Cyclops beobachtet. In seiner Monographie (1912) gibt der Autor als einzigen Fundort der Varietät einen Sumpf in der Côte d'Or an. Auch er fand das Infusor an dieser Lokalität stark mit der Stammform vermischt, doch in nicht so grosser Individuenzahl wie sie. Wie aus meinen Funden entnommen werden kann, stellen die Cyclopiden die specifischen Wirte des Suctors dar. Ob wir in 
der Varietät nicht eine selbständige Art zu erblicken haben, kann ich nicht entscheiden, da Material zur Entscheidung dieser Frage fehlte. Die gegenwärtigen Bauten des Basler Rhein-Hafens haben die reiche Fundgrube auf der Schusterinsel zerstört. An andern Lokalitäten habe ich bis jetzt dieses Infusor nicht wieder finden können.

\section{Genus : Acineta Ehrenberg (Collin emend.). Acineta tuberosa Ehrenberg.}

Als einzigen Vertreter dieses Genus fand ich Acineta tuberosa und zwar auf:

\begin{tabular}{|c|c|c|c|c|}
\hline Träger. & Besetzte Teile. & Häufigk. & Fundort. & Datum. \\
\hline Nepa cinerea. & B. E. & ++ & Schusterinsel. & 16.1.
\end{tabular}

Ehrenberg (1838) beobachtete A cineta tuberosa auf Meerespflanzen, Stern (1854) auf Pflanzen und Tieren der Nord- und Ost-See. Zacharias (1902) auf dem Algenüberzug der Halme von Phragmites communis. DadaY (1910) auf Cyclops-Arten. BolochonzefF nach Schröder (1914) auf Melosira. Heuscher (1890-91) auf Asterionella. AmBerg (1900) auf Diatomeen. Godet (1900) beobachtete Acinetacucullus, die mit Acineta tuberosa identisch ist, auf Fredericella suttanea.

Dasselbe, was schon bei Tokophrya quadripartita gesagt wurde, kann auch auf Acineta tuberosa übertragen werden. Der längsgestreifte Stiel erlaubt auch ihr, auf tierischen, beweglichen Wirten sich festzusetzen.

Genus : Periacineta Collin.

Periacineta linguifera (Claparède und Lachmann).

Ich konnte dieses Suctor auf folgenden Wirten feststellen:

\begin{tabular}{|c|c|c|c|c|}
\hline Träger. & Besetzte Teile. & Häufigk. | & Fundort. & Datum. \\
\hline $\begin{array}{l}\text { Haliplus amoenus. } \\
\text { II. ruficollis. } \\
\text { II. " } \\
\text { II. longicollis. } \\
\text { Hydroporus spec. } \\
\text { II. palustris. }\end{array}$ & \begin{tabular}{|c} 
rord. B. paare. \\
$" n$ \\
$"$, Er. \\
$"$ \\
$"$ \\
$"$
\end{tabular} & $\begin{array}{l}1-+ \\
++ \\
+ \\
1-+ \\
1-+ \\
1-+\end{array}$ & $\begin{array}{c}\text { Schusterinsel. } \\
n \\
" \\
" \\
"\end{array}$ & $\begin{array}{ll}\text { 7. } & 3 . \\
7 . & 3 . \\
7 . & 3 . \\
7 . & 3 . \\
7 . & 3 . \\
7 . & 3 .\end{array}$ \\
\hline
\end{tabular}


Stein (1854) beobachtete die "Acinete mit dem zungenförmigen Fortsatz " und die "Acinete der Opercularia berberina ", die beide mit Periacineta linguifera identisch sind, auf Noterus crassicornis, Laccophilus minutus (= hyalinus), Hydroporus (= Hygrotus) inaequalis, Hydroporus palustris, und Haliplus impressus = = flavicollis $\downarrow$. Wie Steın, so bemerkte auch ich, dass von Periacineta linguifera nur ausnahmsweise die Schwimmbeine, in der grössten Mehrzahl der Fälle jedoch die vordern Beinpaare der Käfer besetzt wurden. Claparède und Lachmann (1858-59) fanden Acineta linguifera auf verschiedenen Wasserkäfern. SAnd (1901) auf Wasserkäfern. Collin (1912) stellte die Art zum Genus Periacineta und gibt als Wirte Dytiscus und Hydrophiliden an, deren Flügel und Beine er von der Art oft besetzt fand. LE Roux (1907) auf Polypothrix. Koford (1908) auf Wasserkäfern aller Art.

Aus meinen Funden und den Literaturangaben ergibt sich für Periacineta linguifera ein specifischer Symphorismus für Wasserkäfer. Den heftigen Bewegungen der Wirte kann das Epizoon infolge seines kurzen Stieles Stand halten. Durch ihn wird der Infusorienkörper ganz in die Nähe des sich bewegenden Organes des Käfers gezogen, wodurch eine Herabsetzung der Stärke und Wucht der Bewegung erzielt wird.

Periacineta buckei (Kent).

Es gelang mir zweimal dieses für die Infusorienfauna der Schweiz neue Suctor nachzuweisen und zwar auf:

\begin{tabular}{|c|c|c|c|c|}
\hline Träger. & Besetzte Teile. & Häufigk. & Fundort. & Datum. \\
\hline Nepa cinerea. & $\begin{array}{l}\text { B. K., Atemröhre. } \\
\text { B. K., }\end{array}$ & $\begin{array}{l}++ \\
++\end{array}$ & Schusterinsel. & $\begin{aligned} 16 . & 1 . \\
7 . & 3 .\end{aligned}$ \\
\hline
\end{tabular}

Das Suctor ist von Kent (1880-82) als Podophrya buckei beschrieben worden. SAND $(1899,1901)$ beobachtete die mit Periacineta buckei identische Hallezia buckei zwischen Algen. Collon (1912) verwies das Suctor ins neue Genus Periacineta, er fand dasselbe öfters auf den Gehäusen von Limnaea stagnalis und einige Male auch auf Ranatra linearis.

Wie diese Angaben zeigen, besetzt Periacineta buckei ausnahmslos langsam sich bewegende, träge Tiere und geht zuweilen auch auf Wasserpflanzen über. 
Familie: Discophryidae Collin.

Genus : Discophrya Lachmann.

Discophrya steini (Claparède und Lachmann).

Dieses Suctor konnte von mir einmal beobachtet werden und zwar auf :

\begin{tabular}{|c|c|c|c|c|}
\hline Träger. & Besetzte Teile. $\mid$ Häufigk. & Fundort. & Datum. \\
\hline $\begin{array}{c}\text { Dytiscus } \\
\text { marginalis } \text { ㅇ. }\end{array}$ & E. & ++ & Liestal. & 8. 1.
\end{tabular}

STEIN (185') beobachtete seine "Acineta der Opercularia articulata» auf Brust und Beinen von Ilybius fenestratus und Agabus (=Platambus) maculatus, fernerauf Dytiscus marginalis, Colymbetes fuscus, Cybister roeseli = laterimarginalis) und Dytiscus punctulatus. Sand (1901) und Collin (1912) auf Dytiscus marginalis. Letzterer bemerkt über das Vorkommen von Discophrya steini auf Dytiscus, dass die gerippten Flügeldecken der Weibchen einen günstigen Aufenthaltsort bilden.

Auch bei diesem Suctor ist die Ursache des specifischen Symphorismus in der Ausbildung des Stieles zu suchen. Seine Kürze erlaubt dem Infusor die Besiedlung der lebhaften Käfer. Auf die Erscheinung, dass von Discophrya steini mit Vorliebe die gefurchten Elytren der Dytiscus-Weibchen aufgesucht werden, komme ich in dritten Teile meiner Arbeit zurück.

\section{Discophrya acilii Collin.}

Dieses Infusor wurde von mir einmal auf seinem specifischen Wirte gefunden :

\begin{tabular}{|c|c|c|c|}
\hline Träger. & Besetzte Teile. Häufıgk. & Fundort. & Datum. \\
\hline
\end{tabular}

Collin (1912), der die Art beschrieben hat, stellte sie ebenfalls auf den Flügeldecken eines Acilius sulcatus Weibchens fest. Auch bei diesem Infusor tritt uns die gleiche Erscheinung entgegen wie bei Discophrya steini. Nur die gerippten Elytren 
der weiblichen Käfer werden befallen, während die glatten der Männchen von einer Besetzung verschont bleiben.

Discophrya lichtensteini (Claparède und Lachmann).

Als einzigen Wirt dieser Species kann ich den folgenden angeben :

\begin{tabular}{|c|c|c|c|c|}
\hline Träger. & Besetzte Teile. & Häufigk. & Fundort. & Datum. \\
\hline \begin{tabular}{c|c|c|c|} 
Hyphydrus \\
ferrugineus. \\
$n$
\end{tabular} & \begin{tabular}{|l|l|l} 
Er., Bauchseite. \\
E.
\end{tabular} & $\begin{array}{c}++ \\
++\end{array}$ & Schusterinsel. & 7.3. \\
\hline
\end{tabular}

Die Zahl der Wirte wird durch nachstehende Literaturcitate vermehrt. Stern (1854) fand seine "Acinete der (Ipercularia lichtensteinii" auf den Beinen von Hyphydrus ovatus (=-ferrugineus) und Hydaticus transversalis. Wrzesniowsky (1877) beobachtete die Acineta hyphydri in grossen Mengen auf den Elytren von Hydoporus picipes (=? Hygrotus impressopunctatus). Kent (1880-82) stellte seine neue Art, Podophryar wzesniowskyi, die von Colnin(1912) mit Discophrya lichtensteini identificiert wurde, auf Hygrotus spec. fest.

Discophrya lichtensteini verdankt, wie so viele andere Suctorien, die Möglichkeit, die verschiedensten Wasserkäfer zu besiedeln, der Ausbildung ihres kurzen Fixationsorganes.

Discophrya elongata (Claparède und Lachmann).

Als Wirte, auf denen ich das Suctor finden konnte, seien folgende angegeben :

\begin{tabular}{|c|c|c|c|c|}
\hline Träger. & Besetzte Teile. & Häufigk. | & Fundort. & Datum. \\
\hline $\begin{array}{l}\text { Ranatra linearis. } \\
\text { Nepa cinerea. } \\
"\end{array}$ & $\begin{array}{l}\text { B., E., Ko., Atemr. } \\
\text { B., E., Ko., Atemr. } \\
\text { B. }\end{array}$ & $\begin{array}{l}++ \\
+ \\
+\end{array}$ & $\begin{array}{l}\text { Liestal. } \\
\text { Schusterinsel. }\end{array}$ & $\begin{aligned} 8 . & 1 . \\
16 . & 1 . \\
7 . & 3 .\end{aligned}$ \\
\hline
\end{tabular}

Discophrya elongata wurde von Claparède und Lachmann (1858-59) als Podophrya elongata beschrieben und auf den Gehäusen von Paludina vivipara gefunden. Bürschlı (1889) stellte das Suctor zum Genus Tokophrya und gibt als Fundorte Schneckengehäuse an. SAND (1901) auf Algen, Conferven und Ranunculus. Colcis (1911) auf den Gehäusen von Limnaea auricularia. 
Wie Periacineta buckei, so setzt sich auch Discophrya elongata, wie aus den Literaturnachweisen und meinen Funden zu entnehmen ist, regelmässig auf trägen Tieren und auch auf Wasserpflanzen fest. Bei ihr kann ebensowenig, wie bei ersterer, von einem specifischen Symphorismus gesprochen werden.

Fam. Dendrocometidae Stein.

Genus: Dendrocometes Stein.

Dendrocometes paradoxus Stein.

Wie Spirochona gemmipara, so ist auch Dendrocometes paradoxus an das Verbreitungsgebiet seines Wirtes, Gammarus pulex, gebunden. Für Dendrocomeles, wie für Spirochona, muss ein höherer Sauerstoffgehalt der Gewässer Existenzbedingung sein. An vielen Orten wurde der Wirt erbeutet, ohne dass aber auf ihm die specifischen Symphorionten nachgewiesen werden konnten. Meine Fundorte für Dendrocometes sind :

\begin{tabular}{|c|c|c|c|c|}
\hline 'Träger. & | Besetzte Teile. | & Häufigk. | & Fundort. & Datum. \\
\hline Gammarus pulex. & |Kb. sp. d. Rand.| & + & Schusterinsel. & 24. 8 . \\
\hline 》) & $"$ & l & Münchenstein. & $22 . \quad 1$. \\
\hline$"$ & ). & + & Arlesheim. & 7. 3 . \\
\hline$"$ & 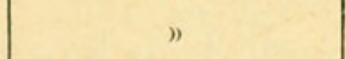 & ++ & Schusterinsel. & 9. 2 . \\
\hline ) & ” & ++ & ” & 27. 2. \\
\hline$”$ & ") & + & ) & 16. 1. \\
\hline$"$ & " & + & Allschwil (Schiessı.) & 6. 1. \\
\hline ) & ” & ++ & 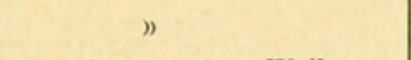 & 15. 2 . \\
\hline ) & $"$ & + & Görbelhofer Weiher. & 11. 10 . \\
\hline$n$ & ) & ++ & Kaltbrunnental. & 29. 10 . \\
\hline
\end{tabular}

Stern (1854) fand Dendrocomeles paradoxus immer auf den Kiemen von Gammarus pulex, wo er oft dicht gedrängt einen ansehnlichen Teil der Kiemenoberfläche bedeckte. Diese Beobachtung konnte ich allerdings nicht machen; dafür ist es mir möglich, den andern Befund Steins zu bestätigen, dass die Suctorien sich am Rand der Respirationsorgane des Krebses festsetzen. Ich glaube, dass erst

Rev. Suisse de Zool. T. 28. 1921. 
wenn dieser übervölkert ist, auch die freie Kiemenfläche der Besiedlung durch Dendrocometes anheimfällt. Ebenfalls auf den Kiemen von Gammarus wurde das Suctor beobachtet von Claparède und Lachmann (1858-59), Bütschli (1877), Wrzesniowsky (1877), Plate (1886), Blanchard und Richard (1897), Richard (1899), Hickson (1902), Thienemann (1913), André (1915), Lapage und Wadsworth (1916). Von Uвіsch (1913) fand Dendrocometes sowohl auf den Kiemenblättern von Gammarus pulex als auch auf denjenigen von Asellus aquaticus.

Gestützt auf meine Befunde und den Grossteil der Literaturangaben möchte ich Dendrocometes paradoxus einen specifischen Symphorionten s. str. nennen. Sein Vorkommen beschränkt sich fast ausschliesslich auf Gammarus pulex und speziell werden auf dem Träger die Kiemen von dem Suctor besiedelt. Auf andern Körperteilen des Krebses konnte ich den Symphorionten nie finden. Auch sind mir in der Literatur Angaben über solche Beobachtungen nicht zu Gesicht gekommen. Den von von Uвгsсн (1913) angeführten Befund über das Vorkommen von Dendrocometes auf den Kiemen von Asellus konnte ich, da mir geeignetes Material fehlte, nicht näher prüfen. Auf den von mir untersuchten Asellus-Kiemen konnte ich das Suctor nie finden. Ein Uebergang des Suctors auf die Atmungsorgane eines neuen Wirtes ist wohl denkbar, wenn dieser und der specifische Träger der Art in dem gleichen Gewässer vorkommen und wenn das Epizoon auf beiden die gleichen, ihm zusagenden Lebensbedingungen findet.

Dass Dendrocometes paradoxus den freien Rand der Kiemenblätter von Gammarus besiedeln kann, also einen Ort, welcher vom Bewegungscentrum weit entfernt ist, verdankt er der Art und Weise seiner Fixation. Mit breiter Basis liegt er der Unterlage auf und ist dadurch auf ihr mit einer grossen Fläche festgeheftet. Durch diesen Umstand ist er gegen die Wirkungen der Bewegungen der Atmungsorgane des Krebses gesichert. 


\section{Verzeichnis der vom Verfasser gefundenen Infusorien.}

Infusorien.

HYPOTRICHA.

Kerona pediculus.

\section{PERITRICHA.}

Spirochona gemmipara.

Urceolaria mitra.

Anhymenia steini.

Trichodina pediculus.
Träger, auf denen die Epizoen beobachtet wurden.

Hydra oulgaris.
Gammarus pulex.

Polycelis nigra, P. cornuta.

Frei, Polycelis nigra.

Hydra vulgaris, H. oligactis, H. viridis, Phoxinus laevis, Gasterosteus aculeatus, Triton-Larven.

Glossatella tintinnabulum Triton-Larven.

Vorticella alba.

Potamogeton natans, Spongilla fragilis, Cyclops albidus, C. viridis, Gammarus pulex, Chirotonetes juv.

V. nebulifera.

V. campanula.

V. microstoma.

V. putrinum.
Pflanzenreste, Algenfäden, Spirogyra, Lemna minor, Cyclops strenuus, C. viridis, Planorbis contortus, Limnaea peregra, Agrion puella juv., Limnophilus rhombicus juv., Stenophylax concentricus juv., Agabus juv., Larvenhaut, Cloeon juv.

Algenfilze, Rhiccia, Myriophyllum demersum, Elodea canadensis, Ranunculus fluitans, Cyclops viridis, Gammarus pulex, Planorbis contortus, Pl. carinatus, Nepa cinerea, Ilybius juv., Agabus juv., Chirotonetes juv., Limnophilus rhombicus juv.

Strohhalme, Grashalme, Cyclops strenuus, C. viridis, Limnophilus politus juv.

Pflanzenteile, faule Blätter, Lemna trisulea L.minor, Spirogyra, Myriophyllum, Cyclops viridis, Chirotonetes juv., Cloeon juv.., Aeschna cyanea juv., llybius juv. 
Infusorien .

V. convallaria.

Vort. monilata.

Carchesium aselli.

C. polypinum.

C. epistylidis.

Zoothamnium affine.

Z. parasita.

Epistylis steini.

E. digitalis.

E. plicatilis.

E. umbilicata,

E. branchiophila.

E. anastatica.

E. nympharum.
Träger, auf denen die Epizoen beobachtet wurden. Pflanzenreste, Detritus, Spirogyra, Mnium hornum, Myriophillum, Potamogeton, Ranunculus fluitans, Simocephalus vetulus, Cyclops fuscus, C. albidus, C. strenuus, C. viridis, Cyclocypris ovum, Gammarus pulex, Naucoris spec., Pyrrhosoma nymphula juv., llybius juv., Planorbis contortus.

Algen, Lemna minor, Cyclops viridis.

Asellus aquaticus.

Detrilus, Spongilla fragilis, Limnaea peregra.

Dero spec., Cyclops viridis, Chirotonetes juv., Cloeon juv. Limnophilus rhombicus juv., Limnophilus spec., Sienophylax concentricus juv., Perla maxima juv., Ilybius juv.

Gammarus pulex, Chirotonetes juv., Limnophilus rhombicus juv.

Daphnia longispina, Cyclops albidus, $C$. strenuus, Diaptomus pulgaris.

Gammarus pulex.

Cyclops fuscus, C. serrulatus, C. bisetosus.

Pflanzenreste, S'pirogyra, Lemna minor, Cyclops fuscus, $C$. strenuus, $C$. vernalis, C. serrulatus, Gammarus pulex, Chirotonetes juv., Platambus maculatus, Physa fontinalis, Planorbis contortus. Nais spec., Tubifex spec., Cyclops fuscus, C. albidus.

Phryganea grandis juv., Phryganea spec., Limnophilus spec., Limnoph. rhombicus juv., Glyphothaelius pellucidus juv., Stenophylax concentricus juv.

Spirogyra, Lemna minor, Phragmites, Simocephalıs vetulus, Cyclops fuscus, C. albidus, C. strenuus, C. serrulatus, C.vernalis, C. viridis, Copepoditen, Chirotonetes juv.

Cyclops albidus, Chirctonetes juv., Cloeon juv., Chironomus spec., Limno- 
Infusorien.

Epistylis lacustris.

Rhabdostyla ovum.

$R$. inclinans.

Opercularia coarctata.

$O$. berberina.

Operc. articulata.

O. lichtensteini.

O. nutans.

Pyxidium cothurnoides.

Cothurnia crystallina.

Vaginicola longicollis.

Cothurniopsis raga.

Lagenophrys labiata.

L. ampulla.

L. vaginicola.

L. nassa.
Träger, auf denen die Epizoen beobachtet wurden. philus centralis juv., Limnoph. spec., Phryganea grandis juv.

Simocephalus vetulus, Cyclops fuscus, C.albidus, C. viridis, C. serrulatus, C.leuckarti, Diaptomus gracilis.

Cyclops fuscus, C. strenuus, C. albidus, C. viridis, C. serrulatus, C. vernalis, C. bisetosus, C. leuckarti, Ceriodaphnia reticulata, Candona neglecta, C. candida, C. rostrata, Cypridopsis elongata, C. vidua. Cyprois marginata, Cyclocypris ovum, Cyprinotus incongruens, Eucypris virens, Potamocypris villosa Nais spec.

Spirogyra, Rhiccia fluitans.

Bidessus gemminatus.

A sellus aquaticus, Gammarus pulex, Limnophilus spec., Agabus sturmi, A. didymus, A. "ndulatus, Rhantus punctatus, Platambus maculalus, Dytiscus marginalis.

Asellus aquaticus.

Lemna minor, Gammarus pulex, Laccobius nigriceps.

Cypridopsis vidua, Cyclocypris, os"lm, Candona candida.

Spirogyra.

Rhiccia fluitans, Mnium hornum, Planorbis contortus, Pl. carinatus.

Spirogyra, Lemna minor. Cyclops albidus. Cyclocypris ovum, Candona neglecıa, Cypridopsis vidua.

Gammarus pulex.

Canthocampus staphylinus.

Gammarus pulex.

\section{SUCTORIA.}

Tokophryaquadripartita. Spirogyra, Epistylis plicatilis. Agabus juv., Agrion puella juv.

T. cyclopum.

Cyclops fuscus, C. albidus, C. strenuus, $C$. bisetosus, C. viridis, C. serrulatus, C.fimbriatus, Gammarus pulex. 
Infusorien .

Acineta tuberosa.

Periacineta linguifera.
Träger, auf denen die Epizoen beobachtet wurden. Nepa cinerea.

Haliplus amoenus, H. ruficollis, H. longicollis, Hydroporus spec. H. palustris.

Dendrocometes paradoxus. Gammarus pulex.

Neu für die Infusorienfauna der Schweiz sind folgende Arten : PERITRICHA

Scyphidia limacina.

Planorbis, contortus, Pl. planorbis, Limnaea ovata, L. auricularia.

Vorticella crassicaulis. Asellus aquaticus.

V. microstoma var. abreviata.

Alona intermedia, Simocephalus vetulus, Chydorus sphaericus, Cyclops strenuus, C. viridis, C.vernalis, Cloeon juv.

Zoothamnium aselli. Gammarus pulex, Niphargus puteanus, Asellus aquaticus.

Epistylis diaptomi.

Opercularia gracilis.

Diaptomus oulgaris.

Planorbis contortus.

O. cylindrata.

O. corethrae.

O. zschokkei.

Cyclops fuscus, Potamocypris villosa, Cyprinotus incongruens.

Corethra plumicornis juv.

Cyclops fuscus, C. strenuus, C. viridis, C. serrulatus, C. fimbriatus, Canthocamptus staphylinus, C. microstaphylinus.

Pyxidium henneguyi. Cyclops serrulatus.

Cothurniopsis plectostyla. Canthocamptus staphylinus, C. microstaphylinus.

Lagenophrys aselli. Asellus aquaticus.

\section{SUCTORIA}

Tokophryacyclopum var. Cyclops fuscus, C. albidus, C. streactinostyla.

Periacineta buckei.

Discophrya steini.

D. acilii.

D. lichtensteini.

D. elongata. nuus, C. piridis, C. serrulatus.

Nepa cinerea.

Dytiscus marginalis $\$$.

Acilius sulcatus ․

Hyphydrus ferrugineus.

Ranatra linearis, Nepacinerea.

Die gesperrt gedruckten Namen in der zweiten Kolonne stellen für die einzelnen lnfusorien-Arten neue Träger dar, auf denen bis jetzt die Epizoen noch nicht nachgewiesen waren. 


\section{ALLGEMEINER TEIL}

\section{Bedingungen der Besiedlung und der Verteilung der Epizoen auf die verschiedenen Wirtstiere.}

Wenn wir die im systematisch-faunistischen Kapitel aufgestellten Reihen der mit sessilen Infusorien behafteten Wirtstiere einer Prüfung unterziehen, so fällt uns die Dominanz gewisser Tiergruppen oder -Arten auf, während andere in unsern Gewässern häufige Süsswassertiere ganz in den Hintergrund zurückgedrängt worden oder gar nicht vorhanden sind. So erscheinen regelmässig oder sehr häufig die Copepoden und Ostracoden, gewisse Käfer- und Ephemeriden-Larven, einige Süsswassergastropoden, Malacostracen, Coleoptern und Hemiptern als Infusorienträger. Sehr selten sind in den Listen die Dipternlarven, wie Ceratopogon, Corethra, Chironomus und fast gänzlich wird man das grosse Heer der Cladoceren vermissen. Diese auffallende Erscheinung wird noch vermehrt durch einige interessante Beobachtungen früherer Forscher, auf die immer wieder hingewiesen wurde, ohne dass ein Erklärungsversuch gemacht wurde. Es sind nämlich die Epizoen einiger Ostracoden, der Coleoptern und Hemiptern, des Amphipoden Gammarus und der Dipteren-Larven Chironomus und Corethra auf ganz bestimmten Körperstellen oder Organen lokalisiert.

Es ist die Aufgabe dieses Abschnittes, ein solches Verhalten näher zu untersuchen und eine vorläufige Erklärung dafür zu finden. Von Wichtigkeit zur Beleuchtung der uns beschäftigenden Frage ist uns die Arbeit von Ввоснев (1909-11) über die Kapillarphänomene. Sie kann vielleicht zu einem befriedigenden Resultat den Weg weisen.

Brocher teilt die aquatile Fauna mit Rücksicht auf die Kapillarphänomene in zwei Gruppen ein, und zwar wie folgt: 


\section{Gruppe.}

Hierhin gehören die Tierformen, deren Körper ganz oder zum grössten Teil unbenetzbar ist.

\section{Gruppe.}

In diese Gruppe sind alle die Tierformen zu stellen, deren Körper ganz oder doch zum grössten Teil benetzbar ist.

Ввоснен kommt in seiner sehr interessanten Arbeit, auf die ich verweise, zum Resultat, dass zwei Körper, die entweder beide vom Wasser benetzbar oder unbenetzbar sind, sich bei Annäherung lebhaft anziehen; sie stürzen sich förmlich einer auf den andern und bleiben verbunden. Wenn dagegen ein Körper benetzbar, der andere unbenetzbar ist, so findet zwischen den beiden eine Abstossung statt. Mit Hilfe dieser beiden Sätze wird uns die Möglichkeit gegeben, das weiter oben angeführte merkwürdige Verhalten der sessilen Infusorien und Suctorien einigen Tiergruppen gegenüber einigermassen zu erklären.

Auch ich möchte, wie Brocher, die aquatile Fauna in die beiden Hauptgruppen teilen, in solche mit benetzbarem und solche mit unbenetzbarem Körper.

\section{Gruppe: Der Körper ist unbenetzbar.}

An den Anfang dieser Gruppe stellte ich die überall weitverbreitete Ordnung der Cladoceren. Der Körper aller Vertreter dieser Crustaceen ist nicht benetzbar. Kommt eine Cladocere der Wasseroberfläche zu nahe, so wird sie durch die Kapillarkraft auf dieselbe hinauf gehoben. Das Wasser fliesst von der Schale ab, und auf dem Wasserspiegel treibend geht der Krebs zu Grunde, denn er hat nicht die Kraft, die Kapillarkraft des Wassers zu überwinden und in sein Element zurückzu- 
kehren. Anders liegen die Verhältnisse, wenn die Cladocere in der Tiefe des Wassers bleibt. Hier wirken keine Kapillarkräfte auf sie ein, sondern das Tier ist von einer dünnen Luftschicht umgeben, an die sich der Oberflächen-Film anschliesst. Unter dem Oberflächen-Film verstehe ich die Grenzschicht zwischen dem Wasser und der den unbenetzbaren Tierkörper umgebenden Lufthülle.

Zwischen dem nicht benetzbaren Cladocerenkörper und dem ihn umgebenden Oberflächen-Film befindet sich also eine sehr dünne Luftschicht. Eine solche fehlt hingegen dem benetzbaren Infusorienkörper. Das freischwimmende Infusor gelangt mit Hilfe seines Wimperapparates an den Oberflächen-Film der Cladocere; seine Kraft genügt aber nicht, diesen zu durchstossen, und auf dem Fremdkörper, dem Tier, sich anzusiedeln. Aus diesem Grunde finden wir Cladoceren nie mit Infusorien behaftet. Nur ganz ausnahmsweise kann eine Besiedlung stattfinden. Auf die Bedingungen, unter denen dies vorzukommen scheint, werde ich weiter unten zu sprechen kommen. Dass die Oberflächenspannung tatsächlich eine Grösse ist, mit welcher wir hier rechnen können und müssen, geht daraus hervor, dass sie grossen und relativ schweren Tieren, wie Hydrometra, Gyrinus natator, einigen A raneinen erlaubt, auf der Wasseroberfläche zu leben ohne unterzusinken. Wäre aber umgekehrt der Infusorienkörper auch nicht benetzbar, also auch von einem Film umgeben, so würden bei der Annäherung der beiden Organismen die Oberflächen-Filme infolge der Kapillarkräfte zusammenfliessen, und eine Festsetzung wäre unter diesen Verhältnissen möglich.

Wenn man meine Listen und die Literaturcitate durchgeht, so stösst man einige Male auf Angaben, nach welchen Cladoceren mit sessilen Infusorien behaftet gefunden wurden. In allen Fällen aber ist die Zahl der Epizoen und auch der tragenden Crustaceen eine kleine, und der Ort, der von den Epizoen aufgesucht wurde, ist nicht die freie Schalenfläche, sondern fast stets nur der ventrale Schalenrand. Nur in drei Fällen konnte ein massenhaftes Auftreten von drei kolonialen Peri- 
trichen auf Daphnia longispina, Simocephalus vetulus und Chydorus sphaericus beobachtet werden.

Im ersten Falle handelt es sich um Zoothamnium parasita auf Daphnia longispina. Das Material stammte aus dem Bottminger-Weiher in der Nähe Basels. In ihm konnte Zoothamnium parasita sofort nach Einbringung des Materials auf Cyclops strenuus (Weibchen und Männchen) in grosser Zahl nachgewiesen werden. Nach zwei Tagen machte sich das Infusor auch auf Diaptomus vulgaris bemerkbar und nach Verlauf von weitern sechs Tagen konnte ich die Peritriche auf Daphnia finden, und zwar in grossen und zahlreichen Kolonien. Das Wasser war inzwischen stinkend geworden, die Besiedlung dauerte noch einige Zeit weiter fort.

Den zweiten Fall eines Massenauftretens einer Peritrichen auf einer Cladocere bildet mein Befund von Vorticella microstoma var. abreviata, welche Chydorus sphaericus und andere Cladoceren (vide Fundortliste dieses Infusors pag. 240) stark besetzte. Das Material sammelte ich in einem kleinen Weiher, der organische Abfälle in grosser Menge enthielt. Die Untersuchung geschah sofort nach Einbringung der Beute. Die Besetzung konnte also nicht künstlich hervorgerufen worden sein, sondern musste schon in freier Natur stattgefunden haben. Typisch scheint mir auch in diesem Falle die starke Verunreinigung des Wassers zu sein, der ich wieder die Ursache der Erscheinung zuschreiben möchte.

Eingehender habe ich den dritten Fall studieren können, wo Epistylis anastatica in grosser Menge auf Simocephalus vetulus auftrat. Das Material sammelte ich in einem Fischteich am Fusse des Passwang (südl. Basel). Es enthielt neben der genannten Cladocere Cyclops albidus und Cyclops strenuus, die am Abdomen oder Cephalothorax häufig grössere und kleinere Kolonien von Epistylis anastatica trugen. Die Untersuchung des Materials ergab die absolute Infusorienfreiheit von Simocephalus. Eine Aenderung des Zustandes trat nach acht Tagen ein, eine Massenvermehrung von Epistylis anastatica griff Platz und damit zugleich eine starke Besetzung 
sowohl der Cyclopiden, als auch der Cladoceren und anderer Substrate. Nicht nur kurzgestielte Einzelindividuen von Epistylis konnte ich beobachten, sondern auch junge Kolonien, die im Laufe der nächsten zwei Tage ansehnliche Grössen erreichten. Während dieser acht Tage war das Wasser trübe geworden und durch die vielen Abfallstoffe, Tier-und Pflanzenleichen in Fäulnis übergegangen. Der Höhepunkt der Fäule war noch nicht eingetreten, als bereits die Massenvermehrung der Peritrichen einsetzte. Nach dem dritten Tage war von den vielen Epistylis-Individuen und -Kolonien auf ihren Trägern nicht mehr die geringste Spur zu finden; am Boden des Gefässes allerdings lagen in Menge ihre Cysten. Von den verschiedensten Autoren ist schon darauf hingewiesen worden, dass zunehmende Verderbnis des Wassers Cystenbildung veranlasse. Neu war für uns nur die rasch sich vollziehende Vermehrung der Peritrichen. Die in Menge erzeugten Infusorien waren gezwungen, dann nicht nur ihre eigentlichen Träger, die Cyclopiden, sondern auch Cladoceren, Schneckenund Phryganidengehäuse zu besetzen.

Die fortgesetzte Neubildung von bei der Fäulnis entstehenden Stoffen ändert die physikalischen Eigenschaften des Wassers. Für unsern Fall ist besonders der eintretende Wechsel der Oberflächenspannung von Wichtigkeit. Diése Spannung ist in einer Lösung kleiner als im reinen Lösungsmittel, sie nimmt mit der Concentration der Lösung ab. In durch Fäulnisstoffe verunreinigtem Wasser haben sich also auch die Bedingungen, die für eine Festsetzung von Epizoen auf Fremdkörpern massgebend waren, geändert. Kommt jetzt eine freischwimmende Peritriche gegen den die Cladocere umgebenden OberflächenFilm, so reicht unter den herrschenden Umständen ihre Kraft aus, den Film zu durchbrechen, und die Möglichkeit, sich festzusetzen, ist gegeben.

Es muss aber betont werden, dass die Fixation der EpistylisKolonien auf Simocephalus keine solide war. Schon nach kurzer Zeit sah man unter dem Mikroskop die Kolonien ihre Träger verlassen und frei im Tropfen auf dem Objektträger herum- 
schwimmen. Dem allseitig von frischer Luft umgebenen Wassertropfen entsteigen die Fäulnisgase, und durch Oxydationsvorgänge nähert sich die kleine Wassermenge allmählich wieder ihrem Normalzustand. Mit dieser chemischen Aenderung geht auch Hand in Hand die physikalische, die Oberflächenspannung nimmt wieder zu und veranlasst wohl die Ablösung der Kolonien vom Träger.

Durch diese Betrachtungen scheint mir das Verhältnis der sessilen Peritrichen zu den Cladoceren einigermassen charakterisiert zu sein. Weitere Beobachtungen werden vollständigere Resultate zeitigen.

Für die Ostracoden gelten in Bezug auf die Unbenetzbarkeit ihres Körpers im allgemeinen dieselben Bemerkungen, wie sie für die Cladoceren gemacht wurden. Als Symphorionten dieser Crustaceen sind zu nennen: Rabdostyla ovum, Pyxidium cothurnoides, Lagenophrys labiata und in einem Falle auch Opercularia cylindrata. Bei vielen Arten finden sich diese Epizoen fast ständig, während andere wieder ganz verschont bleiben. Die gestielten Infusorien wählen als ihren Aufenthaltsort stets nur den Schalenrand, während die gehäusebildende Lagenophrys labiata sich auf der freien Schalenfläche ansiedelt. Im allgemeinen sind die Bodenformen der Ostracoden, wie die Arten von Candona, Herpetocypris, Iliodromus und andere, die den Detritus durchwühlen, frei von Infusorien, oder aber wenn solche auftreten, beobachten wir sie gewöhnlich nur in sehr kleiner Individuenzahl. Diese Erscheinung erklärt sich ganz aus der Biologie dieser Crustaceen. Das Leben der genannten Ostracoden im Schlamm der Gewässer verhindert eine Besetzung ihrer Schale durch sessile Peritrichen. Anders liegen dagegen die Verhältnisse bei den freischwimmenden Formen, so den Eucypris-, Cypridopsis-, Cyclocypris-, CypriaArten. Hier ist die Möglirhkeit einer mechanischen Schädigung des Infusors behoben, und einer Besetzung steht nichts im Wege.

Auffallend ist, dass die unbenetzbaren Ostracoden relativ häufig von Epizoen aufgesucht werden, und es fällt schwer, 
wenn die Einteilung von Brocher beibehalten werden soll, eine Erklärung für diese Tatsache zu finden. Ich glaube annehmen zu dürfen, dass durch die Skulpturierung und noch mehr durch die Behaarung des Randes der Ostracodenschale die Besetzungsmöglickeit gesteigert wird. Am stels beborsteten Schalenrand stossen die mehr oder weniger unbenetzbare äussere Schalenseite und das benetzbare Innere des Tieres zusammen. Die Beborstung verursacht vielleicht eine Aenderung der Kapillarphänomene und ermöglicht daher die Besiedlung dieses Schalenteiles in solchem Masse.

Einzig steht in dieser Gruppe unter den Malacostracen Gammarus pulex da. Im Hinblick auf die Benetzbarkeit zerfällt sein Körper in zwei Teile, in den obern unbenetzbaren Teil, der die cephalen, thoracalen und abdominalen Segmente mit den Epimeren umfasst. Dazu kommen noch sämtliche Gliedmassen. Der untere benetzbare Teil umfasst die Respirationsorgane. Wir werden also bei der Untersuchung von Gammarus stets an diesem Teile Epizoen antreffen können. Doch sind das nicht die einzigen Orte, es tritt uns hier eine merkwürdige Tatsache entgegen. In den vorhergehenden Listen wurden für Lagenophrys nassa, Opercularia articulata, Epistylis plicatilis, Vorticella alba, V. campanula, V. convallaria, Zoothamnium affine, Zooth. aselli als Festset\%ungsorte die Thoracalbeine des Amphipoden angegeben. Es erhebt sich die Frage, wie diese Erscheinung mit unserer Theorie in Einklang zubringen ist, nach der sich ein Infusor auf einem unbenetzbaren Frentkörper unter normalen Bedingungen nicht festsetzen kann.

Bei der genauen Durchsicht des umfangreichen Materials konnte immer wieder festgestellt werden, dass die Stelle an den Thoracalbeinen, die die genannten Epizoen besetzen, immer eine ganz bestimmte ist. Es sind nicht die freien, unbeborsteten Bezirke dieser Körperteile, sondern stets die Bezirke um die Gelenke, wo grosse Borsten und Stacheln inseriert sind. Diese sind nicht hydrofuger Natur, sondern ziehen das Wasser an und bewirken deshalb eine Benetzung: der Gelenke. Den Peritrichen ist es nun möglich, auf Borsten 
und Stacheln selbst oder doch in ihrem nähern Umkreise sich anzusiedeln. Mit dieser einzigen Festsetzungsmöglichkeit ist ausserdem noch ein Nutzen verbunden. Die sessilen Infusorien entbehren der aktiven Bewegung, sind deshalb feindlichen Angriffen gegenüber nur mangelhaft geschützt. Schutz vor Feinden und andern schädigenden Insulten bietet den Epizoen der Festsetzungsort selbst. Denn bei der Contraction verschwinden die Kolonien ganz in den Stacheln und Borsten, welche die Gelenke der Thoracalbeine kranzartig umgeben.

Eine interessante Erscheinung darf nicht unerwähnt gelassen werden. Speziell die Coxa der Thoracalbeine ist oft mit zahlreichen Individuen von Lagenophrys nassa und grossen Familien der drei angeführten Vorticella-Species besetzt. Die Frage, warum gerade hier vorzugsweise eine Besetzung erfolgen kann, muss einstweilen noch offen gelassen werden.

$\mathrm{Zu}$ den Insekten-Larven, auf deren Körper ich nie sessile Infusorien oder Suctorien gefunden habe, gehören Ceratopogon, Corethra, und Chironomus. Diese Diptern-Larven haben die Eigentümlichkeit, dass ihr Körper unbenetzbar ist. Es treten bei ihnen also die nämlichen physikalischen Erscheinungen wie bei den Cladoceren zu Tage. Wie bei Gammarus, so muss auch hier auf einen interessanten Befund aufmerksam gemacht werden. An den Chironomus-Larven werden sehr häufig kleinere Kolonien von Epistylis nympharum gefunden, und zwar immer nur um die Mundteile herum. An demselben Orte wurde sie auch von ThiEnEmann (1911-12) an verschiedenen Chironomiden nachgewiesen. Es muss angenommen werden, dass an dieser Körperstelle andere Kapillarverhältnisse herrschen als auf dem übrigen Körper. Eine solche Veränderung. muss auch am letzten Segment dieser Larven eingetreten sein, da hier Zscнокке (1901) stets Kolonien derselben Vorticellide finden konnte. Also nicht nur bessere Ernährungsverhältnisse veranlassen Epistylis, sich in der Nähe das Mundes anzusiedeln. In höherem Masse scheinen physikalische Bedingungen bei der Auswahl des Besetzungsortes mitzusprechen. Eine zweite Form, die sich ebenfalls an einer bestimmten Körpergegend 
einer Diptern-Larve ansiedelt, ist Opercularia corethrae, die im Schwanzfächer der Larve von Corethra plumicornis sitzt. Der Fächer wirkt in seiner Gesamtheit wohl als hydrophiles Organ, das vom Wasser ganz benetzt wird, und den Epizoen daher eine Besiedlung erlaubt. In diesem Falle kommt der ernährungs-physiologische Vorteil - Nutzen aus den Faekalmassen der Larve zu ziehen - ziemlich sicher erst in zweiter Linie in Betracht.

Im formenreichen Stamm der aquatilen Insekten-Imagines finden wir in Bezug auf die Benetzungsverhältnisse die verschiedensten Uebergänge zwischen der ersten und der weiter unten zu behandelnden zweiten Gruppe. Eine scharfe Trennung. in einzelne Kategorien ist hier zum grössten Teil nicht möglich, und ich ziehe es daher vor, diejenigen Fälle, die besonderes Interesse bieten, einzeln kurz zu streifen.

An die Spitze stelle ich die Hemipteren. Einen ganz benetzbaren Körper haben Nepa und Ranatra. Infusorien und Suctorien finden sich deshalb auf ihren Körpern überall zerstreut, ohne an bestimmte Regionen gebunden zu sein. Gar nicht benetzbar ist wohl der Körper der kleinen Formen Ploa und Sigarra, und nur teilweise benetzbar ist er bei den andern Arten des Süsswassers: Notonecta, Naucoris und Corixa. Auf den dem Wasser nicht zugänglichen Stellen des Körpers wird man natürlich vergebens nach Epizoen suchen. Die unbenetzbaren Regionen sind bei dieser Kategorie der Kopf, die Flügeldecken und die Bauchseite, benetzbar sind nur die Schwimmbeine. Hier ist der Ort, wo Einzelinfusorien sich annähern, festsetzen und zur Koloniebildung schreiten können. Die kolonialen Epizoen, welche wir an den Schwimmbeinen unserer grössern Hemiptern finden, gehören ausschliesslich zum acontractilen Genus Opercularia. Sie sind speziell von FauréFrémiet (1906 a, b, c,) untersucht worden. Auf Grund eines reichen Vergleichsmaterials und von Experimenten ist der Autor zum Schlusse gekommen, dass die Symphorionten von Notonecta und Corixa und einiger Coleoptern specifisch verschieden sind und nicht Varietäten einer Art darstellen. Die 
jeder Bewegung unfähigen Tiere bedürfen, um vor Feinden einigermassen gesichert zu sein, eines Schutzes, dieser wird ihnen in der Schwimmbehaarung der Beine ihres Wirtes zuteil. Aber nicht die am dichtesten mit Haaren bestandenen Teile der Gliedmassen sind es, die besetzt werden, sondern die Bezirke um die Gelenke, wo die Behaarung lichter ist. Auch hier ist mit der einzigen Festsetzungsmöglichkeit auf den behaarten Schwimmbeinen einer Notonecta ein Vorteil verbunden, wie das weiter oben schon einmal bei Gammarus beschrieben worden ist.

Verschiedenartiger als bei den Hemiptern sind die Fixationsverhältnisse bei den Wasser-Coleopteren.

Fast ganz frei von sessilen Infusorien und Suctorien fand ich immer, obwohl sie in grossen Mengen untersucht wurden, die Hydrophiliden, Hydrophorus-, Hygrotus-, Haliplus-, Hydrovatus- und andere Arten. Die Hydrophiliden erscheinen in der von Brocher gegebenen Tabelle an verschiedenen Orten. Der Hauptsache nach ist der Körper dieser Käfer infolge der Bedeckung mit hydrofugen Haaren unbenetzbar. Wegen der geringen Körpergrösse der Träger werden die benetzbaren Teile in ihrer Bedeutung für eine Besetzung noch mehr in den Hintergrund gestellt. Die Ansiedlungsmöglichkeit für die Epizoen ist aus diesem Grunde auf ein Minimun herabgesetzt. Bei den benetzbaren Formen muss die Kleinheit des Körpers als Ursache für das fast ausnahmslose Fehlen von sessilen Infusorien und Suctorien angesehen werden.

Die Kolonien von Opercularia-Arten, die die Grosskäfer unserer Gewässer gerne befallen, scheinen in den Klein-Hydrophiliden keine zweckmässige Unterlage zu finden. In den drei Fällen, wo Opercularia-Kolonien auf Kleinkäfern beobachtet werden konnten, musste konstatiert werden, dass ihre Höhe und Individuenzahl weit hinter dem Normalen blieb. Die Kolonien waren kurzgestielt und enthielten nur wenige Individuen. Ich sehe daher in dieser Erscheinung eine Stütze für die Richtigkeit meiner Annahme, dass geringe Körperfläche der Träger eine Besetzung mit Infusorien erschwert, und dass, 
wenn sie doch vorkommt, nur kümmerliche Kolonien entwickelt werden. Auch bei Stein (1854) findet sich eine diesbezügliche Bemerkung; er fand Opercularia berberina häufig auf den grössern Wasserkäfern, dagegen weit seltener auf den Hydrophiliden.

Auf die specielle Lokalisation von Infusorien auf dem Coleopternkörper komme ich bei der Behandlung der Grosskäfer zu sprechen.

Verschiedene Fälle sind bei den Grosskäfern, den Dytiscus-, Hyphydrus-, Rhantus-, Agabus-, Colymbetes-Arten zu verzeichnen. Da bei diesen Tieren die Kolonien der Peritrichen und die Suctorien auf bestimmte Körperregionen lokalisiert zu sein scheinen, so ziehe ich vor, zunächst die letztern einer kurzen Prüfung zu unterziehen.

Betrachten wir die Flügeldecken der Wasserkäfer genauer, so fallen uns zwei Typen auf : glatte und gerippte Elytren. Die glatten Flügeldecken werden vom Wasser nicht benetzt, sie sind von einem Oberflächen-Film umgeben und freischwimmenden Einzeltieren von sessilen Infusorien und Schwärmern von Suctorien daher nicht zugänglich. Ganz andere physikalische Bedingungen rufen die gerippten oder stark skulpturierten Flügel hervor. Dank ihrer Unebenheit sind sie benetzbar und können aus diesem Grunde Suctorien und Peritrichen als Aufenthaltsort dienen. Als Belege für diese Feststellung führe ich nur zwei Befunde an. Ich fand Discophrya acilii in den Furchen der Flügel von Acilius sulcatus 우, Discophrya steini in grosser Zahl auf den gerippten Flügeln von Dytiscus marginalis $\$$. Auf den oft untersuchten männlichen Tieren der beiden Species, deren Elytren glatt sind und daher unbenetzbar, konnte ich nie Suctorien feststellen.

Als benetzbar muss der Flügeldeckenrand und der Rand des Thoraxschildes der Wassercoleoptern betrachtet werden. An diesen Körperteilen werden oft Kolonien von Peritrichen angetroffen. So konnte ich Opercularia articulata am Elytrenrand von Agabus sturmi, Opercularia berberina am Flügeldeckenund Thoraxschildrand von Haliplus ruficollis beobachten.

Rev. Suisse de Zool. T. 28. 1921. 
Die freie Bauchseite kommt für die Besetzung durch sessile Infusorien nicht in Frage. Ganz abgesehen von der Unbenetzbarkeit dieses Körperteiles sind es hier mechanische Einflüsse, die eine Besiedlung nicht ermöglichen. Bei Dytiscus z. B. treten die betreffenden Verhältnisse klar zu Tage. Der Käfer fegt beim Schwimmen mit seinen Beinen über die Bauchfläche; die scheuernde Wirkung der Bewegung gestattet eine Bildung von Kolonien noch weniger als eine Festsetzung.

Nur an den Hüftgelenken der Grosskäfer können fast regelmässig Infusorienkolonien als weisse Punkte beobachtet werden. Diese Teile sind zwar von Natur aus unbenetzbar, durch die Annäherung der rechten und linken Coxa findet indessen ein Zusammenfluss der beiden Oberflächen-Filme statt. Die Folge davon ist, dass ein kleiner benetzbarer Raum entsteht, der, weil er zudem noch Schutz vor schädigenden Einflüssen bietet, gerne von verschiedenen Opercularia-Species aufgesucht wird. Als Belege führe ich meine Funde von Discophrya lichtensteini auf Hyphydrus ferrugineus und Opercularia articulata auf Rhantus punctatus an.

Als letzter Teil des Coleoptern-Körpers, der oft von Infusorien und Suctorien besetzt wird, verdienen noch die Beine Erwähnung. Nehmen wir einen Dytiscus oder Agabus aus dem Wasser, so sehen wir, wie die Flüssigkeit von den Flügeldecken und der Bauchseite abfliesst und beide Teile ganz trocken werden, während die Beine nass bleiben. Bei näherer Untersuchung der Gliedmassen bemerkt man an ihnen Haare und Borsten, und da dieselben hydrophil sind, ist auch die Benetzbarkeit der ganzen Extremität erklärlich. Es ist daher auch nicht verwunderlich, dass wir an diesen Organen Kolonien von Opercularien und sehr häufig verschiedene Suctorien finden. Allerdings ist der morphologische Einfluss, den der Ort der Festsetzung auf die Epizoen ausübt, nicht unbedeutend. Die energische Schwimmbewegung der Beine und auch des ganzen Körpers verlangt von den Infusorien einige Anpassung. Um die Wirkung der Bewegung ertragen zu können, ist das Fixationsorgan der meisten Suctorien der Käfer kurz aus- 
gebildet. Die Möglichkeit, von Fremdkörpern der Umgebung von der Unterlage abgestreift zu werden, wird durch diese Einrichtung behoben.

2. Gruppe: Träger, deren Körper benetzbar ist.

In dieser Gruppe vereinigen wir alle die Tierformen und -Gruppen, die in der vorhergehenden Abteilung ausgeschaltet waren. Es handelt sich hauptsächlich um Oligochaeten, Copepoden, verschiedene Insekten-Larven, wie Libellen-, Ephemeriden-, Trichoptern-, Coleoptern-Larven, Mollusken und die aquatilen Vertebraten.

Ich sehe davon ab, die Tiergruppen einzeln zu behandeln, da Wiederholungen in diesem Falle unvermeidlich wären. Die Möglichkeit, dass sessile Infusorien und Suctorien benetzbare Tiere besiedeln können, ist durch den ersten Satz Brochers (vd. pg. 308) erklärt. Infusor und Träger sind beide benetzbar, infolge der Kapillarkräfte findet zwischen beiden Anziehung statt, die eine dauernde Festsetzung gestattet.

Die Turbellarien unserer Gewässer, die häufig untersucht wurden, wiesen als einzige Symphorionten die freien Infusorien-Arten Anhymenia steini und Urceolaria mitra auf. Nie konnten auf ihnen sessile Epizoen beobachtet werden. Der Grund dieser Erscheinung ist nicht, wie es auf den ersten Blick scheinen möchte, in der Beschaffenheit der äussern Körperdecke, die ein Wimperepithel ist, zu suchen, sondern vielmehr in biologischen Faktoren. Dass die Bewimperung der Körperhaut nicht das Ausschlaggebende für das Nichtvorhandensein von sessilen Infusorien ist, zeigt uns die Parallelerscheinung bei den Gastropoden, wo auf dem Flimmerepithel der Fühler und des Kopfes sich häufig Scyphidia limacina und Scyphidia physarum ansiedeln. Auch die von einem Flimmerepithel bedekten Kiemen der jungen Triton-Larven tragen oft in grosser Menge die Glossatella tintinnabulum. Es ist auch nicht die Kleinheit der Turbellarien, welche doch Copepoden 
um ein bedeutendes an Grösse übertreffen, die eine Besetzung nicht zuliesse, sondern warhrscheinlich die Lebensweise. Die Tricladen, die unsere Gewässer bevölkern, leben unter Steinen, zwischen denen sie sich infolge des Metabolismus ihres Körpers hindurchwinden können. Dieser Aufenthaltsort wird sessilen Epizoen nicht zusagen; Kolonien oder Einzeltiere würden durch die sie umgebenden Fremdkörper geschädigt und von der Unterlage abgestreift. Nur freie Formen, wie Anhymenia und Urceolaria, die ihren Wirt verlassen können, werden daher auf Tricladen zu finden sein. Dass trotzdem gelegentlich eine Besiedlung von Planarien durch sessile Infusorien möglich ist, wenn wohl auch nur ganz ausnahmsweise vorkommt, konnte ich einmal beobachten. Ich fand Vorticella convallaria in zwei Exemplaren auf einer Polycelis nigra. Aus der gesamten Literatur ist mir nur ein Fall bekannt geworden, wo eine gestielte Vorticellide, Vorticella nebulifera, auf Planarien festgestellt worden ist (Schrank 1776).

Eine sehr auffallende, mir bis jetzt aber unerklärliche Tatsache, möchte ich hier kurz streifen. Diaptomus wird in meinen vorhergehenden Trägerlisten sehr selten angeführt, obwohl er zu wiederholten Malen und in grossen Mengen, aus den verschiedensten Lokalitäten stammend, untersucht werden konnte. Als Symphorionten dieser Crustaceen werden nur Epistylis diaptomi, E. lacustris, Zoothamnium parasita beobachtet, und in der Literatur ist als weiteres Epizoon von Diaptomus noch Tokophrya diaptomi zu finden. Vergleichen wir damit die reiche Epizoenfauna der Cyclopiden, so fällt uns die geringe Zahl der auf Diaptomus gefundenen sessilen Infusorien auf. Was für Faktoren diese Armut hervorrufen, kann ich nicht entscheiden.

Wie aus der weiler oben angegebenen Tabelle von Ввоснев zu entnehmen ist, gibt es auch in dieser zweiten Gruppe Tiere, bei denen einzelne Körperstellen unbenetzbar sind. Diese Stellen kommen natürlich für eine Besetzung durch Infusorien nicht in Betracht. So ist die Körperhaut der meisten Phryganiden-Larven, wie Limnophilus, Glyphothaelius u. a., soweit 
ich es beobachten konnte, nicht benetzbar. Die Eigenschaft der Unbenetzbarkeit kommt aber den Respirationsorganen, dem Kopf und letztem Hinterleibssegment dieser Insekten-Larven nicht $\mathrm{zu}$, und darum finden wir die genannten Körperteile oft massenhaft mit koloniebildenden Vorticelliden bedeckt.

\section{Zur Variabilität der sessilen Peritrichen.}

Es scheint mir hier der Ort zu sein, auf eine Beobachtung hinzuweisen, die ich während meiner Untersuchungen häufig: machen konnte, und deren genaue Verfolgung ich mir für spätere Untersuchungen vorbehalten habe. Sie betrifft die Variabilität der Infusorien; über sie hat Entz (1903) seine Beobachtungen in einer Arbeit niedergelegt. Die Grössenvariation, von der hier die Rede sein soll, betrifft hauptsächlich eine Art des Genus Vorticella, nämlich Vorticella microstoma in ihren auf Cyclopiden und Cladoceren lebenden Exemplaren. Es konnte auf verschiedenen Crustaceen sehr häufig eine Vorticella gefunden werden, die ihrer äussern Körpergestalt nach wohl mit Vorticella microstoma, ihren Körpermassen nach aber nicht mit dieser in Zusammenhang gebracht werden konnte. Während die Normalmasse von Vorticella microstoma in der Länge zwischen 80-100 $\mu$ und in der Breite von 32-54 $\mu$ schwanken, zeigte die von mir gefundene Form als Mittelwerte in der Länge $36 \mu$ und in der Breite $25 \mu$. Ob diese Form als Varietät oder gar als selbständige Art aufgefasst werden muss, kann vorläufig noch nicht entschieden werden. Einstweilen habe ich sie im speziellen Teil dieser Arbeit als Varietät unter dem Namen Vorticella microstoma var. abreviata beschrieben. Ebenfalls muss die Frage offen gelassen werden, ob die Variabilität in der Art des besetzten Substrates ihre Ursache hat. Wie weit die Infusorien von ihrer Unterlage in Bezug auf die Körpergrösse abhängig sind, zeigt uns eine Notiz aus der citierten Arbeit von Eviz. In dieser Abhandlung wird auf ein Ver- 
halten der Cothurnia crystallina aufmerksam gemacht, indem die an dünnen Algenfäden sesshaften Individuen Zwerge sind gegen die Exemplare, welche sich auf dickern Algenfäden festsetzen.

\section{Morphologische Anpassungen der Epizoen an die Wirtstiere.}

Die Versuche von Fauré-Frémiet (1906a, b, c) mit specifischen Opercularien der Wasserinsekten, haben ergeben, dass die Bewegungsfähigkeit des Wirtes die einzige Bedingung ist, welche die Opercularien an den Träger stellen. Dieses Ergebnis möchte ich auf Grund meiner Untersuchungen auf alle specifischen Symphorionten erweitern und auch noch in gewissem Grade auf die weniger specifischen Formen anwenden. Gestützt auf meine eigenen Funde, und die Literaturnachweise habe ich bei den einzelnen Peritrichen-Arten die Höhe ihres Symphorismus festzustellen versucht. Ich bin dazu gekommen, die Symphorionten in folgende drei Gruppen zu teilen, wobei die Wahl und Zahl der Träger-Arten durch die Epizoen für mich massgebend war:

A. Gewöhnliche Symphorionten s. $l$. Als Wirte dienen ihnen Wasserpflanzen und Tiere aus den verschiedensten Gruppen.

B. Specifische Symphorionten s. l. Sie beschränken ihr Vorkommen auf systematisch grössere oder kleinere Gruppen der aquatilen Fauna.

C. Specifische Symphorionten s. str. Sie sind gekennzeichnet durch den Besitz eines einzigen Wirtes.

Wenn in der Bewegung des Wirtes ein Faktor festgestellt wurde, der auf die Specifität seiner Symphorionten bestimmend wirkt, so wird, da die Bewegungsart bei den verschiedenen Trägern verschieden ist, eine Anpassung des specifischen Epizoons an die Bewegungseigentümlichkeiten seines Wirtes nicht ausbleiben. Bei den Symphorionten s. l. und den 
specifischen Symphorionten s. l. werden Einrichtungen zu finden sein, die eine Verbreitung auf viele Wirte gestalten. Der Stiel, welcher den oft lebhaften Bewegungen des Wirtes gewachsen sein muss, wird in aller erster Linie an sie angepasst sein. Die Ausbildung des Fixationsorganes erfolgt bei den stieltragenden Peritrichen nach zwei Richtungen, er ist entweder steif oder von einem contractilen Stielmuskel durchzogen. Auf Grund dieser Erscheinung teilen wir diese Infusorienabteilung in die beiden Gruppen der Acontractilea und der Contractilea ein. Eine Sonderstellung nehmen im System die Loricata ein.

Es soll der Versuch gemacht werden, bei einigen Symphorionten die Stielstruktur einer nähern Prüfung zu unterziehen, um aus ihr die Specifität oder Nichtspecifität des Epizoons zu erklären.

\section{A. Acontractilea.}

Im speciellen Teil wurde bei dieser Gruppe darauf hingewiesen, dass bei den einzelnen Arten drei Typen der Stielausbildung auftreten.

Den ersten Typus finden wir bei Opercularia lichtensteini, O. corethrae, Pyxidium, Rhabdostyla, Discophrya steini, D. acilii und andern Suctorien. Hier ist der Stiel kurz und dick. Da diese Epizoen ausnahmslos lebhaft sich bewegende Wirte bewohnen, musste eine Ausbildung des Stieles getroffen werden, die ihnen das Vorkommen auf diesen Trägern ermöglichte. Die Wucht der Bewegung wird durch die Verkürzung des Stieles herabgesetzt, da durch sie eine Heranziehung des Infusorienkörpers an das Bewegungscentrum erfolgt.

Das zweite Princip der Stielstruktur finden wir bei den Acontractilen, deren Stiele eine Querstreifung aufzuweisen haben. Als Beispiel, bei dem diese Erscheinung am deutlichsten hervortritt, sei Epistylis digitalis erwähnt. Der Fall ist jedoch nicht alleinstehend, sondern er findet sich mit steter Regelmässigkeit bei solchen acontractilen Peritrichen, die lebhaft 
bewegliche Wirte besiedeln. Bei der Ausbildung des Stieles scheint Epistylia digitalis dasselbe Princip verfolgt zu haben, das wir bei den Gramineen beobachten können. Eine Verstärkung des langen Halmes wird erzielt durch die Ausbildung der Knoten, die bei Epistylis digitalis durch die Querringe dargestellt sind. Je nach der Stärke der Bewegung des Wirtes sind in der Querringelung des Stieles Unterschiede zu verzeichnen. Sehr lebhaft sich bewegende Träger lassen sich nur von solchen Epizoen besiedeln, bei denen die Querringe des Stieles in kurzen Abständen auf einander folgen, während auf ruhigeren Trägern Symphorionten sich festsetzen, deren Querringe grössere Internodialabstände zeigen. Als Beispiel für den ersten Fall möchte ich Epistylis digitalis mit der dicht gedrängten Stielringelung anführen. Ich habe dagegen die Beobachtung gemacht, dass die kolonialen Peritrichen, wie Opercılaria nulans und $O$. berberina, nie die Schwimmbeine der Käfer besetzen. Die Stielstruktur erlaubt diesnicht, da die Transversalringe bei den genannten Infusorien in grössern Abständen sich folgen, wodurch die Festigkeit des Stieles etwas vermindert wird. Von diesen beiden Peritrichen können also nur solche Körperteile aufgesucht werden, die keine Eigenbewegung besitzen.

Éine bei den Acontractilen und auch Contractilen wiederkehrende Erscheinung ist die Längs stre ifung des Stieles. Sie tritt bei Epizoen auf, welche ebenfalls starke Bewegungen ihrer Wirte auszuhalten haben. Auch in ihr erkenne ich eine Anpassung an die Träger. Sie ist nicht nur vielen Epistylis-Arten eigen, sondern kann auch bei Opercularia-Species, Carchesium aselli, beobachtet werden. Zur Erklärung der Erscheinung ziehe ich die Arbeit von Fauré-Frémiet (1905) zu Rate. Der Autor hat bei den sich eben festsetzenden Epistylis-Individuen die Struktur und Ausbildung des Fixationsapparates verfolgt. Der ausgewachsene längsgestreifte Stiel dieser Infusorien besteht aus zwei Teilen: Der äussern chitinösen Hülle und einem innern Bündel röhrenartiger chitinöser Cylinder. Durch die Auflösung der innern Stielmasse in diese Gylinder wird die Zuglestigkeit 
des Organes erheblich vergrössert, und sie ist es, welche den acontractilen Peritrichen ermöglicht, auf tierischen Wirten sich festzusetzen. Opercularia coarctala und Cothurnia pyxidiformis sind zwei Epizoen, bei denen ein ungestreifter Stiel beobachtet wird, eine Auflösung des Stielinnern in Cylinder ist nicht erfolgt, das Fixationsorgan ist deshalb starr und darum nicht geeignet, für die Fixation auf beweglichen Wirten in Betracht zu kommen. Wir finden aus diesem Grunde die beiden Peritrichen stets nur auf Pflanzen oder toten Substraten angesiedelt. Epistylis anastatica weist gewöhnlich einen glatten, nicht gestreiften Stiel auf. Aus diesem Befund ist zu schliessen, dass wir in ihr ein Epizoon von Wasserpflanzen erkennen müssen. Hin und wieder wollte mir aber scheinen, als sei eine feine Längsstreifung im Stiel zu beobachten. Diese würde den Peritrichen die Festsetzung auf beweglichen Wirten ermöglichen.

Eine Vergleichung der Wirtslisten mit nur durch längsgestreiften Stiel charakterisierten Infusorien-Arten zeigt eine bestimmte Auswahl der Träger und der Aufenthaltsorte auf denselben. Epistylis plicatilis setzt sich auf Wasserpflanzen und -Schnecken fest, wird aber auch häufig auf Copepoden gefunden. Doch besetzt sie auf diesen nie die Füsse oder das Abdomen, sondern stets nur den Cephalothorax. Aehnliches kann auch von Epistylis anastatica gesagt werden. Epistylis umbilicata ist ein Epizoon von Insekten-Larven und Oligochaeten. Opercularia glomerata wurde von Roux (1899, 1901) an den Flügeldecken von Hydrophilus gefunden. Meine Funde haben ergeben, dass diese Infusorien nur an solchen Körperteilen ihrer Träger zu finden sind, die keine Eigenbewegung: haben. Für eine Besetzung von Organen mit Eigenbewegung ist der Stiel nicht stark genug, da durch die Längsstreifung: nicht eine Verstärkung erzielt worden ist, sondern nur die Zugfestigkeit vergrössert wurde.

Um nun aber eine Besiedlung von Körperteilen, die Eigenbewegung aufweisen, zu ermöglichen, werden oft zwei der Stielstrukturen kominiert. So haben viele Peritriche und 
Suctorien, die auf den Bewegungsorganen ihrer Wirte anzutreffen sind, kurze längsgestreifte Stiele (Opercularia lichtensteini), andere dagegen besitzen lange quer-und längsgestreifte Fixationsapparate (Opercularia articulata). Dem letztgenannten Epizoon stehen infolge dieser Ausbildung seines Stieles in der Besetzung die grössten Möglichkeiten offen, es hat der Doppelstreifung des Stieles die reiche Auswahl der Wirte zu verdanken.

\section{B. Contractilea.}

Eine Durchsicht der Trägerlisten der Contractilen zeigt, dass diese Infusorien mit ganz wenigen Ausnahmen keine specifischen Wirte haben. Von ihnen werden Pflanzen und auch die verschiedensten Tiere besetzt. Dieser Vielseitigkeit der Träger entspricht wieder die Ausbildung des Stieles. Er ist in diesem Falle nicht steif, sondern von einem contractilen Muskel durchzogen. Im Augenblick, in dem das Tier, auf dem sich eine Familie von Vorticellen angesiedelt hat, eine Bewegung ausführt, ziehen sich die Stiele der Epizoen zusammen, dadurch tritt Stielverkürzung ein. Die vom Bewegungscentrum am weitesten entfernten Teile des Getragenen werden an dieses herangezogen, die Wucht der Bewegung verkleinert sich und so wird einem Zerreissen des Fixationsorganes vorgebeugt. Diese Einrichtung erlaubt den Contractilen, sich auch auf Körperteilen der Wirte festzusetzen, die eine Eigenbewegung aufweisen. Bei den Formen, welche sich in der Regel nur auf solchen festzusetzen pflegen, hat sich zudem noch, wie bei Carchesium aselli, Längs- und Querstreifung als besondere Verstärkung des Stieles ausgebildet.

\section{Loricata.}

Auf die Verteilung der Loricata auf den verschiedenen bebesetzten Substraten wurde bei den einzelnen Arten schon aufmerksam gemacht.

Das mit dünnem Stiel versehene Gehäuse von Cothurnia pyxidiformis und die stiellosen Gehäuse der Cothurnia crys- 
tallina und $C$. truncata, die mit dem aboralen Pol dem Substrate aufsitzen, lassen eine Besetzung von beweglichen Trägern nicht zu, da der Zusammenhang mit ihnen zu wenig. solide und die Gefahr des Losgerissenwerdens zu gross ist.

Dem Uebelstand begegnen Vaginicola und die LagenophrysArten dadurch, dass ihre Gehäuse mit einer grossen abgeplatteten Fläche der Unterlage aufliegteu. Dadurch wird eine festere Fixation erzielt.

Cothurniopsis-Arten bilden einen kurzen dicken Stiel aus, kehren also zu dem Princip zurück, das gewisse Opercularien schon angewendet hatten. Eine solche Stielausbildung erlaubt ihnen, schnell sich bewegende Wirte zu besiedeln.

\section{Zur Biologie der sessilen Peritrichen und Suctorien.}

Die vorliegenden Betrachtungen veranlassen uns, noch kurz auf die verschiedenen biologischen Begriffe, unter denen die sessilen Peritrichen und Suctorien zusammengefasst wurden, näher einzutreten. Es wird die Frage gestellt, unter welchen Begriff der Vergesellschaftung die sessilen Infusorien fallen. Wie kann ihr Verhalten zum Träger biologisch benannt werden? Es fallen dabei folgende Begriffe in Betracht:

A. Commensalismus. In der Literatur, auch schon in der ältern, werden die sessilen Infusorien als Commensalen, speziell als Ecto-Commensalen bezeichnet. Unter Commensalismus verstehen wir eine Tischgenossenschaft, ein Zusammenleben eines Tieres mit einem andern, im oder am Körper des letzteren, wobei das erste Tier den Körper des zweiten nicht schädigt, sondern nur seine Nahrung mitgeniesst (Ziegler, Zoolog. Wörterbuch, 1912). Wenn tatsächlich die sessilen Infusorien als Commensalen anzusprechen wären, so müsste angenommen werden, dass von ihnen nur solche Körperteile des Wirtes besetzt werden, wo die Aussicht, an seiner Nahrung teilhaftig: 
zu sein, eine möglichst grosse ist. Von einer Besetzung sollten also die Mund- und auch die Aftergegend, wo die Faekalmassen des Trägers den Epizoen reiche Nahrung bieten könnten, besonders stark betroffen sein. Eine ausgiebige Besetzung von Mund-und Afterbezirk trifft nun allerdings, wie mèine Funde gezeigt haben, bei den meisten Arten nicht zu. Nur wenige Infusorien beschränken im allgemeinen ihr Vorkommen auf die genannten Körperregionen. Diese wenigen wären daher allein als echte Ecto-Commensalen zu bezeichnen. Ich erinnere hier an Tokophrya cyclopum, Choanophrya infundibulifera, Opercularia corethrae, O. zschoklei, Epistylis nympharum.

Beim grössten Teile der sessilen Peritrichen und Suctorien konnte aber die Erscheinung der Besiedlung der Mund- und Afterbezirke nicht nachgewiesen werden. Ihr Festsetzungsort liegt oft weit weg von Mund und After des Wirtes, und es kann infolge dessen von einer Teilnahme an seiner Nahrung: nicht gesprochen werden. Das bestätigten auch einige von mir angestellten Experimente. Der Tod des Wirtes hatte nicht auch den Tod der Epizoen im Gefolge. Die Einzeltiere einiger Infusorien-Arten verliessen erst kürzere oder längere Zeit nach dem Tode des Trägers die Stiele, um auf einem lebenden Wirt bessere Existenzbedingungen zu suchen. Für die sich so verhaltenden Infusorien-Formen wird also der Begriff “Commensalen " hinfällig, er muss durch einen andern ersetzt werden. Der Wirt dient wohl den meisten Arten als Fahrzeug, das seine Gäste fortwährend neuen Orten zuführt und ihnen auf diese Weise die verlorengegangene selbstätige Bewegung: ersetzt. Die Wahl beweglicher Träger bringt zwei Vorteile: 1. sie sorgt für eine Verbesserung der Ernährungsmöglichkeit, und 2. für die Verbreitung und damit auch für die Erhaltung: der Art. Lang (1888) machte darauf aufmerksam, dass Pflanzen oder andere ruhende Gegenstände nur als zufällig besetzte Substrate sessiler Infusorien anzusehen sind. Diese Ansicht kann ich nicht vollständig teilen, sie hat nach meinen Befunden Gültigkeit für die Vorticella-Arten, einige Epistylis-, Opercularia-, Colhurniopsis- und die Vaginicola-Species. Für eine 
kleine Gruppe aber, zu der Opercularia coarctata und Cothurnia crystallina gehören, trifft sie nicht zu. Diese Formen benützen ausschliesslich Wasserpflanzen und andere festliegende Gegenstände als Unterlage. Durch die Vergleichung: der Struktur der Fixationsorgane der Peritrichen bin ich zur Ueberzeugung gekommen, dass auch Epistylis anastatica primär der nur Wasserpflanzen besiedelnden Infusorien-Gruppe angehörte. Die Stiele dieser Peritrichen, dazu kommen noch einige Suctorien, wie Tokophrya lemnarum u. a., sind nicht gestreift. Das Stielinnere stellt eine einheitliche Masse dar, wodurch das ganze Fixationsorgan als starres, unelastisches Gebilde erscheint. Bewegliche Wirte können daher nicht besiedelt werden, da der Stiel den oft sehr energischen Bewegungen der Träger zu wenig nachgeben kann. Es bleiben also für die Infusorien mit solchen einfach gebauten Stielen nur ruhende Träger zur Besiedlung übrig. Durch die Besetzung unbeweglicher Substrate werden die Epizoen in einer ausgiebigen Verbreitung gehindert, was auch für die Erhaltung der Art von Nachteil werden kann. Daher haben diese InfusorienArten ihre Stiele an die Bewegungseigentümlichkeiten der Wirte angepasst, um durch bewegliche Träger neuen Lokalitäten zugeführt zu werden. Eine Anpassungserscheinung ist in der Contractilität des Stieles zu suchen (Vorticella, Carchesium, Zoothamnium), eine andere liegt in der Längs- und Querstreifung des Fixationsorganes vor (Epistylis, Opercularia, Tokophrya u. a.). Ich bin also zum Schlusse gekommen, dass die Besetzung von Wasserpflanzen oder toten Substraten die primäre gewesen sei, erst sekundär erfolgte eine solche von beweglichen Wirten.

B. Epizoon. Die Versuche von Fauré-Frémiet (1906a, b, c) und meine Experimente mit Epistylis haben ergeben, dass bei den acontractilen Peritrichen in der Bewegung des Wirtes ein wichtiger Faktor zu suchen ist, der für die Specifität bestimmend wirkt. Es besteht somit zwischen Infusor und Träger eine Beziehung, deren Vorteil allerdings einseitig ist. 
Der Begriff "Epizoon », welcher in vorliegender Arbeit des öftern gebraucht wurde, ist von Schröper (1914) folgendermassen definiert worden: Ein Epizoon ist ein Tier, das Pflanzen oder andere Tiere besetzt. Diese Definition ist für unsere Zwecke ungenügend, da unter ihr auch die EctoParasiten verstanden werden können. Wenden wir sie auf sessile Infusorien an, so kommt in ihr die einseitige Beziehung, die zwischen Träger und Getragenen besteht, nicht zum Ausdruck.

C. Mutualismus. Unzutreffend scheint mir für diese Gruppe von sessilen Tieren auch die Bezeichnung (Mutualisten» zu sein. Richard (1899) verstand darunter solche Tiere, die auf einem andern leben, ohne Parasit oder Commensale zu sein, die aber von ihrer Lage Nutzen ziehen. Heute definieren wir aber den Mutualismus als das Verhältnis eines wechselseitigen Nutzen, insbesondere das Zusammenleben verschiedener Tierarten, wenn sie sich gegenseitig. Vorteil bringen (Ziegler, 1912). Von einem gegenseitigen Nutzen kann hier nicht gesprochen werden, ein Copepode kann auch ohne Epistylis-Kolonien leben, er ist von ihnen nicht abhängig, wohl ist es aber Epistylis von seinem Träger.

D. Symbiose und Biocoenose. Damit fällt auch der Begriff der Symbiose für diese Tiergesellschaften dahin. Auf den ersten Blick möchte es scheinen, dass im Zusammenleben von Wirt und Infusor eine Biocoenose erkannt werden könnte. Nach der neuen Definition, die Thienemans (1918) gegeben hat, muss auch das verneint werden, da nach ihr Träger undEpizoon, einander gegenseitig bedingen müssten. Dass aber ein gegenseitiges Sich-Bedingen nicht zutrifft, bewiesen mir meine Beobachtungen. Wohl gibt es Peritriche und Suctorien, die ihre specifischen Wirte haben, aber in vielen Fällen werden diese auch ohne ihre specifischen Gäste gefunden.

E. Sym phoris mus. DeEgener (1918) stellt in seinem System die sessilen Infusorien unter den Begriff (Symphorium». Ein 
solches entsteht, wenn ein lebendes Tier oder mehere auf dem Körper eines artfremden Tieres sich ansiedelı; dem Träger wird aber durch das Getragene nicht in der Weise Schaden zugefügt', dass ihm parasitisch Nahrung entzogen wird. Zwischen beiden besteht auch nie ein mutualistisches Verhältnis. Durch diese Definition scheint mir die Vergesellschaftung von sessilem Infusor und Wirt am besten charakterisiert zu sein. Unter dem in dieser Arbeit oft gebrauchten Ausdruck " Sy mphoriont" verstehe ich eine sessile Peritriche oder ein sessiles Suctor, das auf Pflanzen oder Tieren sich festsetzt. Das Wort "Wirt», das mit "Träger» als gleichbedeutend aufzufassen ist, wird nicht in parasitologischem Sinne verstanden. Der Gast entzieht dem Wirt keine Nahrung, sondern benützt ihn lediglich als Fahrzeug. Das Symphorium ist immer heterotypisch und sekundär. Da nun aber der Vorteil, den die Vergesellschaftung bietet, nur einseitig ist, nennt Dezgener diese Art von Vergesellschaftung ein irreciprokes Symphorium. Den Wirten erwächst aus dem Zusammenleben kein Vorteil, es bleibt für ihn gleichgültig oder wird nachteilig, wenn z. B. ein mit EpistylisKolonien ganz bedeckter Cyclops durch die Menge der Epizoen in seiner Bewegungsfreiheit gehindert wird. Das Symphorium aber selbst hat äusserlich grosse Aehnlichkeit mit dem EctoParasitismus, der sich vielleicht aus ihm entwickelt hat. 


\section{ZUZAMMENFASSUNG DER RESULTATE}

\section{Systematisch-faunistische Resultate.}

1. Von den bis zum Jahre 1919 aus der Schweiz bekannten 66 Peritrichen-Arten habe ich in meinem Untersuchungsgebiet 41 Arten wiedergefunden. Neu für die schweizerische Peritrichenfauna sind 11 Arten, darunter befinden sich 2 für die Wissenschaft neue Species und 1 Varietät.

Neu für die Schweiz sind:

Scyphidia limacina Lachmann.

Vorticella crassicaulis Kent.

Zoothamnium aselli Claparède und Lachmann.

Epistylis diaptomi Fauré-Frémiet.

Opercularia gracilis Fauré-Frémiet.

Opercularia cylindrata Wrzesniowsky.

Pyxidium Henneguyi (Fauré-Frémiet).

Lagenophrys aselli Plate.

Neu für die Wissenschaft sind :

Opercularia corethrae nov. spec.

Opercularia zschokkei nov. spec.

Vorticella microstoma var. abreviata nov. var.

Von 13 in der Schweiz bekannten Suctorien-Arten konnten 5 von mir beobachtet werden. 6 Arten wurden für die schweizerische Suctorienfauna neu nachgewiesen:

Tokophrya cyclopum var. actinostyla Collin.

Periacineta buckei (Kent).

Discophrya steini (Claparède und Lachmann).

Discophrya lichtensteini (Claparède und Lachmann).

Discophrya acilii Collin.

Discophrya elongata (Claparède und Lachmann). 
II. Biologisch-morphologische Resultate.

2. Die sessilen Infusorien bilden mit ihren Wirten eine Tiergesellschaft von bestimmtem Charakter. Die Vergesellschaftung, die nur dem Getragenen Vorteil bringt, dem Träger aber gleichgültig bleibt, jedenfalls nicht nachteilig auf ihn wirkt, indem ihm nicht parasitisch Nahrung entzogen wird, nannte ich nach DeEgener (1918) ein Symphorium.

Com mensalis mus konnte ich nur für einige wenige InfusorienArten nachweisen. Nach den neuern Forschungen müssen Bezeichnungen wie Mutualismus, Symbiose oder Biocoenose für die Vergesellschaftung von Infusorien mit toten und lebenden Substraten dahinfallen.

3. Die vergleichende Untersuchung der Fixationsorgane der sessilen Infusorien macht es wahrscheinlich, dass die Wasserpflanzen und andere ruhende Substrate als die ursprünglichen Träger angesehen werden müssen. Erst sekundär haben sich die Epizoen auf beweglichen Wirten festgesetzt. Von Wasserpflanzen ausgehend, sind vielleicht zunächst nur langsam sich bewegende Tiere, wie z. B. Mollusken, einige Insekten-Larven, besiedelt worden. Aus den Epizoen dieser trägen Tiere mögen sich dann die Symphorionten der lebhaft sich bewegenden Vertreter der aquatilen Fauna, der Copepoden, Wasserkäfer u. a., entwickelt haben.

4. Ich habe die sessilen Infusorien nach der Wahl der von ihnen besetzten Substrate in 3 biologische Gruppen geteilt :

Symphorionten s. $l$.: Träger sind Wasserpflanzen allein oder Wasserpflanzen und Tiere aus den systematisch verschiedensten Gruppen.

Specifische Symphorionten s. l.: Unter den zu besetzenden Substraten fehlen die Wasserpflanzen gänzlich, die Wirtstiere werden aus systematisch enger umschriebenen Gruppen gewählt.

Specifische Symphorionten s. str.: Diese Infusorien kommen nur auf einem einzigen Wirte vor.

Rev. Suisse de Zool. T. 28. 1921. 
5. Die morphologische Anpassung der Epizoen an ihre Träger äussert sich hauptsächlich in der Beschaffenheit des Stieles.

Während die acontractilen Peritrichen, (Epistylis, Opercularia, Rhabdostyla, Pyxidium) von Wasserpflanzen oder langsam sich bewegenden Tieren glatte und nicht gestreifte Stiele aufzuweisen haben, sind diejenigen Acontractilen, die auf lebhaft sich bewegenden Trägern sich festsetzen, durch Längsund Querstreifung der Fixationsorgane und oft durch Verkürzung derselben ausgezeichnet. Diese Streifung bewirkt eine Verstärkung der Stiele.

Infolge der Contractilität des Fixationsorganes bei den contractilen Peritrichen (Vorticella, Carchesium, Zoothamnium) steht dieser Infusoriengruppe in der Wahl ihrer Träger die grösste Möglichkeit offen.

Die loricaten Peritrichen, die sich auf Wasserpflanzen festsetzen, weisen keine oder nur sehr dünne Stiele auf(C'othurnia). Die Loricata beweglicher Wirte ermangeln eines Fixationsorganes (Lagenophrys, Vaginicola), oder das Gehäuse wird von einem dicken kurzen Stielchen getragen (Cothurniopsis).

Die Suctorien schliessen sich in der Ausbildung des Stieles und in dessen Anpassung an die Wirte den acontractilen und loricaten Peritrichen an.

6. Wichtig für die Besiedlung durch die sessilen Infusorien ist die Beschaffenheit der Oberfläche der Träger in Bezug auf ihre Benetzbarkeit durch Wasser. Nur auf benetzbaren Substraten können sich die Infusorien ansiedeln. Auf unbenetzbaren Körperstellen von Wirtstieren können sie sich infolge der Kapillarphänomene nicht festsetzen. Eine Besiedlung wird nur dann möglich, wenn die betreffenden, von Hause aus unbenetzbaren Körperteile, durch die Anwesenheit von hydrophilen Haaren benetzbar gemacht werden, oder wenn durch chemische Veränderung des Wassers die Oberflächenspannung herabgesetzt wird. 


\section{LITERATUR=VERZEICHNIS}

Um das Literaturverzeichnis nicht unnötig zu belasten, habe ich alle die von mir benützte Literatur hier nicht aufgeführt, die schon in den Verzeichnissen von Bütschli (1889), André (1912) und Collin (1912) zusammengestellt wurde.

1. André, E. Catalogue des Invertébrés de la Suisse. Fase. 6, Infusoires. Genève, 1912.

2. ID. Recherches sur la faune pélagique du Léman et descriptions de nouveaux genres d'Infusoires. Rev. suisse Zool., Vol. 22, 1914.

3. Io. Contributions a l'étude de la faune infusorienne du lac majeur. Rev. suisse Zool., Vol. 23, 1915.

4. ID. Contributions à l'étude de la faune infusorienne du lac Léman. Rev. suisse Zool., Vol. 24, 1916.

5. Annandale, N. Notes on the fresh-water fauna of India. Zool. Centralbl., Bd. 14, 1917. (Referat.).

6. Blanchard, K. et Richard, J. Sur la faune des lacs des Hautes Alpes. Mém. Soc. zool. de France, Tome 10, 1897.

7. Blochmann, Fr. Die mikroskopische Tierwelt des Süsswassers, Braunschweig, 1895.

8. Bourqun-Lindt, E. Contribution à l'étude des Protozoaires de la vallée de la Chanx-de-Fonds. Bull. Soc. neuchàteloise Sc. nat., Vol. 42, 1918.

9. Bresslau, E. Systylis Hoffi, nov. gen. nov. spec., eine neue Vorticellide. Biol. Centralbl., Bd. 39, 1919.

10. Ввоснек, F. Les phénomènes capillaires. Leur importance dans la biologie aquatique. Ann. Biol. lac., Tome 4, 1909-11.

11. Iр. L'aquarium de chambre, Lausanne, 1913.

12. Brons, H. G. Klassen und Ordnungen des Tierreichs, I. Band: Protozoa. 3. Abteil. Infusoria. Bearbeitet von O. Bütschu, Heidelberg u. Leipzig, 1889.

13. Chatron, E. Protozoaires parasites des branchies des Labres, Arch. Zool. expérim. et génér., Tome 5, 1910.

14. Caullery, M. et Mesnil, F. Sur la Trichodina patellae Cuénot, C. R. Soc. Biol., Tome 78, 1915. 
15. Colur, B. Etude monographique surles Acinétiens. I. Recherches expérimentales sur l'étendue des variations et les facteurs tératogènes. Arch. Zool. expérim. et génér. (5), Tome 8, 1911-12.

16. ID. Id. Il. Morphologie, Physiologie, Systématique. Ibid. T. 51, 1912-1913.

17. Cunnington, H. A. Studien an einer Daphnide, Simocephalus sima. Zeitschr. f. Naturw., Bd. 37, 1903.

18. Daday, E. Die anatomischen Verhältnisse der Cyprois dispar (Entz). Természetrajzi Füzetek. Beil. z. Bd. 18. 1895.

19. ID. Beiträge zur Kenntnis der Mikrofauna des Kossogol-Beckens in der nord-westl. Mongolei. Mathem. und Naturwiss. Ber. aus Ungarn, Bd. 26. 1908.

20. ID. Die Süsswasser-Mikrofauna Deutsch-Ost-Afrikas. Zoologica, Bd. 23, Heft 59, Stuttgart, 1910.

21. In. Deux Infusoires nouseaux de la région antarclique. Allatani Közlemények., Bd. 10, 1911.

22. Dанц, F. Grundsätze und Grundbegriffe der biocönotischen Forschung. Zool. Anz., Bd. 33, 1909.

23. Dalla Torne, W. Studien über die mikroskopische Tierwelt Tirols. Ferdinandeums Zeitschr., 3. Folge, Heft 35, 1891.

24. Davaine, M. Sur les Urcéolaires parasites dans la vessie urinaire des Tritons. C. R. Soc. Biol. (2), Tome 1, 1854.

25. Deegener, P. Versuch zu einem System der Assoziations- und Sozietätsformen im Tierreich. Zool. Anz., Bd. 49, 1917.

26. ID. Die Formen der Vergesellschafung im Tierreiche. Leipzig, 1918.

27. Doflein, F. Das System der Protozoen. Arch. für Protistenkunde, Bd. 1, 1902.

28. ID. Lehrbuch der Protozoenkunde. Jena, 1916.

29. Dunkentey, J. S. Flagellata and Ciliata. Proc. R. Irish Acad., Vol. 31, 1913.

30. Emmondon, C. H. The Protozoa of lowa, Proc. Davenport Acad. of Science, Vol. 11, 1906.

31. Entz, G. Ueber die Variabilität der Infusorien. Zool. Centralbl., Bd. 10, 1903 (Ref.).

32. Iv. Beiträge zur Kenntnis des Planktons des Balatonsees. Zool. Centralbl., Bd. 11, 1904 (Ref.).

33. Fauré-Frémiet, E. Note sur un groupe nouseau d'Opercularia. Arch. Anat. microse., Tome 7, Fasc. 1, 1904. 
34. Fauré-Fréniet, E. La structure de l'appareil fixateur chez les Vorticellidae. Arch. f. Protistenkunde, Bd. 6, 1905.

35. ID. (a). Le commensalisme spécifique chez les Vorticelles d'eau douce, C. R. Soc. Biol., Vol. 58, 1906.

36. ID. (b). Le commensalisme des Opercularia : Le facteur mousement. C. R. Soc. Biol., Vol. 58, 1906.

37. Iр. (c). Le commensalisme des Opercularia: Les facteurs de la spécifici. C. R. Soc. Biol., Vol. 58, 1906.

38. Iv. (d). Variation expérimentale chez Vorticella microstoma. Bull. sc. de la Belgique et de la France, Tome 60, 1906.

39. ID. (e). Note sur quelques formes nouvelles de Vorticellidae. Zool. Anz. Bd. 29, 1906.

40. In. Sur la variabilité de quelques Opercularia commensaux, C. R. Soc. Biol., Vol. 62, 1907.

41. In. La fixation chez les Infusoires ciliés. Bull. sc. de la Belgique et de la France (7), Tome 44, 1910.

42. Francé, R. Die Protozoen des Balaton (Plaltensee). Res. d. wiss. Erforsch. d. Balatonsees, Bd. 2, 1897.

43. Grier, N. M. A new spezies of Opercularia: Opercularia wallgrenin. s; . Trans. americ. microsc. Soc., Vol. 35, 1911.

44. Gruber, A. Kleiner Beitragr zur Biologie der Uferfauna des Bodensees. Ber. d. Naturforsch. Ges. Freiburg i/Br., Bd. 20. 1914.

45. Нжвевцi, A. Biologische Untersuchungen im Löhrmoos. Ein Beilrag zur Kenntnis der schweiz. Moorfauna. Rev. suisse Zool., Vol. 26, 1918.

46. Henpel, O. Zur Kenntnis einiger Alpenseen, mit besonderer. Berücksichtigung ihrer biologischen und Fischereiverhältnisse. I. Der Halbstältersee. Rev. d.ges. Hydrobiol. u. Hydrograph., Bd. 8, 1917-18.

47. Hamann, O. Europäische Höhlenfauna. Eine Darstellung der in den Höhlen Europas lebenden Tierwelt, mit besonderer Berücksichtiguing der Höhlenfauna Krains. Jena, 1896.

48. Kisshalt und Hartmann. Praktikum der Bakteriologie und Protozoologie. 2. Teil, Protozoologie. Jena, 1915.

49. Hempel, A. Description of new species of Rotifera and Protozoa from the Illinois-River and adjacent waters. Bull. Ill. State Laboratory, Vol. 4, 1896.

50. Handerson, W. Notes on the Infusoria of Freiburg i/Breisgau, Zool. Anz., Bd. 29, 1905. 
51. Hentschel, E. Biologische Untersuchungen über den tierischen und pflanzlichen Bewuchs im Hamburger Hafen. Mitt. aus d. Zool. Museum Hamburg, Bd. 33, 1916.

52. Heuscher, H. Das Zooplankton des Zürichsees. Arch. f. Hydrobiol. u. Planktonkunde., Bd. 1i, 1917.

53. Huber, G. Monographische Studien im Gebiete der Montigglerseen (Südtirol) mit besonderer Berücksichtigung ihrer Biologie. Arch. f. Hydrobiol. u. Planktonkunde, Bd. 1, 1905.

54. Kueiber, O. Die Tierwelt des Moorgebietes von Jungholz. Ein Beitrag zur Kenntnis der Hochmoorfauna. Arch. f. Naturgeschichte. Jahrg. 1911, I. Bd., 3. Suppl.

55. Koppel, A. Die koloniebildenden Peritrichen. Mikrokosmos, Jahrg. 1917-18, Heft 3-4

56. Koford, C. A. The plancton of the Illinois-River, 1894-1899, with introductory notes upon the hydrographie of the Illinois-River and its bassins. Part. II. Continuent organisms and their seasonal distribution. Bull. Illinois State Labor. of Nat. Hist., Vol. 8, 1908.

57. Kolkwitz, R. et Marsson, M. Oekologie der tierischen Saprobien. Intern. Rev. ges. Hydrograph. u. Hydrobiol., Bd. 2, 1909.

58. Krause, F. Planktonproben aus ost-und westpreussischen Seen. Arch. f. Hydrobiol. u. Planktonkunde, Bd. 2, 1906.

59. Lang, A. Ueber den Einfluss der festsitzenden Lebensweise auf die Tiere. Jena, 1888.

60. Lauterborn, R. Die sapropelische Lebewelt. Zool Anz., Bd. 24, 1901.

61. ID. Die Ergebnisse einer biologischen Probeuntersuchung des Rheins. Arb. kais. Gesundheitsamt, Berlin, Bd. 22, 1905.

62. Iр. Die sapropelische Lebewelt. Ein Beitrag zur Biologie des Faulschlammes der natürlichen Gewässer. Verh. nat. hist. Ver., Heidelberg, Bd. 13, 1916.

63. Levander, K. M. Zur Kenntnis der Fauna und Flora finnischer Binnenseen. Acta Soc. pro Fauna et Flora Fennica, Vol. 19, 1900.

64. ID. Beiträge zur Fauna und Algenflora der süssen Gewässer an der Murmanküste. Acta Soc. pro Fauna et Flora Fennica, Vol. 20, 1901.

65. Marsson, M. Die Fauna und Flora des verschmulzten Wassers und ihre Beziehung zur biologischen Wasseranalyse. Forsch. ber. d. Stat. Plön., Bd. 10, 1903. 
66. Mermod, G. Recherches sur la faune infusorienne des tourbières et des eaux poisines de Ste-Croix (Jura paudois). Rev. suisse Zool., Vol. 22, 1914.

67. Monard, A. Sur la faune profonde du lac de Neuchâtel. Description de quelques nouvelles espèces. Rev. suisse Zool., Vol. 26, 1918.

68. In. La faune profonde du lac de Neuchâtel. Bull. Soc. neuchâteloise des Sc. nat., Tome 44, 1919.

69. Monız, R. Faune des eaux souterraines du département du Nord et en particulier de la ville de Lille. Rev. biolog. du nord de la France, T. 1, 1889.

70. Montı, R. I protisti della Risaje. Rend. Ist. lomb., Vol. 32, 1899.

71. Packand, A. S. Life history of the Protozoa and Sponges. The americ. Naturalist, Vol. 9, 1875.

72. Parona, C. Essai d'une protistologie de la Sardaigne avec la description de quelques protistes nouveaux ou peu connus. Arch. Sc. phys. et nat. (3), Tome 10, 1883.

73. Penard, E. Observations sur quelques Protozoaires peu connus ou nouveaux. Rev. suisse Zool., Vol. 25, 1917.

74. Richard, J. Essai sur les parasites et les commensaux des Crustacées. Arch. d. Parasit., Vol. 2, 1899.

75. Roвerts, E. W. Vaginicola, an interesting Protozoon. Trans. americ. micr. Soc., Vol. 32, 1913.

76. Rousseau, E. \& Schouteden, H. Les Acinétiens d'eau douce. Ann. d. biol. lac., T. 2, 1907-08.

77. Rousseau, E. Révision des Acinétiens d'eau douce. Ann. d. biol. lac., T. 5, 1912.

78. Schedel, A. Producenten und Konsumenten im Teichplankton. Arch. f. Hydrobiol. u. Plkde. Bd. 11, 1916.

79. Sснешікоғ, W. Ueber einige ecto- und entoparasitische Protozoen der Cyclopiden. Bull. Soc. imp. Nat. Moscou (n. s.), Bd. 7, 1893.

80. Schonichen, W. Eyferth's einfachste Lebensformen des Tier-und Pflanzenreichs. Braunschweig, 1909.

81. Sснröder, B. Ueber Planktonepibionten. Biol. Centralbl., Bd. 34, 1914.

82. Schröder, O. Beiträge zur Kenntnis son Vorticella monilata. Arch. f. Protistenkunde, Bd. 7, 1906. 
83. Sснвӧдеr, O. Beitıäge zur Kenntnis yon Epistylis plicatilis. Arch. f. Protistenkunde, Bd. 7, 1906.

84. Seligo, A. Untersuchungen in den Stuhmer-Seen, Danzig, 1900.

85. Steinmann, P. \& Surbeck, G. Die Wirkung organischer Verunreinigungen auf die Fauna schweizerischerfliessender Gewässer. (Preisschrift d. schweiz. zool. Gesellschaft), Bern, 1918.

86. Stevens, N. M. Studies on ciliate Infusoria. Proc. California Acad. Sc., Vol. 3, 1901.

87. Svec, F. Beiträge zur Kenntnis der Infusorien Böhmens. I. Die ciliaten Infusorien des Unterpocernitzer Teiches. Bull. intern. Acad. Sc. Bohême, 1879.

88. Tanner. Der Hüttwiler-oder Steineggersee. Mitt. thurg. Naturforsch. Ges., Heft 20, 1913.

89. Thienemann, A. Die Faktoren, die die Verbreitung der SüsswasserOrganismen regeln. Arch. f. Hydrobiol. u. Planktonkde., Bd. 8. 1913.

90. lo. Lebensgemeinschaft und Lebensraum. Naturwiss. Wochenschr. (N. Folge), Bd. 17, 1918.

91. In. Die Tierwelt der Bäche des Sauerlandes. Jahresber. westfäl. Prov. Ver., 1911-12.

92. In. Die Tierwelt der kalten Bäche und Quellen auf Rügen. Mitt. Nat. Ver. Neu-Pommern-Rügen, Jahrg. 38, 1907.

93. v. Uвısch, M. Ein Beitrag zur Kenntnis der Gattung Lagenophrys. Arch. f. Protistenkunde, Bd. 28. 1913.

94. Vivrieux, J. A propos d'Opercularia articulata. Feuille des jeunes Natural., $4^{\mathrm{me}}$ série, $10^{\mathrm{me}}$ année, 1909-10.

95. Voigt, M. Mitleilungen aus der biologischen Station z"l Plön. Ueber einige bisher unbekannte Süsswasserorganismen. Zool. Anz., Bd. 24.

96. Iь. Neue Organismen aus den Plöner Gewässern. Forschungsber. d. Stat. Plön, Bd. 9, 1902.

97. ID. Beiträge zur Kenntnis des Planktons pommerscher Seen. Forschungsber. Stat. Plön. Bd. 9, 1902.

98. VoLk, R. Allgemeines über die biologischen Verhälınisse der Elbe bei Hamburg und über die Einwirkung der Sielwässer auf die Organismen des Stromes. Mitt. nat. hist. Museum Hamburg, Jahrg. 19, 1903.

99. Iv. Studien über die Einwirkung der Trockenperiode im Sommer 1904 auf die biologischen Verhältnisse der Elbe bei Hamburg. Mitt. nat. hist. Museum Hamburg, Jahrg. 23, 1906. 
100. Vulpian, M. Sur la présence d'Urcéolaires dans la cavité branchiale des têtards de grenouilles, des épinoches, et à la surface du corps de ces animaux, et des larves de triton. C. R. Soc. Biol. (2), Tome 4, 1857.

101. v. Wagner, W. Ueber die Genesis und Entwicklung der Geselligkeit im Tierreich. C. R. $6^{\text {me }}$ Congrès intern. de Zoologie, Berne, 1904.

102. Whicengrex, H. Uebersicht von der Gattung Lagenophrys St. Biol. Centralbl., Bd. 20. 1900.

103. Wesenberg-Lund, C. Studier over de danske sers plankton. Dansk Ferskvands-biologisk Laboratorium, Op. 5, 1904.

104. Wietrzykowsкi, W. Eine neue Infusorienspecies, Discophrya coperniciana (n. sp.) aus der Gruppe der Sukloria. Centralbl. f. Zool., Bd. 6, 1916. (Ref.).

105. Wolf, E. Die Fortpflanzungsverhältnisse unserer einheimischen Copepoden. Zool. Jahrb. (Abt. System.). Bd. 22, 1905.

106. Zacharias, O. Trichodina pediculus, als Milglied des Planktons der Binnenseen. Biol. Centralbl., Bd. 20, 1900.

107. Iр. Zur Kenntnis der Planktonverhältnisse des Schöh- und Schluensees. Forschungsber. Stat. Plön., Bd. 9. 1902.

108. Iv. Zur Flora und Fauna der Schilfstengel im grossen PlönerSee. Forschungsber. Stat. Plön, Bd. 9, 1902.

109. In. Biologische Charakteristik des Klinkerteiches zu Plön. Forschungsber. Stat. Plön, Bd. 10, 1903.

110. Conu, W. A preliminary report on the Protozoa of the fieshwraters of Connecticut. State geol. and nat. Hist. Survey State Connecticut, Bull. 2, 1905.

111. Wolf, I. P. Die Ostracoden der Umgebung von Basel. Arch.f. Naturgesch., Jahrg. 1920, H. 3. 


\section{$2 \mathrm{BHL}$ Biodiversity Heritage Library}

Keiser, Alfred. 1921. "Die sessilen peritrichen Infusorien und Suctorien von Basel und Umgebung." Revue suisse de zoologie 28, 221-341. https://doi.org/10.5962/bhl.part.84688.

View This Item Online: https://www.biodiversitylibrary.org/item/40661

DOI: https://doi.org/10.5962/bhl.part.84688

Permalink: https://www.biodiversitylibrary.org/partpdf/84688

\section{Holding Institution}

MBLWHOI Library

\section{Sponsored by}

MBLWHOI Library

\section{Copyright \& Reuse}

Copyright Status: NOT_IN_COPYRIGHT

This document was created from content at the Biodiversity Heritage Library, the world's largest open access digital library for biodiversity literature and archives. Visit BHL at https://www.biodiversitylibrary.org. 